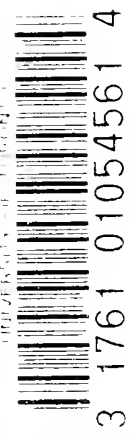

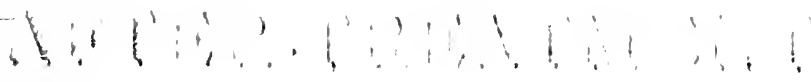

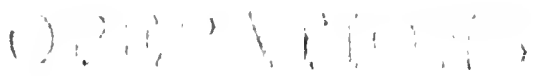
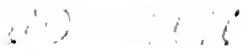


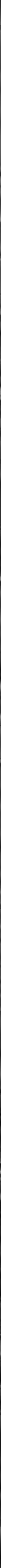



6.

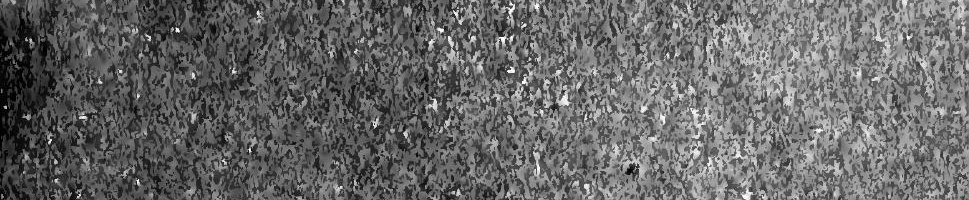
PN

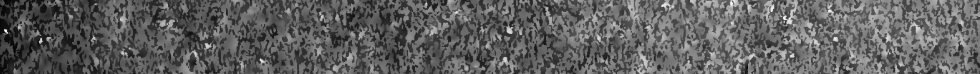

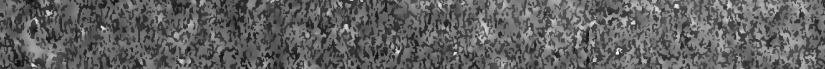

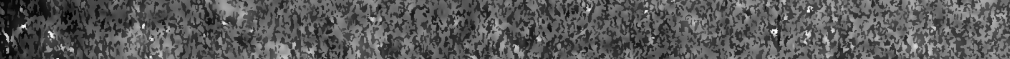
4.

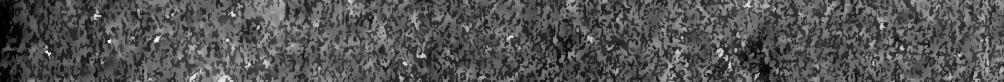
3 3.

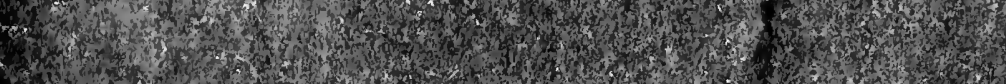
1.5.

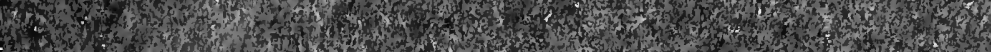

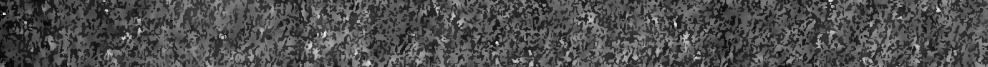

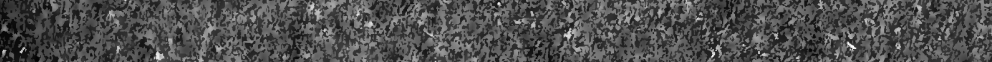

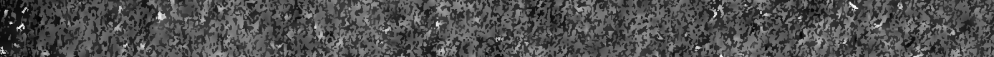

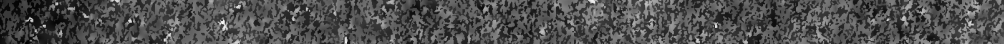
1.7.

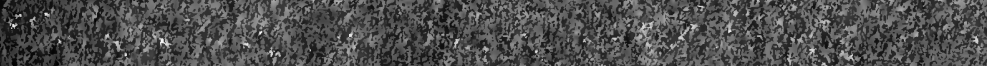

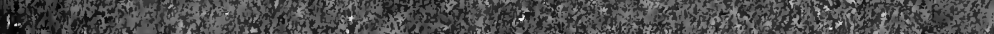
3.

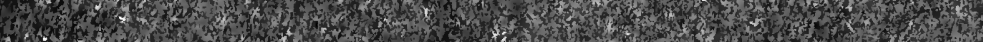

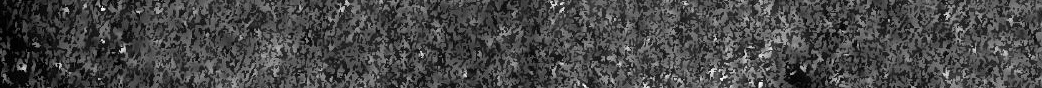
1.

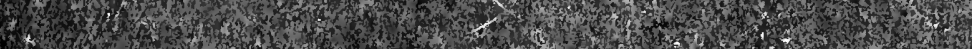

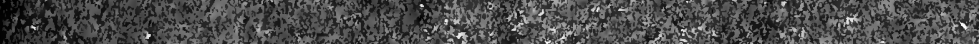

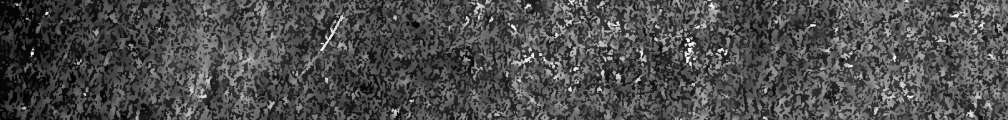

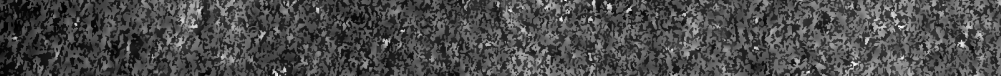

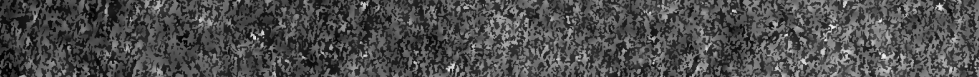

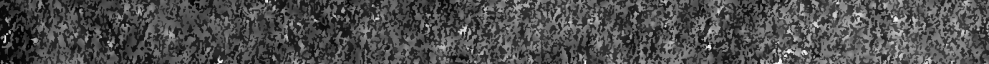

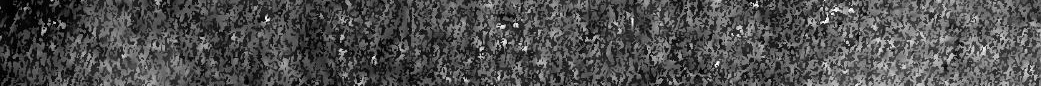

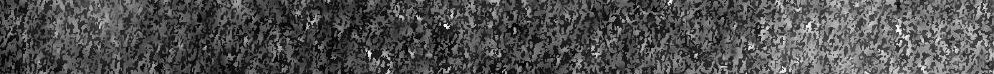

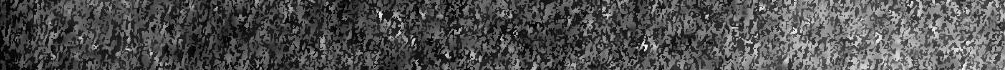

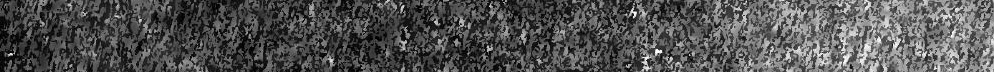

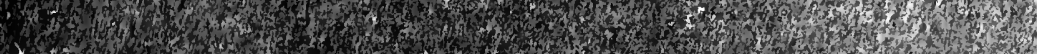
6. 



THE AFTER-TREATMENT OF OPERATIONS 
HORKS BY THE SAME AUTHOR

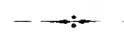

DISEASES OF THE COLON.

DISEASES OF THE RECTUM AND AnUs.

THE SIGMOIDOSCOPE. 


\section{THE AFTER-TREATMENT OF OPERATIONS}

\section{A sibamal for practitioncrs and lbonse suligons}

BY'

P. LOCKHART-MUMMERY, F.R.C S. ENG. B.A., M.B., B.C. Cantaf.

Scnior Surront, St. Wark's llostitizl for Cancer, Fistula, and other Diseases of the Rectum: The Cueen's Howital for Chitirin, London;

and Honorary Surseon to King Edilard ITllit's Hosfital for Officirs;

Stecial Consulting Surgeon to City of London Miliary Hospital and Fulidu: Military Hespital:

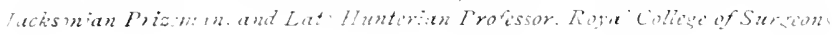

FOTRTH EIITION

$$
\text { TORONTO }
$$

MACMILLAN COMPANY OF C.NNADA. LTU. 


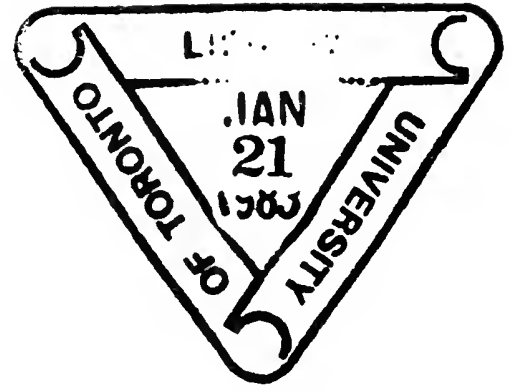




\section{PREFACE TO THE FOURTH EDITION}

The continued popularity of this book and the call for a fourth edition are very gratifying, and show that it has, at any rate, proved of real value to those readers for whom it was designed. In the present edition much new matter has been added, and the whole hook, as far as is possible, brought completely up to date. In particular the chapter on Surgical Shock has been entirely rewritten in the light of more recent work on this subject. Although the treatment of Gunshot Wounds is, perhaps, not strictly within the scope of this bnok, there are so many medical men at present acting as surgeons in charge of military hospitals of one lind or another, that the author thinks a chapter on this sulject will be a useful addition, more especially as he has received rejuests from old readers to include such a chapter in the present edition.

A very natural criticism that has been made by some reviewers of previous editions is, that while the aftertreatment of some operations is very fully described, that of others is only scantily treated. The author wishes to point out that this is necessarily so in a work of this size, as without greatly enlarging the book it would be impossible to describe the after-treatment of all the operations in any detail. Operations like gastrostomy, operations 


\section{vi Preface to the Fourth Edition}

on the brain, and, in general, those which are only performed by expert surgeons, do not require the same detailed consideration here, since the after-treatment of these cases usually is, and always should be, under the direct supervision of the operating surgeon, who, one may assume, does not require instruction on the subject. The after-treatment of the more common and less serious operations is, as far as possible, described fully, as these are the cases in which the after-treatment is most likely to be left to the general practitioner or house surgeon.

$$
\text { P. LOCKHART-MUMMERY. }
$$

9. Hyde Park Place, iv.

Afril, IgIt. 


\section{PREFACE TO THE FIRST EDITION}

THE after-treatment of operation cases is a subject of such importance that it is not a little surprising to find how little has hitherto been written about it. What has been written is to be found, for the most part, in a somewhat fragmentary form in the larger text-books, and is not convenient for reference.

I have attempted in the present manual to put the subject in a useful and practical form for ready reference by those who, having to treat such cases, wish to know what complications may be expected, and how they are to be met when present.

The after-treatment of operation cases adopted by different surgeons varies very considerably. But as no good purpose would be served by a recital of all the different methods, I have given in each case that line of treatment which seems to be the most practical, and have avoided entering into any discussion upon the relative merits of the different forms of treatment sometimes adopted.

In the chapter on shock, a short description of the more recent physiology of this condition has been included, in the hope that it may assist the reader in the treatment of this most important complication. 
viii Preface to the First Edition

Considerable space has been deroted to the after-treatment of abdominal cases, as it is here, perhaps more than anywhere else, of importance.

I have to offer my best thanks to MIr. Herbert Allingham for kindly looking through the manuscript, and to those others of my friends who have assisted me.

\section{P. LOCKHART-MUMAERY.}

Septimiver, 1903. 


\section{CONTENTS}

CHAPTER

I. INTRODECTORY

TAGF.

I1. TREATMENT OF THE WOUND - - $\quad-25$

III. TREATMENT OF GUNSHOT WOLNDS - - 43

IV. H.EMORRIAAE AFTER OPERATIRS - - 5I

V. SLRIICAL SHOCK $\quad-\quad$ - $\quad$ - $\quad$ - $\quad$ - 74

VI. POALANASTHETIC COIIPLICATIONS - - 97

VII. THROMBOSIS FULIOWING OPERAIIONS - IO6

VIII. POST OPERATIVE RASHES AND DRUG-POISONING IJ6

IX. OPERATIONS ON THE MOUTH, NOSE, AND PHARYNS - $\quad$ - $\quad$ - $\quad$ -

X. OPERATIONS ON THE HEAD - - - I I I

XI. OPERATIONS ON THE NECh - - = $1+9$

XII. OPERATIONS ON THE THORAX - - - I - IS

XIII. OPERATIONS ON THE ABDOMEN - GENER.IL

TREATMENT AND COMPLICATIONS - I69

XIV. OPERATIONS ON THE ABDOMEN (continued) - I97

XV. OPERATIONS ON THE GENITO-URINARY TRACT- 215

XVI. OPERATIONS ON THE RECTUN, AND COLOTOMY 228

XVII. OPERATIONS ON THE JOINTS - - $\quad 239$

XVIII. THE AFTER-TREATMENT OF AMPUTATIONS, AND

SOME SPECIAL OPFRATIONS - - - $\quad 250$

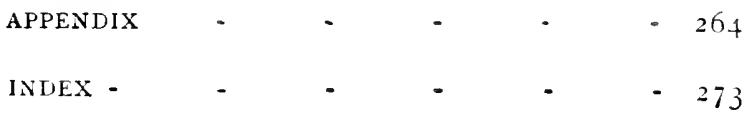

ix 



\section{TIE AFTER-TREATMENT OF OPERATIONS}

\section{CIIAPTER I \\ INTRODUCTORY}

THE after-treatment of operation cases is one of the most interesting studies in surgery, and at the same time one of the most important. Nothing will better repay careful and intelligent observation by those having such cases under their care. Whether an operation is successful or otherwise depends, of course, to a large extent upon the manner in which the operation is carried out and upon the skill of the operator, but it also depends to no small extent upon the care and attention which is paid to the after-treatment. The operation is the most showy and impressive part of the treatment of the disease or condition, and, in consequence, it has become too common to think that the operation is everything, and that the after-treatment is merely a matter of course. This is, however, not the case. Many operations depend for their success on the way in which the treatment afterwards is carried out, and many an almost hopeless case has been saved by skilful after-trcatment. 


\section{The After-Treatment of Operations}

To no branch of medicine or surgery does the old maxim 'Prevention is better than cure' apply more aptly than it does here. The best results will always be obtained by anticipating complications, and taking steps to prevent their occurrence, rather than by treating them after they are well established. Our line of treatment should be to put the patient under the most favourable circumstances for rapid recovery, and by bearing in mind the complications that are liable to occur, to anticipate then, and so treat the patient that they are avoided. A surgeon may perhaps get great credit for saving a patient by brilliant treatment when he is in extremis, but the best surgeon will, nevertheless, be he whose patient has never got into this condition. Artificial conditions should be avoided as far as possible, and when a patient has a natural desire for any particular thing, it should be gratified, unless there is some reasonable objection to doing so. Nature is, after all, the best judge of what is good for a patient or what is not good, and, as a rule, the patient will not wish for those things which are dangerous in his condition. There should be a definite reason for every course of treatment, and ruleof-thumb methods must especially be avoided. No two cases are exactly alike, even after an almost identical operation, and exactly the same treatment need not necessarily be adopted. When, after an operation, complications occur, the treatment should be prompt and thorough. Meddlesome interference, however, must be avoided, and as long as the patient is doing well he should be left alone. The after-treatment of operations may be said to be the study of details, and the two most useful adjuncts to success are careful observation and common-sense. There is a saying of the great physician Sydenham which is well worth bearing in mind: "More 


\section{Introductory}

importance is to be attached to the decires and feelings of the patient, provided that they are not excessive, than to the doubtful and fallacious rules of medical art.'

\section{The Importance of Posture in the After-Treatment of Operation Cases.}

It seenrs to have become an accepted dictum with many people that, after operations of a certain degree of severity, the proper position to nurse the patient in is the dorsal recumbent one. This seems to have been assumed on somewhat insufficient grounds. As regards the comfort of the patient, this position is not a success. It is not a natural position. Few people sleep on their

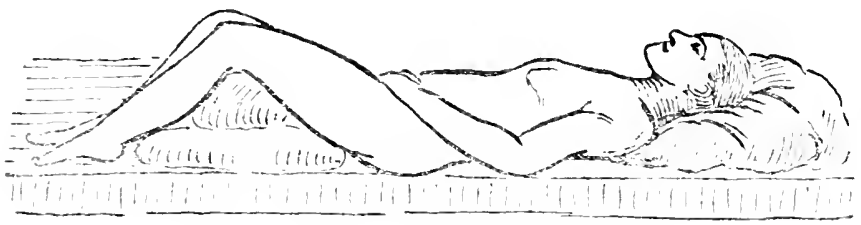

Fig. I.-DORSAL Recumbevit Posttiun

backs, and when those who are unaccustomed to it are obliged to do so they are often unable to sleep well. It is a very common experience to hear patients who are under treatment for fractures or some other complaint necessitating the dorsal position complain that their backs hurt them more than the injury, and who say that they would be quite comfortable if they were allowed to turn on to their side. Often their only complaint is the discomfort of the position.

The recumbent position on the back is not anatomically sound. The skin covering the sacrum and lower lumbar region is very badly supported for withstanding 


\section{The After-Treatment of Operations}

continuous pressure. The sacrum is very superficial, and in the majority of individuals there is but little fat and muscle between it and the skin. The same may also be said of the other bony points on the back. The angle of the spine of the scapula is just beneath the skin, and but slightly covered. The spines of the vertebræ also are immediately beneath the skin, and the latter is unduly subjected to pressure, owing to the prominent position of the spines. There are many other objections to the position. Women who are kept long in this position are very liable to develop cystitis from the presence of residual urine in the bladder, as most women are unable to empty their bladders completely when lying on their backs. This fact should be remembered, as it is a very common cause of cystitis in women after operations. It may be prevented by passing a catheter occasionally, but a much better way is to allow the patient to turn on to her side in order to micturate, or, if possible, to sit up for the purpose.

The Prone Position (Fig. 2).-This is often very much better than the dorsal position, and is particularly suitable when it is desired to drain a wound opening upon the anterior surface of the body, as in some cases of appendix abscess, psoas abscess, etc., or, again, when the dorsal position has resulted in the formation of bedsore, or it is feared will do so. In this position the patient lies on the face with a pillow under the chest, and another is placed to rest the side of the head upon. Patients soon become accustomed to this position, and often find it more comfortable when unable to move than the dorsal one. The front of the body is well provided against pressure, and bed-sores are practically never seen. (The knees are the only places where sores are at all likely to occur.) The tendency to distension of the 


\section{Introductory}

abdomen, which is common in the dorsal position, and especially when the patient is on a fluid diet, is much less, and the cystitis just mentioned in connection with the dorsal position in women does not occur, as the bladder is able to empty itself easily by gravity.

The late Mr. Allingham also pointed out the value of this position after injury to the main femoral vessels. Under such circumstances the integrity of the limb

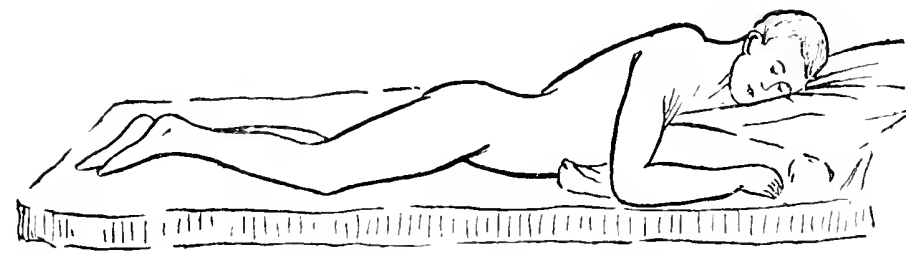

Fig. 2.-Prone Position.

depends upon the rapid development of a collateral circulation, and it is therefore of the greatest importance that the collateral vessels should be relieved from all pressure. As many of these collateral vessels are in the gluteal region and back of the thigh, the dorsal position is very unsuitable to this end, and the prone position should be adopted. Mr. Allingham had a case where it was necessary to resect a portion of both the main femoral vessels in removing a tumour of the femur, and in which the prone position was adopted; the collateral circulation was soon established, and the limb recovered perfectly.

Semi-Recumbent Position (Fig. 3).- - Here the patient is proped up into a half-sitting posture with pillows and a bed-rest; a bolster is also placed under the thighs to prevent the patient from slipping down in the bed. Care must be taken to see that there is not undue pressure 


\section{The After-Treatment of Operations}

on the lower part of the sacrum, otherwise bed-sore is apt to occur at this spot; this may be prevented by flexing the knees over a bolster or junk, and allowing the weight to

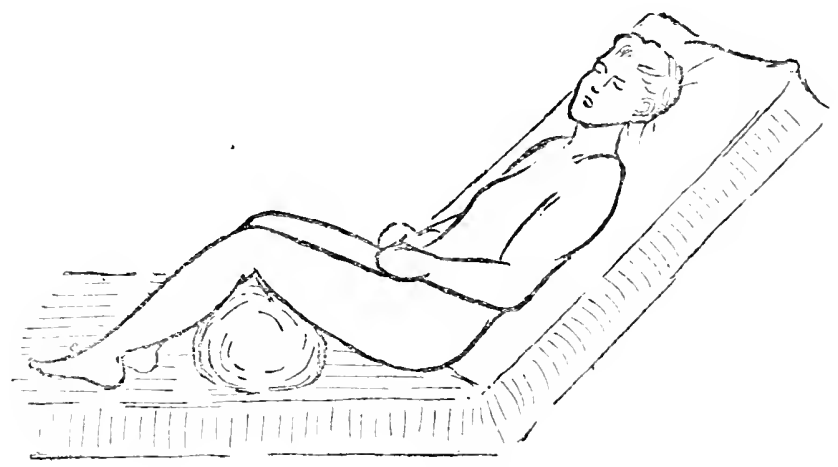

Fig. 3.- Semi-Recuntent Position.

be taken on the under-surfaces of the thighs. The bolster should be a stiff one (a good size is 3 feet long by 9 inches diameter), and should be attached to the head of the bed at either end with straps. A good substitute can be made by wrapping a blanket round a broomstick and tying the ends of the latter to the head of the bed.

This is the position in which all elderly people should be nursed whenerer possible. The recumbent position is particularly unsuitable for such patients, as, although their lungs may have been previously healthy, they are very liable to develop a moist bronchitis or hypostatic congestion of the lungs if kept lying down for any length of time, and this is particularly the case when the operation interferes with the thoracic or diaphragmatic movenents, as after removal of the breast or crerati ns on 


\section{Introductory}

the stomach, etc. This position is the best after most operations on the stomach, after operations on the thorax, and many others which will be mentioned later. It is also preferable to the recumbent position in many cases of weak or failing circulation, when this weakness or failure is in any way dependent upon deficient aeration of the blood in the lungs. This is probably to be accounted for by the greater freedom of the chest novements allowed by the position. This is also the position in which all patients should be nursed, if possible, who are suffering from peritonitis or in whom this complica. tion is feared. It allows the products of inflammation within the abdominal cavity to gravitate into the pelvis, where they will do least harm and can be most easily and safely dealt with. This is now often called 'the Fowler' position.

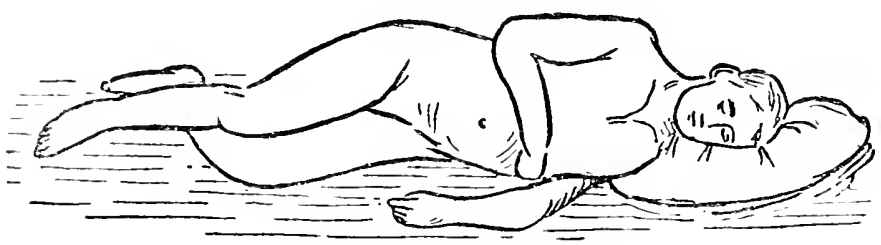

Fig. 4.--Lateral Position.

The Lateral Position (Fig. + ). - This is the natural resting position of most people, and it is the most comfortable position for many patients when circumstances will allow of its being permitted. The patient lies on the side with the under-knee well flexed and the upper one slightly so; the trunk should also be a little flexed. Many patients are rendered more comfortable if a pillow or bolster is put to support the back.

Position after Laparotomy.- - It has been, and to a 


\section{The After-Treatment of Operations}

large extent still is, customary to consider that the best position for patien:s after abdominal section-at any rate for the first few days-is lying on their backs; this is, however, unnecessary and inadvisable except in special cases. Comf rrt and sleep are here of the greatest importance, and if the patient can be got quietly to sleep during the first twenty-four hours after the operation, much will have been gained. As it is advisable in these cases to avoid the use of opiates as much as possible, it becomes all the more important to secure the patient's comfort. Patients after laparotomy are, as a rule, much easier if allowed to turn on to the sicle; they should be moved on to that side on which they are accustomed to sleep, and carefully assisted into the position which they find most comfortable, and in many cases they will drop off to sleep in a few minutes. No harm to the wound need be apprehended, and the position on the side with the knees well drawn up, by relaxing the recti muscles, often gets rid of the pain which sometimes follows the operation. This pain is no doubt often due to spasm of the abdominal muscles resulting from the traumatism, and relaxing these muscles by slightly flexing the trunk is often quite enough to stop the pain. When the abdominal wound is to one side and has not been closed, as in colotomy and appendix abscess, it is best not to allow the patient to turn on to the wounded side, as this might result in prolapse of the intestine; he may, however, be turned on to the opposite side with safety.

After abdominal section in children it is particularly important that no unnecessary restraint should be insisted upon. No child, unless it is very ill indeed, will remain for long in the recumbent position without constant watching or the use of some retentive apparatus; and constraint soon renders children restless and irritable, 


\section{Introductory}

and prevents them sleeping. If allowed to move about as they choose they seldom come to any harm, and, as a rule, keep much quieter than if subjected to restraint. In young children it is best to fix the dressing with broad pieces of strapping encircling the body; this prevents the movement of the child from disturbing the dressings, and at the same time supports the stitches. When it is necessary to keep a child on its back for any length of time, a preferable method to the use of shoulder straps is to apply extension strapping to the child's legs and to sling both legs up to a cross-bar, as in the treatment of fractured femur by Bryant's method. This is a much more effectual method than the use of shoulder straps, and children do not object to it so much; it also enables the child to be kept clean very easily.

As little restraint as possible should be put upon a child's movements after an operation, and the younger the child the more important this becomes.

Lastly, it should always be remembered in connection with the position of a patient after an operation, that the position of greatest comfort is also that of greatest rest, and therefore the best.

Illustrutive Case.-A child, aged six months, was admitted to the hospital for acute intussusception. Abdominal section was performed, and a large ileo-cæcal intussusception found which involved nearly the whole of the large intestine; the bowel was black and œedematous, but still shiny. This was reduced and the abdomen closed with fisi-gut sutures. The operation took about twenty-five minutes. Two broad pieces of strapping were fixed round the child's body over the first layer of dressings, so as to take the strain off the stitches. Previous to the operation the child had been entirely breast-fed. After the operation the child was not weaned, but was taken out of the cot by its mother and put to the breast every three or four hours. The first feed was given six hours after the operation. The child's movements were not restrained in any way, and it was fed exactly as if no operation had 


\section{Io The After-Treatment of Operations}

been performed. In spite of its youth and the damaged condition of the bowel it made an uninterrupted recovery, and left the hospital on the sixteenth day.

\section{Sieeplessness after Operations.}

This may be due to a variety of causes, and must be treated accordingly. Then due to pain, morphia must usually be given so as to secure a good night's rest. The commonest cause is undoubtedly discomfort, and everything should be done to make the patient as comfortable as is possible under the circumstances. If the patient complains that the bandages are too tight, these may be loosened a little; if he finds his position uncomfortable, he should be moved into a new one, and especially into that position in which he is accustomed to sleep; if he is thirsty, he should be allowed a drink of water, milk, or lemonade, etc. An ounce of whisky or brandy given in hot water will often act as a most effectual sleepingdraught, and can be very seliom contra-indicated. A very useful sleeping-draught for use after operations is the following :

$\begin{array}{llll}\text { R. Liq. morphine tartratis } & - & - & - \\ \text { Aquam pimentæ } & - & - & - \\ & - & \text { ad } \overline{3} \mathrm{i}\end{array}$

If morphia is not advisable chloral may be given, or any of the nunerous drugs which are now in use for insomnia; of these trional is one of the best, and should be given in 20-grain doses; it is often rendered more effective if administered with a little whisky and hot water. Paraldehyde is a very effective drug, but owing to its unpleasant property of making the patient's breath smell it often cannot be used; it should be administered in peppermint water with some syrup to disguise the taste:

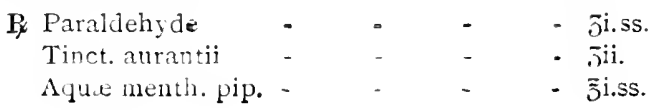




\section{Introductory}

It is always better to avoid the use of sleeping-draughts if possible, and they should never be made use of as a routine practice.

\section{Pain after Operations.}

A certain amount of pain after an operation is common, and may be due to a variety of different causes, such as tightly tied sutures, tight packing with gauze, powerful antiseptics in contuct with exposed nerve-endings, etc. In an ideal operation on a healthy subject there should be no pain afterwards, and after many operations, where healthy tissues have been cleanly cut, there is no pain. Unfortunately, a certain amount of pain is the rule after most operations, and it ought to be our olject to prevent, or at least ameliorate, this as far as possible. There is probably nothing which will make patients more grateful or bring the surgeon more credit than the relief of pain after an operation; and if patients find that they can undergo operations without suffering pain, much will have been done in making operation: less dreaded by the general public than they are at present.

Pain is due to the stimulation of nerve-tissue, and more especially of nerve-endings, and in a clean-cut wound this stimulation ceases when the cutting is finished; any pain that occurs after that is either the result of mosement in the part wounded or of tension, and in some cases of stimulation of the nerve elements by irritants. Movement taking place in the wound can be gurirded against by proper splinting, etc., except in the neighbourhood of the thorax, where it is more or less inevitable. Tension may occur in several ways: it may be from too tight splints or bandages, or tight sutures; in many cases it is due to congestion and swelling of the tissues of the 


\section{The After-Treatment of Operations}

wound. Pain from this cause is particularly well marked in acute inflammation. Thus, during the formation of an acute abscess, the tension in the abscess causes pressure upon the nerve-endings, and pain is the result, the severity of the latter being proportionate to the elasticity and nerve-supply of the part affected. Thus, when acute inflammation attacks the tightly bound down skin of the nose (as when boils occur at the margin of the nostril), or the pulp of the finger (as is the case in whitlow in this neighbourhood), the pain is out of all proportion to the severity of the inflammation. A certain amount of inflammation is set up locally after any traumatism, and it is the congestion resulting from this that gives rise to the pain in most cases.

In order, therefore, to prevent pain after operations, we should try to relieve this local congestion. The most effectual way of doing this is by elevation of the part. The pain which often follows amputations is often much relieved by well elevating the stump. Any bandages or clothes which, by pressing upon the veins on the proximal side of the wound may tend to keep up this congestion, should be loosened. By keeping in mind this cause of pain, much may often be done by the simplest means to relieve the pain following operations.

Another cause of pain after operations is spasm of the muscles in the neighbourhood of the wound. This spasm sometimes causes intense pain, and prevents the patient going to sleep. Pain from this cause can often be prevented, if the affected muscles are in the limbs, by flexing the joints or altering the position of the limb so as to relax the affected muscles. Spasm is much more likely to occur in a tense than in a relaxed muscle. Gentle smooth rubbing of the muscles, if it can be carried out, will immediately and effectually stop this spasm. 


\section{Introductory}

The value of heat for relieving pain, applied either in the form of fomentations or stupes, is well known, and it may sometimes be made use of in these cases. Unfortunately, it is seldom possible to make use of fomentations or stupes for the relief of pain after operations, as the wound is covered up with dressings which it is not advisable to remove. Cold applied by means of an ice-bag may sometimes be used; after operations upon joints, such as the knee, it is often efficacious in relieving the pain. A heavy ice-bag should not be allowed to rest upon the wound, as its weight will cause more pain than the cold will relieve. The bag must be suspended from a cradle or some other arrangement made to take the weight off the wound.

There are certain operations after which pain is generally severe for a time. Operations involving interference with bones seem to be peculiarly liable to be followed by severe pain, and especially such operations as excision of joints. Well-fitting splints which are not too tight and elevation of the limb will do much to relieve the pain in these cases, but morphia is often necessary as well. The pain can often be relieved in such cases by giving aspirin in Io grain doses every six or eight hours, beginning with 5 grains directly after the operation. The pain after operations on the stomach or intestines is best relieved by small doses of morphia or laudanum given by the mouth.

Drugs should not be given indiscriminately for the relief of pain, but should only be made use of when other means fail, or in conjunction with them. Opium in some form, and especially its derivative morphia, is the most valuable drug we possess for this purpose, but there are several other drugs which are sometimes of value. Phenacetin in 15 to 20 grain doses will often relieve pain 


\section{The After-Treatment of Operations}

if not very severe, and is a very safe drug to give, or Trional may be used. Forty grains of chloralamide placed on the back of the tongue is sometimes very effectual in stopping restlessness and procuring sleep. In all severe pain, however, morphia should be given in doses from $\frac{1}{4}$ to $\frac{1}{2}$ grain hypodermically, unless contraindicated for some other reason. The dose of morphia that has to be given varies very considerably, both as regards the individual and as regards the sererity of the pain, and it is well to bear this in mind. In some cases a small dose is quite as effectual as a much larger one would be; too small a dose, howerer, will in many people produce restlessness and excitement. Morphia must never be given continuously for more than a few days, as there is great danger of setting up the morphia habit. A week is probably the outside that it is safe to continue using the drug, without either intermitting the dose or reducing it. The pain after operations usually ceases after twenty-four or thirty-six hours at most; but when it does not do so, and it is necessary to continue the administration of morphia for its relief, the best plan after the first two or three days is to either reduce the dose by a half or to give an injection of plain water instead of, and at the time for, the usual morphia injection. 'The moral effect of this renders it often quite as effectual as the morphia would be, and this does not apply only to neurotic individuals; the most strong-minded pcople will often be quite satisfied by an injection of sterilized water if they imagine that it is morphia and it is given at the usual time. The results of the continuous use of morphia are so lad and so common that the greatest care must be taken to prevent the habit being established, and such an innocent deception is therefore perfectly justifrable. 


\section{Introductory}

\section{Smoking and Drug Habits.}

Patients often ask how soon they may be allowed to smoke after an operation, and many patients are very anxious to be allowed their pipe or cigarette.

Unless there is some olvious contra-indication, such as is the case after operations upon the throat or pharynx, it is advisahle to allow them to smoke in moderation as soon as they express a desire to do so.

Smoking often makes a patient more contented, and so adds to his general comfort and well-heingr.

It is never wise to entirely stop the use of tobacco in the case of a patient who is an halitual heary smoker. Under such circumstances the sudden abstinence in the use of tobacco is very liable to cause insomnia and indigestion, besides often making the patient miserable and discontented.

The same also applies to other drugs. Thus a patient who is accustomed to take large quantities of alcohol daily should not be entirely forbidden his accustomed stimulant, but should be allowed alcohol in moderation.

And in the case of a morphia maniac it is nerer wise to stop the use of the drug or eren to reduce the dose: the patient should be allowed his ordinary daily dose of morphia at the time at which he is accustomed to have it. These patients are always bad subjects for operations, but it not infrequently happens that it is necessary to operate upon them, and the risks of the operation are much increased if, at the same tine, the drug is stopped.

It must always be remembered when dealing with a patient who is the slave of any drug, whether it be tobacco, alcohol, or morphia, that from long habit his normal condition of both menta! and bodily equilibrium is that in which he is more or less muder the influence of 


\section{The After-Treatment of Operations}

his particular drug; and that to suddenly make him an abstainer is to change him into an abnormal state.

I am sure that the only satisfactory way of obtaining good results from operations performed upon such patients is by assuming that their normal condition is when under the influence of their particular drug, and to treat them accordingly.

\section{Thirst.}

Thirst is a very common complaint of patients after an operation. This thirst is no doubt partly due to an actual loss of fluid from the body. There is generally free perspiration either during or immediately after an operation; the salivary glands also secrete freely, and there may have been fluid in the shape of blood or serum lost from the wound, so that the total fluids lost from the circulation during a long operation may be considerable. Also after operations of any degree of severity there seems to be a tendency for the secretion of mucus from the mucous membranes to be inhibited for a time. This results in the mucous membrane of the mouth being dry, and makes the patient feel thirsty.

The practice of only allowing patients after an operation to have sips of hot water is to be deprecated. It is neither sound in theory nor practice. The body is in need of fluid, and nothing is to be gained by withholding it. Unless there is some very definite contra-indication, which is but seldom the case, the patient should be allowed to slalie his thirst with water or any other suitable fluid, the only restriction being that a large quantity is not swallowed at one time (the quantity should not be more than $\frac{1}{2}$ pint at a time). The contention raised against the practice of allowing fluids in proper quantities is that it causes sickness. As a matter of fact, it does 
not often do so, and when it does the fluid is beneficial in washing out the stomach, and the paticnt is much more comfortable afterwards; while, on the other hand, sips of hot water are just as liable to cause vomiting, and neither satisfy the patient's thirst nor wash out his stomach if he is sick. Hot tea is often very comforting, and can do no harm; a good plan is to give a cup of weak tea with a sliee of lemon and a little sugar in it. Thirst should be looked upon as the natural call of the body for more fluid, which may be administered either by the mouth or rectum, according to circumstances. It is difficult to see how, apart from its causing sickness, water can do harm under any circumstances. It needs no digestior, and does not cause peristalsis.

When thirst is troublesome, and there is some reason which renders it inadvisable to give fluid by the mouth in any quantity, large warm-water enemata should be given. Many surgeons make a practice of giving a warm saline injection por rectum immediately after any long operation; this is an excellent plan. The practice of filling the abdominal cavity with warm saline solution before closing the wound is a most effectual way of preventing the thirst which so commonly follows abdominal operations; and this method is still used by some surgeons, though the majority consider it injurious to the peritoneum, and therefore prefer the administration of water by the rectum or subcutaneously.

\section{Flatulence.}

This is often a troublesome complication after operations, and causes the patient considerable discomfort. The following is an excellent prescription for the relief of this condition :

B. Sal volatile, $\bar{s}^{\mathrm{i}}$.

Sodium bicarbonate (a pinch).

In a wineglassful of water. 


\section{I8 The After-Treatment of Operations}

This generally gives immediate relief. A few drops of peppermint on a lump of sugar or soda-mint tabloids are also very useful. The best way, however, of relieving flatulence is to open the bowels by administering an aperient or to give a turpentine enema:

$$
\begin{aligned}
& \mathrm{R} \text { Turpentine } \quad \text { - } \quad \text { - } \quad \text { - } \quad \text { Jss. }
\end{aligned}
$$

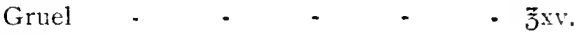

The author has for some years used hypodermic injec. tions of the infundibular portion of the pituitary gland for this purpose, with excellent results. One cubic centimetre of a standard preparation of this drug should be injected about five minutes before the administration of an enema. As a rule, a free evacuation of wind will occur almost immediately. The author has found this drug quite invaluable in bad cases of abdominal distension. Eserine is another drug which has been similarly used.

\section{Bed-Sore.}

This troublesome complication will occasionally arise in spite of the greatest precautions. It is, however, usually a preventable complication, and should not occur when proper trained nursing is obtainable. The question of the relation of the position of the patient after the operation to the formation of bed-sores has already been spoken of (p. 4). Soiling of the bedclothes, due to lack of proper care after the patient has micturated or the catheter has been passed, rucking up of the patient's nightdress or of the bedclothes, are all frequent and easily preventable causes of bed-sore. By far the most potent cause of bed-sore is a moist condition of the skin where it is subjected to pressure, and the greatest care should always be taken to keep the skin as dry as possible. After a bed-sore has formed, the part must be relieved 
from all pressure, either by turning the patient into another position or by the use of ring air-cushions, ete. The sore itself must be kept dry, and must not be treated with strong or irritating antiseptics; boracic powder or Fuller's earth are the best applications to use, but they should not be allowed to form crusts orer the sore. If much sloughing takes place, the patient must be turned over upon the face or side and the sore dressed frequently and kept as ciean as possible. Dry dressings are much preferable to wet ones, unless it is decirable to hasten the separation of the slough, when the following dressing will be found useful:

R. Unguenti sambuci viridis - - - partes ii. Unguenti elemi - • • - ." xvi. Copaibæ - • • • ", iii."

This dressing should not be allowed to come into contact with the healthy skin round the sore.

Painting the sore over with Friar's balsam will some. times hasten the healing process. If there is much destruction of tissue, Thiersch grafting should be $\mathrm{cm}$ ployed to hasten healing and prevent scarring. 'The sore should first of all be got quite clean, and then all the granulation tissue should be scraped away and the grafts laid on the underlying fibrous tissue; the dressing should not be removed for at least a week. Thiersch grafting, if properly done, often gives most excellent results in these cases, and considerably hastens the healing process.

The worst cases of bed-sore are those which occur in pyæmic cases and cases associated with some spinal lesion; in many of these cases a bed-sore will form in spite of the utmost care.

The separation of the slough is often a very slow process in the bad cases, and it is sometimes advisable to

* St. George's Hospital Pharmacopaia. 


\section{The After-Treatment of Operations}

hasten it by occasionally cutting through the toughest bands of fibrous tissue with a pair of scissors, care, of course, being taken not to cut into healthy tissue. Hydrogen peroxide is a most valuable disinfectant and antiseptic to use in these sloughing cases; it should be painted or sprayed on frequently. Sanitas on lint is also a grood dressing.

\section{Post-0perative Insanity or Mania.}

This is a condition which is but seldom met with. It does not seem to bear any definite relation to the operation-that is to say, as regards cause and effect. The symptoms usually first show themselves during convalescence. The onset of insanity or mania is probably to be attributed to the mental anxiety and morbid brooding over the operation by a mind which is naturally unstable rather than to any direct effect of the operation itself. Sometimes a patient who is the subject of re curring attacks of insanity may get an attack after an operation; in this case the operation acts merely as an exciting cause. The condition is more often seen in women than men. It is said that a suicidal tendency is a common and well-marked feature of most cases.

Professor Clifford Allbutt describes the condition as one of neurasthenia rather than of insanity, and says that a certain degree of it more commonly follows operations than is generally supposed. He does not, however, point out why this should be the case; and it is possible that in some of these cases a patient of a particularly morbid turn of mind has thought herself to be suffering from some affection, and has so far deceived her medical attendant that he has advised operative interference, which, having been duly carried out, has subsequently been ascribed as the cause of her mental condition. 
Many of the earlier cases of acute and fatal postoperative insanity which have been reported, or have found their way into the literature on the subject, were in all probability cases of acute sepsis or cerebral abscess resulting from the operation, and were therefore not in reality insanity at all. In one case of supposed postoperative mania which came under the observation of the writer, it was discovered at the post-mortem examination that there was a large abscess in the brain.

Under the name post-operative psychoses, several forms of mental derangement have been described which only affect the intellectual functions; the symptoms are mainly a melancholic type of insanity commonly accompanied by delusions.

This type of insanity seems to be most common after operations upon the sexual organs, such as ovariotomy, hysterectomy, removal of the breast, castration, etc., and after operations such as colotomy, gastrostomy, etc., the results of which constantly remind the patient of his, or her, diseased condition. It has been pointed out that operations upon persons of a highly-strung and nervous temperament may occasionally be followed by a complete nervous breakdown and general neurasthenia, which may persist for a considerable time, and thus greatly delay recovery. Dr. Burr quotes a case where a young man of highly nervous temperament, but whose previous health had been good, was attacked by appendicitis and operated upon. After the operation he made, from a surgical point of view, a good recovery; but he remained prostrate in bed, unable to do anything from complete nervous breakdown, and it was some months before he was well again.

Before operating upon all such patients the greatest care should be talien to prepare them properly for the 


\section{The After-Treatment of Operations}

operation. An attempt should be made to get them into a better mental condition by careful attention to the general nutrition and hygiene, and they should be given, as far as possible, a complete rest in both body and mind, so as to get them into a normal mental condition before performing the operation. There can be no doubt that in the careful preparation of the patient befor ehand lies the chief safeguard against post-operative mental conditions.

In examining the recorded cases where mania has followed an operation, it is noticeable that in a large number of the cases the wound was septic. This suggests that the mania might have been due to septic poisoning rather than to any mental change in the patient produced directly by the operation, and that such cases should really be looked upon as delirium, similar to that which may occur in the course of any acute infection.

A well-marked group of cases are those where delirium tremens follows an operation upon an alcoholic subject. I think that in these cases the partial starvation or alteration in diet necessitated by the operation is more often the cause of the delirium than the actual operation itself. When an alcoholic patient has to be operated upon, the best way of preventing the occurrence of delirium is to first accustom the patient to a reduced and altered diet, and to the change in conditions which the operation necessitates.

Dr. Savage has recorded a large number of cases which seem to show that the anæsthetic alone may be the cause of mental disturbance in some cases. The use of iodoform in the wound has also been considered as the cause by some writers.

As regards the important subject of prognosis, the late 
Mr. Clinton Dent, who collected a large number of cases, came to the following conclusions:

The prognosis is most grave when acute mania occurs shortly after a serious operation, although the purely surgical aspect of the case may be favourable. The more chronic the mania the better is the prognosis so far as life is concerned.

In ordinary insanity the prognosis is farourable if the patient gains weight and strength.

Illustrative Case. - Sarah C., married, aged forty-eight, was admitted to St. George's Hospital. She had had eight children, of whom six were alive and well, and the youngest six years old. She had always lived in the country, was of healthy appearance, of slightly reserved manner. Absolutely no history, even remote, of hereditary disease, and no trace of insanity in her tanily.

Four years previously she had noticed a small swelling in the abdomen on the left side; this increased rapidly up to a certain point, and then appeared to remain stationary.

Ovariotomy was performed. The tumour consisted of one large cyst and several smaller cysts. Ether was given. The progress of the case subsequently for the first six days was satisfactory enough; she was cheerful, anxious to get well, and slept and ate normally. On the sixth day her physical condition was satisfactory, but her expression had entirely altered. She still recognised her husband and those who were immediately concerned with her care, but her mind was full of delusions, varying in their nature, but all, to her, of an alarming character. She was very restless in bed. On the eighth day she was in a condition of acute mania. She recognised no one, attempted to injure those about her, and was very violent. The hair became coarse and rough. There was a little superficial suppuration in the wound, where she had torn the edges apart in her struggles, but in all other respects, so far as the immediate operation was concerned, everything was perfectly satisfactory. During the next eight-and forty hours the mania continued with undiminished intensity. Her physical condition became weaker, and the greatest difficulty was experienced in getting her to take any food. She died exhausted on the eleventh day. No iodoform was used, nor carbolic acid; no peritonitis was found, nor, indeed, anything in the abdomen worthy of note, at the post-mortem examination 


\section{The After-Treatment of Operations}

Illustrative Case.-E. H., an unmarried woman, aged thirty-one, had been suffering for some months from rectal hæmorrhage, and on examination this was found to be due to cancer of the bowel. She was of rather a nervous and excitable temperament, and was just about to be married at the time of this distressing discovery. She was not informed of the nature of the trouble, but was told that an operation was necessary. The operation was agreed to, and I removed the rectum and growth, and was able to bring down the sigmoid and restore the normal anal opening. The result was extremely satisfactory, and the wound healed by first intention without any rise of temperature. She was able to return home in three weeks, and in a short time regained the normal use of her bowels. The result from a surgical point of view was excellent, and the patient appeared contented and most reasonable. But about four months later she began to show signs of severe melancholia, and in spite of the fact that she suffered no inconvenience as the result of the operation, beyond the necessity of occasionally using an enema, she developed suicidal tendencies, and became so unmanageable that she had to be confined in an asylum. Her mental symptoms gradually improved after this, and she made a complete recovery. A year and a half after the operation she was quite well, and six months later she got married.

\section{REFERENCES.}

Picque and Briand: Arhizes de Neurologie, March, Igo3.

'Unusual Forms of Nervous Prostration following Operations': Lancet, May I7, 1902, p. If 5 .

'Paralyses and Psychoses following Prolonged Anæsthesia': Lancet, June 3, I\$99, p. 1508.

Article by Dr. C. Burr, Philadclfhia Medical Joumal, April 19, 1902. 'Insanity following Surgical Operations ': C. T. Dent, Joumal of Mental Science, April, i 889 . 


\section{CHAPTER II}

\section{TREATMENT OF THE WOUND}

IN these days the vast majority of wounds are aseptic and run an aseptic course, and it is not necessary or even advisable to change the dressings often. From one cause and another, however, suppuration will sometimes take place, and it is therefore a matter of considerable importance to detect the presence of suppuration when it does occur at the earliest possible date, so that it may be promptly dealt with; and not to discover, perhaps at the end of a week, on removing the dressings, that the wound has all broken down and the dressings are soaked with discharge. The temperature chart, if properly interpreted, is a most valuable guide to the condition of the wound, and a chart of the temperature should always be kept after any operation.

It is important to remember that a rise of temperature during the first thirty-six or even forty-eight hours is the rule after an operation of any magnitude. On examining a hundred consecutive cases after operation in the wards of St. George's Hospital, in all of which the wound ran a perfectly aseptic course, the writer found that a rise of temperature occurred in 85 per cent. within the first fortyeight hours. The following table will show the results of this investigation : 


\section{The After-Treatment of Operations}

Table of the Temperatures during the first Fortyeight Hours of ioo Consecutive Cases of OperaTION IN WHICH THE WOUND REMAINed ASEPtic.

There was a rise of temperature to or above

Per Cent. $100^{\circ} \mathrm{F}$. in .. $\quad$.

There was a rise to or above $99^{\circ} \mathrm{F}$. in $\quad . \quad \quad \quad . \quad 46$

There was a rise above normal, but below $99^{\circ} \mathrm{F}$. in 12

The temperature remained normal or fell below it

in ..

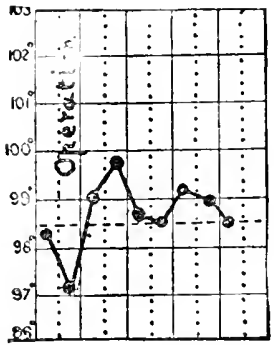

Frg. 5. - Radical CURE OF HERNIA (ASEPTIC).

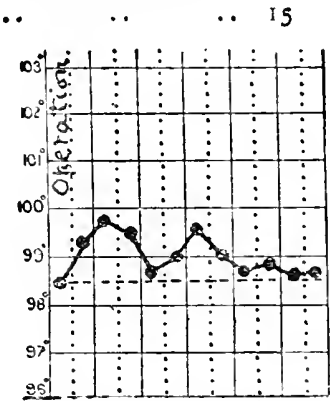

Fig. 6.-Amputation of THE THIGH (ASEPTIC).

This shows the double rise.

It is further noticeable that in children this rise of temperature is often much more marked than in adults; the high temperature is often a morning one, and is followed by an evening drop. The rise in children may be very high sometimes, and in the above Ioo cases one child had a temperature of $104.5^{\circ}$ (Fig. 9), though there was no cause discoverable beyond the operation. After operations involving interference with bone, it is

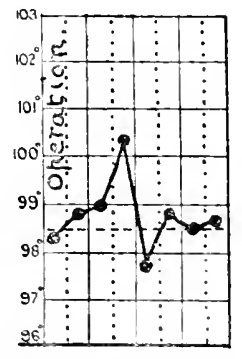

FIG. 7. - AMPUTATION OF THE BREAST (ASEP. TIC). 


\section{Treatment of the Wound}

remarkable that the post-operative pyrexia is often high; the operation for the ligature of piles also

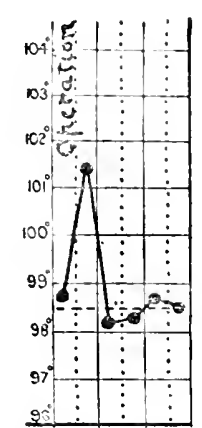

Fig, 8,-Operation FOR HARE-LIT ON A CHILd Five Months OLD.

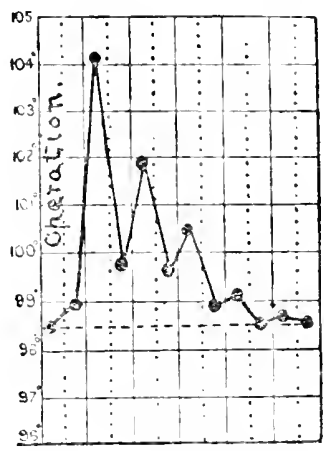

Fig. 9. - LAPAROTOMY FOR INTUSSUSCEPTION ON A CIIILD AGED Two Years (ASEPTIC).

seems often to result in an exceptionally high temperature (Fig. IO). It was found in the investigation of the above 100 cases that a second slight rise in

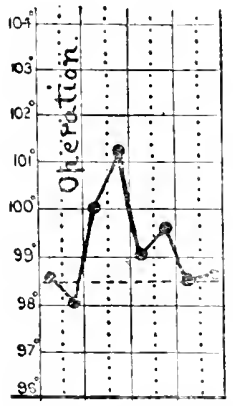

Fig. io - OperaTION FOR PILES BY LIGATURE (ASEPIIC) the temperature not uncommonly followed the first (see Fig. 6).

This rise of temperature is probably due to reaction, and is what the textbooks describe as aseptic fever. There is generally a preliminary drop to a subnormal temperature immediately after the operation, followed by reaction and a rise to about $99^{\circ}$ or $100^{\circ}$ (Fig. 5). In some cases, and especially in children and young adults, the rise is considerably higher; this would naturally be expected, as young patients always react much more 


\section{The After-Treatment of Operations}

violently than older ones. Again, in the case of patients who are in exceptionally good general health at the time of the operation, the reaction and consequent temperature is often high. The rise of temperature usually takes place on the first night after the operation, sometimes on the second. This rise of temperature is a good sign, as it shows reaction, and is very much better than a drop to a subnormal temperature which persists. This postoperative temperature or aseptic fever should therefore

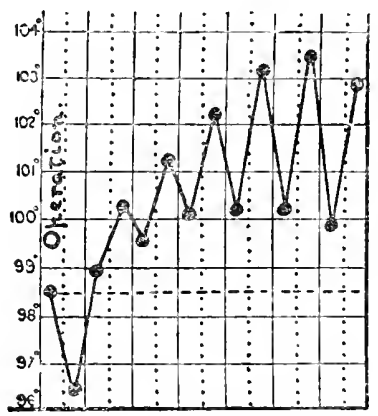

Fig. it.-Operation on the KneE-JoInt (SEPTiC).

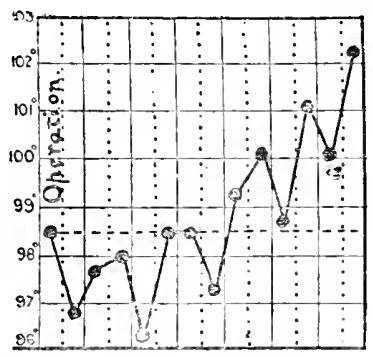

FIG. I2. -OPERATION FOR Radical Cure of Hernia (SEPTIC).*

be expected, and must not be confused with a temperature due to sepsis; it usually falls again at once, and the subsequent temperature is normal. After very severe operations involving much shock, this post-operative temperature, as one would expect, is often delayed until the shock has passed off.

The above was written in 1903 , before the use of rubber gloves and masks became the usual practice, and some modification of these views is now necessary. It has been decided, however, to let the passage stand, as it is

* There was pus in the wound on the fourth day. 


\section{Treatnient of the IVound}

essentially correct, although by the use of the present surgical technique the reactionary temperature is often abolished, and no alteration of temperature occurs. In other words, the high reactionary temperature then seen in the healing process of wounds which healed by first intention was sometimes due to the reaction against micro-organisms introduced into the wound, but which the tissues dealt with successfully. Blood-clot in a wound will, however, often give rise to a sharp reactionary temperature, quite apart from septic infection.

When the wound is septic, this preliminary rise in temperature is not followed by a drop, but persists, often to become intermittent later on (Fig. I 1); or the preliminary rise is absent, being replaced by a slightly subnormal temperature for the first two or three days, and is then followed by a rise to $102^{\circ}$ (Fig. 12) or higher. In most cases when the wound has become septic the temperature rises on the evening of the second or third day, and sometimes as late as the fifth or sixth day after the operation. So that a rise of temperature during the first forty-eight hours, unless accompanied by other local or general signs of sepsis or unless it remain up, need not be looked upon as evidence of sepsis, but, on the other hand, as a favourable sign ; persistence of this temperature, however, especially in the morning, or a rise occurring after the second day following the operation, is to be looked upon as evidence of sepsis, and should be followed at once by an examination of the wound. Unfortunately, in a certain number of cases the chart shows a perfectly normal temperature, except, perhaps, for the reactionary rise; and yet when the wound is examined some days after the operation, it is found to have broken down and contain pus. These are mostly cases where blood-clot has been left in the wound, and some comparatively non-pathogenic organism, such 


\section{The After-Treatment of Operations}

as Staphylococcus pyogenes albus or citreus or the Bacillus epidcrmidis, has obtained access to it and converted it into pus. When a wound that has apparently healed breaks down ten days or a fortnight after the operation, it is generally due to infected catgut used for buried sutures, sepsis commencing at the time when the sutures begin to dissolve.

In such cases there is usually but little local inflamma. tion in the wound, but a cavity is found containing pus which originally contained blood-clot. The condition does not, as a rule, cause any temperature or pain, though the patient may sometimes complain of dis. comfort at the site of the wound. Fortunately, this condition is not of very serious import, and such wounds heal very rapidly after the removal of the pus, providing that care be taken to prevent the wound becoming subsequently infected by some more virulent organism. Pain referred to the site of the wound, if it continues, is often a sign of inflammation and sepsis. After the first twenty-four hours an aseptic wound, unless it be in some special situation, is, as a rule, painless.

At the present time, with the best technique, infection of surgical wounds, unless infection is present at the time of operation, should be a very rare occurrence. Many surgeons have reduced their proportion of cases in which infection of the wound talies place to fractions of I per cent.; and any surgeon who finds infection occurring in even I per cent. of his cases should seriously rerise his methods. The latest figures published from the Mayo clinic are I I 7 cases of infection in 6.825 cases, or 0.017 per cent. (Surgery', Gynecol., and Obstet., May, Ig I. ). 


\section{Treatment of the Wound}

\section{Aseptic Wounds.}

I. Where the Dressings hine not beEN SOAKED THROUGH BY OOZING.-Unless the dressings have become loose or soiled, the wound need not be dressed until the time has come for the removal of the stitches. The time at which the stitches should be remored varies considerably in different cases. In moderately small wounds they should, as a rule, be removed about the sixth or seventh day after the operation. In wounds on the face or neck they may be removed earlier, as healing in this situation is rapid, and it is particularly desirable to avoid scarring; they should be removed about the second or third day. In the case of large wounds, or wounds the edges of which are subject to tension, the stitches should be left for ten days or a fortnight. It is also advisable to leave the stitches somewhat longer when the skin round the wound is not well nourished, as is often the case in wounds for the removal of varicose veins of the leg.

Some surgeons habitually dress all wounds on the second or third day after the operation. This, however, seems unnecessary and inadvisable in the majority of cases. Usually a certain amount of blood oozes from the wound immediately after the dressings are applied. This soaks into the dressings, and, hardening, sticks them to the wound and surrounding skin, thus forming a sort of splint to the wound, which acts very beneficially in keeping it and the surrounding slin at rest. Of course, when this oozing has come to the edge of the dressings, and has come in contact with the air, it should at once be changed, as otherwise it may act as a tract for the entrance of septic organisms.

A pair of scissors and forceps which have been 


\section{The After-Treatment of Operations}

sterilized by boiling should be at hand in a tray containing carbolic lotion. The bandages should then be cut through with a different pair of scissors, and removed, together with the cotton-wool, so that the wound remains covered only with the gauze. A warm towel which has been previously sterilized, either by boiling or immersion for some time in carbolic lotion, should then be placed round the gauze covering the wound. The surgeon should then clean his hands in the ordinary way, by first scrubbing them with soap and water, and then immersing them for a minute or two in some antiseptic solution, preferably an alcoholic solution of biniodide of mercury ( $\mathrm{I}$ in $\mathrm{I}, 000$ ). The gauze should next be removed from the wound. If it is much stuck, it is best to soak it well with some lotion before removing it. As soon as the gauze is removed the wound should be covered with a swab or a piece of gauze, and the skin round swabbed over with lotion to clean it. If the wound appears to be healed, which will probably be the case, the stitches should be removed.

The slim is now often prepared before operation by using iodine, which is painted over the wound area; and in this case, when the dressings are changed or the stitches are to be removed, the wound should be again painted over with the iodine solution. When iodine solution is used, the skin round the wound should not be made wet with a watery lotion, as this interferes with the action of the alcoholic iodine solution.

Removal of Stitches.-This is best done with a pair of blunt-pointed scissors which cut well at the points. All the stitches should be divided first before any of them are removed. The scissors should be used on the flat, one blade being inserted below the stitch, and then the latter cut as close as possible to the slin surface. The forceps 
should be used to steady or lift the stitch if necessary. After all the stitches have been cut they may be removed by pulling on one end with the forceps. If the stitches are not cut through close to the slin an elbow or linki will probably be left in the stitch which will cause pain when it is drawn out through the stitch-tract. This applies especially to stiff sut:ures, such as fish-gut. If the stitches are removed in this way, very little pain will be caused, and with a nervous patient this is a point of some importance. When the stitches have become buried in the skin, as is often the case in abdominal wounds, especially in fat people, the cut ends of the suture, which can always be seen, should be pulled on with forceps until the knot comes into view; then the points of the scissors (held on the flat) must be passed down behind the knot, and the suture divided and withdrawn. It is often advisable not to remove all the stitches at one time, but to leave a few till a later date. If after removal of the stitches the wound is found to be dry and does not gape, it may be sealed up by placing over it a piece of dry gauze cut to the required shape, and painting over the whole with flexible collodion. A large pad of cotton-wool is then placed over it and the bandage applied, or the latter may be dispensed with altogether if the wound is a small one. Should there be any gaping or other reason rendering it undesirable to seal the wound, it may either be redressed as before with wet gauze, or powdered over with boracic acid powder or dermatol, etc., and covered with dry gauze and cottonwool. When there is much gaping of the wound after removal of the stitches, the edges should be drawn together with strapping. The so-called American or Mead's strapping should be used for this purpose, and the part crossing the wound should be cut very narrow. A 


\section{The After-Treatment of Operations}

good plan of cutting the strapping is shown in the ilius. tration (Fig. 13). Two pieces, $A B$ and $C D$, are cut of the shape shown; the part $C$ is fixed to the skin on one side of the wound, and the part $\mathrm{B}$ on the other. The part $\mathrm{A}$ is then passed through the gap in $C D$, and $D$ and $A$ are pulled upon in opposite directions until the gap is closed and the edges of the wound well approximated; they are then stuck down.
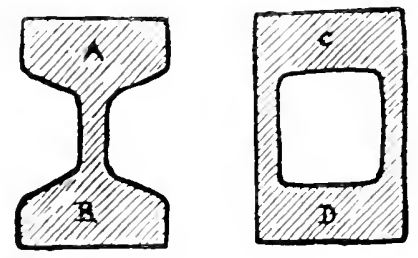

FIG. I3.

2. Where the Dressings have been soaked THROUGH. - When blood from the wound has soaked through the dressings and stained the bandages, the wound should at once be dressed. This should be done in the same way and with even more care than in the case of a wound which is not dressed until the stitches are removed. Even if only a little blood has soaked through at one part of the dressings it is better to change them, as otherwise the blood which has soaked into the dressings may act as a tract for the entrance of organisms to the wound.

3. Where Drainage has been provided for by a Tube or Gauze Plugging at the Operation.-As a rule, it is better to remove the tube at the end of twentyfour or forty-eight hours. This will, however, depend a good deal on the reasons for which the tube was used. It is not desirable to leare a tube in an aseptic wound 


\section{Treatment of the Wound}

longer than is absolutely necessary, as a very unsightly scar with inverted edges is apt to result, and the healing of the wound is delayed. Also there is seldom any necessity for the use of a tube after the first twenty-fuur hours. A very good plan is to pass a stitch through the skin on each side of the tube and to leave the ends untied. The stitch can then be tied up after the tube has been removed. Great care should be taken in dressingr these wounds, as there is of necessity an open tract into the depths of the wound, and healing is at a stage when infection can readily take place. Special care should be taken to clean up the skin round the wound with antiseptic lotion and swabs. This should be done from the wound, and not towards it. Thus a swab which has been used for cleaning the outlying areas of the slin must not subsequently be placed in contact with the wound. The dressing should be carried out in the same way as before, except that the wound should not be sealed up with collodion, and it is best not to apply any of the antiseptic powders, as they are often not sterile.

In many operations, notably in abdominal section for localized peritonitis and operations for necrosis or abscess of bone, it used to be a common practice for the cavity to be left plugged with gauze, the end of the gauze being left protruding from the wound so as to act as a drain. When a large cavity in the abdomen has been plugged in this way, it is often rather difficult to remove the plug without causing the patient a considerable amount of pain. The best plan is to leare the plug in for five or six days or even longer until it has become loosened; it will then, as a rule, be found to come away quite easily. While the gauze is being removed it should be wetted from time to time with some suitable antiseptic lotion, 


\section{${ }_{3} 6$ The After-Treatment of Operations}

or with peroxide of hydrogen, 5 volumes per cent., as it is much more easily removed when it is wet than in a half-dried condition. It should be drawn upon first from one side and then from the other, and considerable patience is often necessary in order to avoid hurting the patient. In cases of acute necrosis of bone, etc., when a cavity in the bone has been packed with gauze, it is not advisable to wait until the gauze has become loose, and the packing should be removed in twenty-four or fortyeight hours; as this is frequently a very painful proceeding, an anæsthetic should be administered. Nitrous oxide is quite sufficient for this purpose, and under its influence the gauze can be quickly removed, and the cavity, if necessary, repacked. This practice of plugging wounds with gauze is now practically obsolete, cavities being simply drained with tubes or left open.

4. When the Wound has become Septic. - When from the condition of the patient's temperature or from some other indication it is suspected that the wound has become septic, it should at once be dressed, the same care being exercised as if dealing with an aseptic wound. It is sometimes thought that it is not necessary to take the same aseptic precautions in dressing a septic wound as with one which is aseptic. This is quite erroneous. Sepsis may result from many different linds of organisms of varying pathogenicity and virulence, and if the wound is carelessly dressed fresh organisms may get in, which will find a congenial soil in the already septic wound, and a much more serious type of sepsis may be the result.

The wound having been exposed and found to be inflamed and septic, a sufficient number of stitclies should be cut through to allow a free exit to the pus and to relieve all the tension on the tissues. This is a very 


\section{Treatment of the Wound}

important point, as if the pus is subjected to tension in any part of the wound it will be much more liable to find its way into the lymphatics and veins, or to push its way along the planes of cellular tissue, than will be the case if it is given a free exit through the slin. All pus should be removed from the wound, and the wound itself dried out with swabs or sponges. Opinion differs a good deal as to whether during the acute stage of the inflammation the wound should be irrigated with some antiseptic lotion or not. The chief objection to the irrigation of the wound with strong antiseptic solutions is that the antiseptic irritates the already inflamed and injured tissues, and is liable to break down the delicate lymph barrier which has probably formed between the pus and the lymphatics, so allowing organisms which before were only local to gain an entrance to the general circulation; while, on the other hand, washing out the wound with an antiseptic will not destroy all the organisms in the tissues surrounding the wound, and therefore cannot arrest the septic process. It is to the tissues themselves that we have to look for an arrest of the condition, and care should therefore be taken to avoid injuring them. There cannot, however, be any objection to gently irrigating the wound with normal salt solution or with some weak antiseptic, so as to wash away as much as possible of the pus and infective material present in the wound. Saline solution previously sterilized is undoubtedly the best fluid for this purpose, though a weak solution of carbolic or biniodide may be used if this is not at hand.

In cases of very severe sepsis, where the tissues show little reactive power and there is evidence of general infection, such as the enlargement of the neighbouring lymphatic glands, lymphangitis, or the presence of severe general symptoms, an attempt may sometimes be made 


\section{$3^{8}$ The After-Treatment of Operations}

to destroy as far as possible the organisms present at the source of infection, with the hope of so preventing any further absorption of their toxic products. To carry this out the wound should be freely opened up, and well swabbed out with some powerful antiseptic, such as $I$ in 20 carbolic acid or $I$ in 500 biniodide. Unfortunately, almost all the present antiseptics in use coagulate albumen, and when used in this way a thin coagulum is formed over the surface of the tissues, so that the action of the antiseptic is limited, as a rule, to the superficial parts of the wound. This method of dealing with septic wounds is not a safe one to use when the wound has an extensive surface, especially in children or old people, as under such circumstances it may be followed by symptoms of poisoning by the drug usecl. Drainage-tubes should be inserted into all the pockets of the wound, and steps taken to keep the wound open by packing it lightly with gauze. If there is much local inflammation, hot fomentations may be made use of with advantage. For this purpose the ordinary boracic fomentation is very unsuitable, as it only remains hot for a very short time, and has very slight absorbent properties, not to speak of the fact that its antiseptic power is practically nil. Most of the ordinary septic organisms can be grown upon it with ease. A very good fomentation can be made by using a thick layer of gauze wrung out in a towel after it has been well soaked in a hot solution of I in Ioo carbolic acid; the carbolic, besides insuring the asepticity of the fomentation, acts as a local anæsthetic and reduces the pain.

Gauze is one of the most absorbent dressings we possess, and it is very important to use a dressing that will quickly soak up all the discharge from the wound. Gauze is, unfortunately, rather expensive, but plain un- 


\section{Treatment of the Wound}

medicated gauze can be used; this is much less expensive than the cyanide or alembroth varieties, and is equally useful for this purpose. A very good fomentation may also be made by using ordinary absorbent cotton-wool instead of the gauze; it has the advantage of remaining hot for a very long time. Whatever is used for the fomentation should be put on as hot as possible, and changed as soon as it has cooled down to the body temperature. This will usually mean changing the fomentation every fifteen or twenty minutes. Fomentations may be made to keep hot for longer than this if they are made very thick, and a thick layer of cotton-wool is placed outside them.

A fomentation to be effective must be hot, and must be capable of soaking up all the discharge from the wound. This latter factor is very important, as the discharge from an acutely septic wound not only swarms with organisms, but contains toxic material formed by these organisms. This toxic material acts as a poison to the tissue cells, tending to paralyze or destroy them, and so prevent their dealing effectually with the organisms.

As soon as the acute inflammation in the wound has to some extent subsided, the fomentations may be left off and the wound dressed with damp gauze-i.e., gauze with a layer of oil-silk or jaconet over it. Damp gauze luas the advantage of being more absorbent than dry gauze. The wound should at first be dressed at least twice a day, and as long as there is any discharge the wound ought to be dressed often enough to insure its being kept free from the accumulation of pus, etc., in it. At this stage the edges of the wound may with advantage be drawn together with strapping, as already described. When all inflammation has subsided, dry dressings may with advantage be substituted for the damp ones. 


\section{The After-Treatment of Operations}

In the case of septic wounds on the extremities, good results often follow the use of the water-bath if the wound is in a suitable position. The water in the bath should be kept as far as possible at an even temperature, and should be kept constantly flowing through so as to keep the water clean. Most limb-baths are now made with a tap at the bottom end, to which an indiarubber tube can be attached passing to a bucket beneath the bed. Another tube connected with a suitable receiver should be arranged to allow water to flow into the bath.

General Treatment of Sepsis.-In all cases where sepsis occurs in the wound a free purge should be administered at the earliest opportunity. Calomel ( 5 grains), followed in four hours by a dose of salts, is one of the best purges for this purpose, and will do a great deal to cut short sepsis and bring down the temperature. A purge administered immediately there is the slightest sign of sepsis will occasionally prevent the wound breaking down, and when it does not succeed in this, will at any rate do a great deal to relieve the symptoms. The way in which a purge acts in diminishing the effects of sepsis in a wound has not been satisfactorily explained. That it does so cannot be doubted. Purgation now takes the place of the blood-letting which was so popular in the treatment of all acute inflammatory conditions a hundred years ago, and no doubt it acts in much the same wayi.e., by depletion. The most probable explanation of the value of purgation in the treatment of sepsis is that, by removing a large quantity of the fluid constituents of the blood, it renders the tissues of the body drier and less œdematous; obviously a wound which is not sodden or oedematous will react to sepsis much more favourably than one that is.

With regard to drugs, no drugs except those used as 


\section{Treatment of the Wound}

aperients are of much value. Quinine is supposed to be efficacious in some cases, and especially in those where there are signs of general septic infection. To be of service it should be given in large doses, 5 grains three times a day.

5. Cases where Symptoms of Septicemia occur.These cases are now, fortunately, rare. They still occur occasionally, however, and, when they do, require prompt and energetic treatment. The chief points in the treat. ment of these cases are:

(I) Disinfection of the wound as effectually as possible and the prevention of tension in it by free drainage.

(2) Keeping up the patient's strength by judicious feeding. These patients need to be fed every two or three hours.

(3) Keeping the bowels acting freely.

(4) Alcohol in the form of brandy or whisky should be given freely -5 or 8 ounces daily.

(5) The administration of quinine or quinine and iron is often useful.

\section{Serum and Vaccine Treatment of Sepsis.}

The treatment of severe cases of sepsis by antistreptococcic or antistaphylococcic serums, and also the more recent method of using vaccines prepared from the pus of the wound, while admirable in theory and occasionally successful, often, unfortunately, fail to produce the beneficial results which it is reasonable to expect. While the success which has attended these methods of treatment does not as yet justify us in using them in place of the older and well-established methods, they may with advantage be used in conjunction with the latter. Before usin ${ }_{0}$ any serum a bacteriological examina- 


\section{The After-Treatment of Operations}

tion of the pus should be made, to ascertain what is the nature of the organism or organisms present, so that a suitable anti-serum may be selected.

The injection of the serum, when successful, has a marked effect in reducing the temperature, and, as a rule, there is a drop of several degrees within a short period after the injection. It is absolutely necessary that the serum should be quite fresh, and serum that has been prepared for more than two weeks is useless.

The usual site for injection is the loin or abdominal wall. The serum should be injected quite slowly and about io c.c. or more used at a time-the exact dose does not seem to matter; the injection should be repeated every twenty-four hours or oftener, if it is doing good. The serum should always be obtained from some reliable source, such as the Lister Institute.

When there is doubt as to the exact nature of the infection, a so-called polyvalent serum may be used. This is prepared from several different strains of streptococci, and consequently the chance of its proving correct is greater. Very little can be expected from a single injection, and if the serum is to be of any real use it must be injected freely and repeated.

In treating a patient by vaccines, his opsonic index is first ascertained, and then a vaccine used which has been prepared from a pure culture of the organism found in the pus from the wound, the object being to raise the patient's natural resistance to the infection.

This method of treatment is difficult and complicated. It can only be satisfactorily carried out by a skilled bacteriologist. It must be confessed that this method of treating septic infection has been very disappointing. 


\section{CHAPTER III}

\section{THE TREATMENT OF GUNSHOT WOUNDS}

Tris subject is such a wide one that no attempt will be made to deal with it $\mathrm{m}$ all its aspects, as this would be quite impossible in the present volume. The following remarks are the result of experience gained by the author in attendance upon the wounded at King Edward VII.'s Hospital for Officers and other military hospitals in the metropolis. Before arriving at these hospitals the patients have already been under treatment for periods varying from a few days to a few weels at hospitals in France or elsewhere. Noattempt will therefore be made to describe here the treatment of wounds as seen on the field, or immediately after an action, but only cases as they present themselves when they come into the base hospitals and into hospitals in England. By this time most of the wounds have passed what we may call the first stage, and at least a week has usually elapsed since the original injury. The methods of dealing with wounds which are described here are those which the author has found most satisfactory, and he does not suggest that they are the only means that can be adopted to obtain good results; but in practice the results obtained by these methods have proved very satisfactory, and he hopes that they may be found a useful guide to those 


\section{The After-Treatment of Operations}

surgeons who find themselves called upon to undertake the care of wounded men, and who have not had much previous experience of such cases.

Clean Bullet IVounds.-These in the present war are unfortunately very few, but, nevertheless, form a certain proportion of the total. When the bullet has passed through soft parts without having met with much resistance, the entrance wound is quite small, and has generally healed by the time the patient has reached his destination. The exit wound is usually about the size of a sixpence, and is covered with a dark brown scab. In most instances the wounds have been treated by painting them with iodine and covering them up with aseptic dressings. The best plan is to continue this treatment, and not to disturb the wounds in any way. The exit wound should be allowed to heal under a scab if it will do so, and should the scab separate an antiseptic dressing should be applied, or the wound dressed with some aseptic ointment, such as one of those men. tioned later. On no account should any attempt be made to probe the wounds, even if they contain foreign bodies.

The Removal of Bullets or Pieces of Shell.-If there is reason to suppose that the bullet has lodged, or that a piece of shell is embedded somewhere in the tissues, this should not be probed for, but at the earliest opportunity the patient should be examined with the X-rays. If then a foreign body is found to be present, the next question will be as to whether it should be removed or not. There should be no rule in this matter. A foreign body, such as a bullet or portion of shell, is not necessarily harmful when retained in the tissues. Its removal is only called for if it is causing symptoms-if, for instance, it is pressing upon the nerves, interfering with the action of a muscle or joint, or if it is causing pain. This does 


\section{The Treatment of Gunshot Wounds 45}

not, however, apply to foreign bodies within the brain, which are a different matter, and for the treatment of which the reader is referred to other authorities. Nuch harm may be done by the removal of foreign bodies which are not causing trouble or inconvenience. The patient may safely be assured that no harm will result from the bullet heing left inside him. In the case of septic wounds there is more reason for removing the foreign body, as it often means that the sinus will refuse to close, although there have been plenty of instances in this war where pieces of shell, etc., in septic wounds have been left and have ceased to give any trouble at all. It is obvious that in many cases the removal of pieces of shell or bullets is quite impossible owing to their situation. For instance, the writer saw one case in which a bullet had lodged in the anterior part of the body of the fourth cervical vertebra, slightly injuring the posterior wall of the pharynx. It is clear that the removal of such a foreign body would be a most dangerous procedure. No attempt was made to remove it, and the patient made a perfect recovery, and suffers 110 inconvenience from the presence of the bullet.

In another case a shrapnel bullet had passed through the sacrum and fractured the anterior surface of the promontory, where with a finger in the rectum one could feel it bulging against the mucous membrane on the posterior wall of the rectum. This foreign body was also impossible of safe removal.

Should it be decided, owing to the persistence of pain or interference with a joint, that a bullet must be removed, this should not be attempted until the bullet has been carefully localized by means of Sir Mackenzie Davidson's or some other reliable X-ray method. To attempt to remove foreign bodies on the strength of $\mathrm{X}$-ray photo- 


\section{The After-Treatment of Operations}

graphs without proper localization is to ask for trouble. Such efforts will almost certainly result in the patient's being damaged by a large wound and the foreign body being left behind, owing to the surgeon's inability to find it. With proper localization, and especially with the aid of Sir Mackenzie Davidson's telephone probe, the surgeon should generally have little difficulty in removing a foreign body through a small incision. As a rule no attempt should be made to remove pieces of bullet, etc., from the chest or abdominal cavity.

Septic Bullet Wounds.-The first question that will arise in dealing with such wounds is whether the drainage is adequate or not. If the patient's temperature is raised at night, and especially if in addition there are local signs of cellulitis and redness of the skin in the neighbourhood of the wound, the drainage is almost certainly in. adequate, and proper drainage must at once be provided. For this purpose it will usually be necessary to administer an anæsthetic and to enlarge the wound or wounds, and to pass the largest bore drainage-tubes that can be conveniently used, provided with plenty of sideholes into every part of the wound, being particularly careful to see that the most dependent part of the wound is properly drained. After this the wound should be irrigated constantly with normal saline or hypertonic solutions, and should also be fomented frequently. For this purpose the ordinary hospital fomentation is quite useless. It generally consists of two or three layers of boracic lint, which are usually cold before the bandages have been applied. It must always be remembered that the object of fomentations is not to apply a warm dressing, but to apply sufficient heat to produce marked hyperæmia of all the tissues in the neighbourhood of the wound, and that no fomentation which does not cause marked 


\section{The Treatment of Gunshot Wounds 47}

reddening of all the tissues is of any use. The best fomentation is $\frac{1}{2}$ pound of cotton-woul thoroughly boiled in a towel and then rung out as dry as possible. This fomentation will keep hot for at least half an hour, and should be changed as often as possible, care being taken not to burn the patient, but to go as near it as possible. Alnost immediate relief of pain and considerable improvement in the wound will follow this treatment. As a rule, within about forty-eight hours the discharge will have begun to diminish and the temperature will have come down. The tubes may then be partially removed or shortened, the patient being carefully watched to see if any rise in temperature, or increase in discharge, follows their removal. Irrigation of the wound should not be overdone. The author is of opinion that little is to be gained by irrigation of the wound after the first day or so, unless it is with the object of washing out some pocket in which pus tends to accumulate. The presence of such a pocket, however, is in itself evidence of inadequate drainage, and further drainage ought to be provided in order that accumulation of pus may not occur.

In all these septic wounds the dressings should be changed frequently, at least twice in the twenty-four hours, and if possible oftener, the object being to keep the wound as free as possible from pus, or contact with pus. Antiseptics, especially strong ones, are of very little use at this stage, and only tend to damage the tissues and delay healing. Sterilized water, or salt solution, or very weak carbolic, are the best solutions. After the wound has taken on a healthy appearance fomentations should be stopped, and a wet, absorbent dressing applied. By this is meant a dressing which is put on wet and covered with a large sheet of oil-silk or jaconet. Wet dressings have the advantage of being more absor- 


\section{$4^{8}$ The After-Treatment of Operations}

bent and of not sticking to the wound. Consequently they do not cause pain when they are being changed, or destroy the growing edge of the wound. If the wound is dirty, as is usually the case, and the surface of it is covered with sloughs and bits of dead tissue, a very good dressing is peroxide of hydrogen, 5 or to volumes per cent. The best way of applying this is to soak small pieces of gauze in the peroxide and pack these into the wound very lightly. The wound should not be so packed, however, that the packing projects above the surface of the skin, or, when the bandages are applied, there will be pressure on the wound which will tend to cause pain. A piece of gauze rung out of the same peroxide should be applied over the packing, and over this a piece of rubber sheeting, in order to keep it wet. This dressing should also be changed two or three times a day. After a few days the wound should take on a healthy appearance, with bright red granulations covering all the surface. When the deep parts of the wound are healed, and there is left only an area covered with healthy granulations, an ointment dressing may with advantage be substituted for the wet dressing, and more rapid healing will occur. It is obvious that ointment dressings must not be applied while there is any discharge from deep sinuses or holes. The following ointment has been found to give excellent results in wounds at this stage:

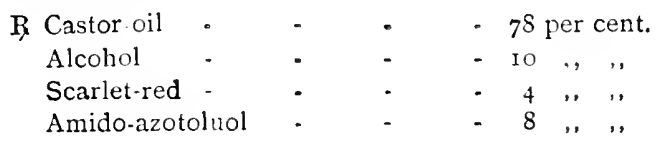

Sterilized vaseline, or equal parts of castor-oil and sterilized olive-oil, may also be used. The red ointment should only be applied in very small quantities, as it tends to spread and make a mess. It has, howerer, the 


\section{The Treatment of Gunshot Itounds 49}

property of healing up epithelinu at an extrac rinary pace. Another good dressing that may he applied at this stage, if the wound is slow in healing, is Iriar's Iratsam.

Septic bullet 11 ounds incolving Finture of the liones.These are some of the most difficult cases to deal with, and only a very general muthe of the treatment can lee indicated here. If a compound fracture of one of the long hones has taken place, the patient must be put in some splint which will keep the limb in as good a position as possible, and which will allow of the wound heing dressed frequently and adequately. It is often a most difficult matter to arrange suitable splints, more particularly where large portions of the bone are missing. Little is to be gained by remoring hroken framents unless these are obviously necrosed, as they may he of use in helping to fill up the gap in the bone, many of them retaining sufficient vitality to act as foci of honeformation.

The remarks already made on free drainace apply with even greater force to these injuries involving bone. It is extraordinary how even the most desperate-looking injuries, accompanied by sepsis, will recover with quite excellent results if properiy treated, and will leave good and useful limbs.

Secondari Ampitatinns.-These should seldom be called for, and are always a confession of failure on the part of the surgeon. The reason why a patient recovers after the amputation of a septic limb is that the drainage of an amputation stump is good, and that conseruently suppuration of the stump is not so serious as that of the previous wound in the limb. In other words, the surgeon amputates the limb because he is mable otherwise to establish free drainage of the wound. It is always wise to bear this in mind, and the moral is that thorough 


\section{The After-Treatment of Operations}

drainage and frequent dressings should save most limbs. The only conditions which necessitate amputation are ulceration of the bloodressels and gangrene, or a completely disorganized limi).

INJURIES OF JOINTS.--Septic injuries of the joints are even more serious than septic compound fractures, ly which, however, they are nearly always accompanied. Experience has shown that even in the case of septic compound fractures associated with suppuration of a joint excellent results can be obtained, and amputation is not necessary. A more or less stiff limb is, however, likely to result, and this should be borne in mind during the healing process, so that the limb, should it become fixed, may be in the best position for subsequent utility. In the case of a hadly septic joint accompanied by much bone injury, sood results may sometimes be obtained by tenotomy of the flexor muscles, In nearly all cases where limbs are affected much may be done by means of massage and exercises, after the wounds are healed, to obtain restoration of function. As a rule, restoration of function takes place much more rapidly in the upper limbs than in the lower. This is due to the fact that no weight has to be transmitted in the case of the arms.

Persistent Sinus. - If it is found that there is a sinus in one of the wounds, which continues to discharge pus, the inference is that there is some foreign body at the bottom of it. This may he a portion of necrosed bone, a piece of clothing carried in on the hullet, a piece of shell, etc. The author has seen one case in which a large plug of wood was driven into the wound. It is obvious that many of these foreign bodies will not show in X-ray photographs. The proper treatment is to open up the sinus, thoroughly scrape it out, and remove any foreign body that is present. Ilealing will then recommence. 


\section{CHAPTER IV \\ HÆEMRRHAGE AFTER OPERATIONS}

THE occurrence of hæmorrhage from the wound after an operation is one of the most troublesome complications that can arise. There are several reasons for this besides the mere fact of its seriousness. There is nothing which is so calculated to alarm a patient, or to make him lose confidence in his medical adviser as hæmorrhage from the wound, even though it may be quite trifling in amount. Blood seems to have a particularly frightening effect upon most people, medical men excepted; and hæmorrhage after an operation, coming on as it usually does quite suddenly and unexpectedly, often has the effect of reducing the patient to a condition of panic, though the amount of blood lost may not be serious. It is also a trying complication to the surgeon. He has, as a rule, to meet it unexpectedly and at a moment's notice. Moreover, no two cases are exactly alike. In some the bleeding is easily stopped, and again in others the greatest difficulty may be experienced. Frequently the proper instruments are not at hand and reliable assistance is unobtainable.

In the following description, hæmorrhage will be divided into recurrent and secondary. The treatment of primary hæmorrhage does not come within the scope of this work. By rccurrent hæmorrhage, or intermediary 


\section{The After-Treatment of Operations}

hæmorrhage, as it is sometimes called, is meant a recurrence of the primary bleeding from imperfect arrest. It usually occurs within twenty-four hours of the operation.

\section{Recurrent Hæmorrhage.}

This may result from various causes. The hæmorrhage may have been entirely stopped before sewing up the wound, but owing to the patient's circulation being feeble and the blood-pressure low at the end of the operation, from shock or some other cause, no bleeding takes place from some of the smaller vessels that have been cut. When, however, the patient comes round from the anæsthetic, and the shock has passed off, the pressure in the vessels increases with the improved circulation, and hæmorrhage occurs. Again, some vessel or vessels have become occluded by clot, and so long as the patient remains quiet this is sufficient to prevent bleeding. On coming round from the anæsthetic, the patient moves about, and bleeding results from the displacement of the clot. These are very common events, and account for most of the cases where hæmorrhage occurs about four or five hours after the operation. A less common cause, but one which may, nevertheless, give rise to serious trouble, is the partial division at the operation of some small artery. The bleeding may be so trifling that it is not noticed, or it is thought that it will stop when the bandages are applied. When an artery, however small, is only partially divided, the contraction of the muscular coats and sheath tends to keep the wound open, so that a vessel thus divided will go on bleeding almost indefinitely. An artery bleeding into a confined space acts like an hydraulic press, and the pressure thus exerted upon the interior of the wound may be very considerable. When bleeding is taking place in this way into a wound, a very large hæmatoma may form, and the slin round the 


\section{Hamorrhage after Operations}

wound be stripped up for a considerable distance. Also, owing to the small size of the vessel which is bleeding, the hæmorrhage takes place slowly, and often does not give any external evidence of its presence for some hours after the operation.

The following case illustrates this form of recurrent hæmorrhage :

A man of about forty-five years of age had his right testicle removed for tubercular diseasc. All bleeding was stopped at the operation, and the wound was sewn up. At r2.30 p.m., and about eight hours after the operation, the patient noticed that the dressings were wet, and on examination the nurse discovered that there was a quantity of blood on them and in the bed. The housesurgeon was sent for, and on his removing the dressings it was found that an enormous hæmatoma had formed under the wound and had stripped up the skin over the abdominal wall half-way to the umbilicus. It was at first thought that the ligature on the cord had given way. An anæsthetic was administered and the wound opened up; it was then found that the bleeding was taking place from a small subcutaneous artery not much larger than a pin in diameter. The vessel was partially divided, and had no doubt been wounded by the needle in sewing up the wound. The ressel was clipped and ligatured, and the wound sewn up again after clearing out the clot. In this case, in spite of the slowness with which the bleeding must have taken place, and the comparatively small amount of blood lost, the patient was suffering from very pronounced symptoms of collapie.

Other causes of recurrent hæmorrhage are softening or slipping of a ligature, and failure to secure the distal end of a divided artery; in the latter case, bleeding will take place as soon as the collateral circulation is established.

Treatment of Recurvent Hamorhage.-The best treatment, when it can be carried out, is to at once reopen the wound and ligature or secure the bleeding vessel. In some cases pressure alone may prove sufficient, but, as already pointed out, this cannot be relied upon. 


\section{The After-Treatment of Operations}

An anæsthetic should, as a rule, be administered, as it is next to impossible to make certain how much may have to be done before the bleeding is stopped; also, the various steps of opening the wound and securing the vessel that is bleeding can then be carried out with much greater deliberation, and there will, in consequence, be less danger of the wound becoming infected.

If the hæmorrhage is found to have stopped by the time the surgeon reaches the patient, or if it should stop after the administration of the anæsthetic, the wound should nevertheless be opened if the previous bleeding has been at all severe, as it will probably recur again, and the risk of this is greater than that of opening the wound. Moreover, the presence in the wound of a large mass of blood-clot will very materially delay healing, and is much better removed.

In cases where the bleeding is venous instead of arterial, pressure should be carefully applied over the bleeding point, and the limb or part well raised on pillows, etc. Care should be taken to see that there are no bandages or straps of splints, etc., constricting the parts above the wound, as this is the commonest cause of such venous bleeding, all that is required in many cases being the removal of the constricting bands and the elevation of the part.

Recurrent Hæmorrhage from the Wound as the Result of Some Constitutional Condition of the Patient.

The treatment of recurrent hæmorrhage by opening the wound and securing the bleeding vessel previously mentioned, though the best procedure in most cases, is not always applicable. There are some cases where a 


\section{Hamorhage after Operations}

general oozing of blood occurs from the wound. This oozing may continue uninterruptedy, or it may stop, and after an interval of hours or days start afresh. The bleeding is usually not copious, but the quantity lost is often considerable, and the patient soon gets into a most dangerous condition.

In some cases of this nature the bleeding does not come on for some days after the operation. The cause is probably always constitutional, and is due to some blood change which interferes with the proper clotting of the blood. What the exact nature of these blood changes is has not yet been determined. One of the best explanations seems to be that it is due to an absence or deficiency of the calcium salts. The constitutional conditions in which this type of hæmorrhage is most commonly met with are hæmophilia, jaundice, and leucocythemia. There are, however, cases which do not apparently come under the head of any of these three diseases, in which bleeding of this nature occurs, and it seems probable that there are other conditions, as yet unrecognised, in which similar blood changes take place.

The best way of treating these cases is by the administration of calcium lactate in large doses. This drug is of most value in preventing hæmorrhage, but unfortu nately it is only seldom that we are able to foresee such hæmorrhage.

If calcium chloride is administered in large doses as soon as the hæmorrhage occurs, it is usually effectual in stopping the bleeding in a short time, though, since it acts by correcting a constitutional deficiency of the blood, it cannot be expected to act rapialy.

It should be given in dozes of from 13 to 20 grains or more three times a day either by the mouth or rectum.

The administration of very large doses of this drus 


\section{The Atter-Treatment of Operations}

would appear on theoretical grounds to be dangerous, though the author knows of no cases where it has proved so. Large doses administered to animals cause intravascular clotting, and one would expect to find thrombosis as a possible consequence of the too free administration of the drug.

The local application of adrenalin is also sometimes effectual in these cases.

JAUNDıCE.-When patients are suffering from jaundice at the time of the operation, as is often the case in opera. tions for occlusion of the common bile-duct, they are very liable to bleed in this way. The bleeding takes place from all parts of the wound and even from the stitchholes. Pressure alone is seldom of much use in stopping the hamorrhage. Styptics may be tried, preferably supraienal extract or Ruspini's styptic. These styptics are best applied by soaking narrow pieces of lint in them, and then packing the lint into the wound and applying pressure over it. Mr. Mayo-Robson has drawn attention to the value of calcium chloride in large doses in the treatment of these cases; he advises the drug to be given by the rectum in 6o-grain doses three times a day, until all signs of oozing from the wound have ceased.

HæMOPHILlA.- These are most serious cases, and often, in spite of all treatment, result fatally. Ruspini's styptic or suprarenal extract should be applied locally and be aided by pressure. These drugs can be given internally at the same time. Ruspini's styptic can be giren in doses of Io minims hourly in about I ounce of water.

Calcinm lactate in so to 20 grain doses, given internally, is also sometimes efficacious; it should be given as soon as pussible after a diagnosis of hamophilia has been made, and repated, as it tidies some time to act. 


\section{Hamorrhage after Operations}

Weil has recently stated that fresh human or animal serum, when adked in a dose of 3 drops to 3 c.c. of the blood of a hamophilic subject, will farour coasulation to a marked chegree in the inherited form, and absulutely in the accidental form of the disease. In the adult, from Io to 20 c.c. of fresh serum is sufficient for a venous, and from 20 to 30 c.c. for a subcutaneous, injection. In children half these doses should be used. The best serum next to that of man is that of the horse or rablit. If these are unobtainatle, Weil advises using antidiphtheritic serum, which is readily obtainable.

Direct transfusion of blood from a healthy person has been used successfully in cases of hemophilia. This requires the performance of a temporary arterial anastomosis between the bloodressels of the patient and the person who is willing to give the blood. This is a delicate operation requiring considerable care. There is no serious risk to the donor of the blood, but a certain amount of temporary wealiness necessarily results. The amount of blood transfused should be about 2 pints.

LEUCOCYTHEMIA, - This is another disease in which bleeding of this nature often occurs. The treatment is the same as in the previous instances.

\section{Secondary Hæmorrhage.}

By this term is usually meant hæmorrhage starting at any time from one day to three weeks after the operation. The cause is either failure in the healing of one of the vessels in the wound or ulceration into a bloodvessel; it usually results from septic arteritis, and consequently does not occur in aseptic wounds. Another factor of importance is disease of the arterial wall; thus extensive atheroma of the arterial walls may he the cause of seccndary hamorrhage in the aged. The trealment is the same as in the 


\section{The After-Treatment of Operations}

case of recurrent hamorrhage; that is to say, opening up the wound and securing the artery, except that it is even more important to do this immediately any signs of bleeding show themselves. The bleeding is usually slight at first, but later may be furious, and it is therefore particularly important to deal with it in the early stage before this has occurred. Pressure should be applied over the main vessel on the proximal side of the bleeding point if this is possible, and then an attempt made to secure the bleeding vessel. In cases where the wound is in a sloughy condition this is often a very difficult matter, and the vessel cannot be secured by a ligature. Under these circumstances a good plan is to underpin it (acupressure). This may be done by passing a stitch deeply through the tissues so as to include the vessel, and then tying the stitch; or another way is to pass a hare-lip pin beneath the vessel, and compress the artery by figure-of-eight turns made with silk round the ends of the pin and over the artery, or a clip can be put on to the bleeding point and left in situ. These methods failing, recourse may be had to the actual cautery. One of the great objections to the latter is the liability to fresh hæmorrhage when the sloughs separate.

Secondary Hemorrhage from Bullet or Shell WounDS.-Secondary hæmorrhage in wounds produced by shell or bullets is of ten a most serious accident, and may call for the very greatest skill and promptitude in order to save the patient's lite. Much will depend upon the nature of the wound, and no definite rules can be laid down for the treatment of such cases, as the conditions cannot always be foreseen, and very often the surgeon will have to depend upon his own ingenuity and resource in order to stop the bleeding. Some of the worst cases are those in which there is a septic wound in the neighbourhood of 


\section{Hrmorrhage after Operations}

one of the main arterial trunks. All patients with such wounds should be kept very quiet until healing has reached a stage at which secondary hæmorrhage is no longer to be feared. Unfortunately, secondary hromorrhage will sometimes occur no matter how carefully the patient is treated. The bleeding generally occurs at any time from a week onwards, and is due to some ulcer eating its way through the coats of the art ry. Usually the hxmorrhage begins slowly by a slight leak, and thi: is the stage at which the surgeon should, if possible, interfere. Presently, as the hole in the vessel enlarges, the bleeding will become furious. The proper treatment is immedately to give the patient a hypodermic of morphia and to administer an anæsthetic. If the bleeding vessel can easily be reached through the wound, the surgeon should expose it and ligature the main vessel above and below the bleeding-point. Before attempting this, however, the main vessel on the central side should, if possible, be controlled by an assistant, in order to save any furious bleeding during the operation. It will often happen that it is not possible or advisable to reach the vessel through the wound, in which case the main artery as near as possible above the wound must be cut down upon and ligatured. When the vessel concerned is the femoral artery or vein. or the axillary artery in the arm, there will be considerable danger of subsequent gangrene of the limb, more particularly in the case of the femoral artery, In order to prevent this, so far as is possible, the limb should be kept warm and should be elerated. In the case of the leg a very good plan is to nurse the patient lying on his face, so as to take the pressure off the vessels at the back of the thigh through which the collateral circulation will, in the main, have to be established. If signs of gangrene occur, amputation offers 


\section{The After-Treatment of Operations}

the only means of saving the patient's life. In some cases ligature of the vessel will not be possible, especially where the wound is somewhere in the trunk. Firm plugging must then be resorted to, together with measures to keep down the patient's blood-pressure. The following cases which occurred recently will illustrate the difficulties that may be experienced.

I. An officer who had been wounded at the Battle of the Marne was brought back to one of the hospitals in London with a bullet wound of the left loin. The bullet had smashed the wing of the ilium and penetrated, together with fragments of the bone, behind the peri. toneum through the lumbar muscles to the opposite side of the spine. The fragment had been driven forwards, and had opened the sigmoid flexure. The patient had a frecal fistula through a compound septic fracture of the ilium, and, soon after his admission, leakage of arterial blood through the wound. The bleeding appeared to be coming from one of the lumbar arteries. In order to deal with this condition the patient was put under an anæsthetic, and the abdomen opened on the left side. The hole in the sigmoid was found, excised, and sewn up. The posterior wound was then investigated and plugged as far back as the spine in order to control the hæmorrhage, which had become severe. Two days later a tremendous hæmorrhage occurred suddenly in spite of the plugging, and very nearly proved fatal. Fortunately, it was again controlled by plugging, and the patient made a good recovery.

2. An officer was wounded at Ypres by a bullet which entered through the left cheel, passed behind the last molar tooth in the upper jaw, and through the centre of the soft palate, and emerged through the right tonsil in the line of the carotid vessels on the right side of the 


\section{Hæmorrhage after Operations}

neck. He was admitted to the hospital in London eight days after injury. Both wounds were almost healed, and his only complaint was of a sore throat, There was a septic-looking wound in the soft palate and a hrematoma on the right side of the neck, but nu pulsation. He had a good pulse in the right temporal artery. He appeared to have quite recovered from the wound. While he was asleep, however, on the twelfth day a large vessel, probably the internal carotid artery, gave way into the mouth behind the soft palate. He woke up with tremendous hæmorrhage, which continued until he fainted, when it fortunately stopped. The author, under whose care he was, was immediately sent for. He found the patient almost dead, but the hæmorrhage had stopped. It was decided that it was not wise to risk a recurrence of the hæmorrhage when the pulse began to recover. Accordingly, in spite of the danger of shock, the patient was put under an anæsthetic at two o'clock in the morning, and the common carotid was tied just below the bifurcation. The patient was then kept lightly under morphia for the next forty-eight hours. He made a perfect recovery.

\section{Internal Hæmorrhage.}

The evidence of this will usually be the onset of symptoms of syncope and collapse, which are otherwise difficult to account for, accompanied by signs indicating the presence of free fluid in the abdomen or chest. It is of interest to notice that a high temperature may accompany internal hæmorrhage. This temperature is probably due to the absorption of some of the constituents of the blood. It is advisable to bear this in mind, as otherwise 


\section{The After-Treatment of Operations}

the symptoms may be ascribed to sepsis, and the true nature of the case not detected till too late.

The proper treatment is to at once open up the wound, expose the bleeding point, and secure it. This in the case of hxmorrhage into the abdominal carity often means an operation of equal or even greater gravity than the original one. The proper treatment of internal hæmorrhage under such circumstances, therefore, may be a matter of the greatest difficulty, or even impossible. The facilities for operating may not be at hand, or the condition of the patient may be such that reopening the abdomen is out of the question. When the source of the hamorrhage cannot be dealt with directly, the patient should be kept as quiet as possible, ice should be applied over the probable source of bleeding, and morphia should be administered subcutaneously to reduce the blood. pressure and to keep the patient quiet. Stimulants are best aroided, as, by raising the blood-pressure, they tend to increase the hamorthage.

\section{The Treatment of Hæmorrhage after Special Operations.}

Henorrhage after the Removal of Tonsils oR ADENoIDs. - The following causes of severe hæmonhage after the removal of tonsils or adenoids are given by Cordes:*

I. Hæmophilia.

2. Cardiac disease or arterio-sclerosis (in adults).

3. Anomalies in the course of the internal carotid.

4. A preparatory application of cocaine.

5. Small shreds of regetations remaining partly at.

* W. Miligan, Mel, Ann, rgor. 


\section{Hæmorrhage after Operations}

tached to the pharynx; the hamonhage ceases when they are removed.

6. Occasionally serere hamorrhage results in females if the operation be performed at the time of the menstrual period.

Hamorrhage after Removal of Tonsils.--The patient should be made to sit up and lreathe with the mouth well open, preferably in a draught of cold air, as, for instance, in front of an open window. The upright position tends to empty the ressels and the cold to make them contract. Ice or iced water may be given to drink, or iced water applied to the side of the face. This is all that is necessary in slight cases of hamorrhage, and serious hæmorrhage is very uncommon.

If, however, the bleeding is severe, and will not yicld to such simple measures, the following nay be tried: When the bleeding is from the tonsil, a piece of lint or a small Turkey sponge previnu ly soaked in turpentine or some other styptic (perchloride of iron should not be used) is twisted round the end of a clip or pair of tongue forceps and pressed against the bleeding surface, counter pressure being at the same time made over the position of the tonsil outside. Pressure should be maintained for some minutes until all bleeding has ceased. If no styptic is available, the lint or sponge must be wrung out of hot water (any heat under a temperature of $100^{\circ} \mathrm{F}$. will tend to increase the bleeding rather than to stop it).

If an artery is spurting, or the bleeding refuses to stop with the above measures, a gag should be placed in the mouth, and an attempt made in a good light to clip the bleeding point. If this is successful, the clip may be left on for a few minutes or the vessel twisted.

Hamorrhage from the Naso-pharym after the Removal of Adenoids.-The bleeding, though often severe at first, 


\section{The After-Treatment of Operations}

stops, as a rule, after a minute or so. If it should not stop, pressure should be applied to the bleeding surface by passing a small Turkey sponge up behind the soft palate and pressing it against the posterior pharyngeal wall with the finger; or the sponge can be wrung out of spirits of turpentine, or any other suitable styptic, and applied in the same manner. The sponge can be held in place either by the finger or a clip. Another plan is to wrap a strip of lint round the end of a Gottstein's ringknife (which will be at hand), and press on the bleeding point with it. When it is not possible to control the bleeding by any of the above measures, and it seems probable that the bleeding is due to the accidental wounding of an abnormally-situated internal carotid or other vessel, it may sometimes be necessary to ligature the common carotid artery. This is, however, a very doubtful expedient, as, if the blood is coming from the internal carotid, it is unlikely that the hæmorrhage will cease even after ligature of that vessel, owing to the free communication from the opposite side. It should certainly not be ligatured unless it is found that compressing the vessel in the neck controls the bleeding.

Bleeding from the Nose after Operations for the Removal of Polypi or one of the Turbinate Bones. -Syringing the nose out with iced or hot water will usually suffice, or a strip of lint soalied in adrenalin or some other styptic may be placed in the nose for a few minutes. In cases of severe hxmorrhage, the following plan, which is advised by Mr. Shield,* may be tried: A small, soft Turkey sponge of suitable size is wrung out of spirits of turpentine, and passed up behind the soft palate; it is then seized by forceps passed through the nose from in front, and the latter are pulled upon so as 


\section{Hamorrhage after Operations}

to draw the spenge against the posterior nares. This will stop any bleeding from the back of the nares, and in the case of bleeding further forward, strips of lint can be pushed into the nostril from which the blood is coming while the sponge is in position, the sponge preventing the lint from going into the naso-pharynx. When the hamorrhage has in this way been controlled, the forceps and sponge can be cautiously removed, leaving the plug in place. Other methous are to plug the nose in the ordinary way for epistaxis, or to insert an inflatable indiarubber tampon (Fig. If). If a plug is inserted, it should be removed in twentyfour hours.

Hemorrhage after Tooth-extracTION.-This is seldom of any consequence, and when it is, usually results from hamophilia, or some other constitutional condition in the patient. The tooth-socket should be plugged with cotton-wool from the bottom, the wool having been first soaked in some suitable styptic; then a pad of folded lint should be placed on the top of the plug. This pad should be of sufficient thickness to prevent the teeth meeting, so that when the jaw is closed and tied up tight with a jaw-bandage, pressure is maintained upon the plug.

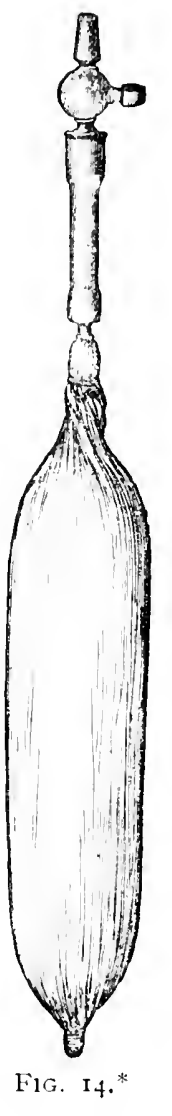

A good plan in some cases is to put a stitch through

* The tampon is smeared with vaseline, passed into the nose, and inflated, 


\section{The After-Treatment of Operations}

the gum on each side of the socket and tie it tightly, so as to close the cavity. This plan is a very useful one, especially when there is not a tooth on each side of the empty socket. The most troublesome cases of hæmorrhage after dental operations are those resulting from a wound of the posterior palatine artery. This accident may happen from the forceps slipping, or from the improper use of an elevator on an upper molar. Pressure may be tried, or an attempt made to clip the vessel. This is, however, seldom successful, as the vessel usually lies in a groove in the hard palate. The bleeding can be stopped by pusting a small wooden plug up the posterior palatine canal The position of the posterior palatine canal is about a quarter of an inch to the inner side of the last molar tooth. An incision must he made in this situation through the mucous membrane and the plug inserted. It should bo removed at the end of twenty-four hours.

Hemorrhage after Removal of the Tongue.--If the wound has been kept aseptic after the operation, this but rarely occurs. When hæmorrhage does occur, however, it is usually very dangerous. If the whole tongue has been removed, it is best to leave a silk thread through the stump, and to secure this outside the mouth with a piece of strapping. In case of bleeding taking place, the stump can then be easily pulled forward and the bleeding point clipped. If no such thread has been placed through the stump, the latter must be caught hold of with a clip or vulsellum forceps and pulled well forwards, so as to expose the bleeding point. Two or three clips should be kept handy in cases where there is any possibility of hæmorrhage. If secondary hæmorrhage does occur, it will probably take place fron a week to ten days after the operation. 


\section{Hæmorrhage after Operations}

Bleeding from the Intercostal Artery aftek Opiration for Empyema, etc.-The bleeding point should be picked up, if possible, with a clip, and ligatured, the wound, if necessary, being enlarged to expose the vessel. Or the centre of a square piece of lint nilay be pushed into the wound, and the cavity so formed packed with cotton-wool ; then, by pulling on the lint, the bleeding can be controlled.

Bleeding from the Frenal Artery after Circuncision, ETC.-The artery should be picked up with a clip, if possible, and ligatured. If this is difficult, a stitch may be inserted beneath the vessel and tied over it. Or a pin can be passed through beneath the vessel and a figure of eight made over it with silk. A strip of lint soaked in lotio plunbi will often stop the slight hæmorrhage that is sometimes seen after circumcision, and makes an excellent dressing.

Bleeding from the Perineun after Lithotomi, ETC.-Any bleeding points that can be seen must be picked up and ligatured, or the clip left on. This failing, a tube with a petticoat tied round it should be inserted into the wound, and gauze or wool packed round the tube. Two strings are then attached to the end of the tube, and fastened to a hand round the patient's waist. If there is no necessity for draining the bladder through the wound, the latter may be simply plugged in the ordinary way, and pressure made on the perineum by a perineal bandage. This bandage is an excellent method of applying pressure to the perineum. It is put on as follows: A piece of 4 -inch bandage is tied round the waist, and the ends cut off. The roll of bandage is then passed under this behind, and carried forwards across the perineum, beneath the waist-bandage in front, and back again. The two free ends of the bandage are then pulled upon, and tied together in the centre of the 


\section{The After-Treatment of Operations}

perineum. In this way considerable pressure can be exerted on any desired point.

Hemorrhage after Operations on the Bladder.This is very seldom met with, but may occur after operations for the relief of enlarged prostate or for the removal of growths, especially papillomata (villous tumour). It may also follow lithotrity, but should not do so if the operation has been properly performed. Again, it may result from the too rapid evacuation of an overdistended bladder, especially in old men. The great difficulty in dealing with the bleeding in these cases depends upon the fact that the bladder is usually filled with blood-clot, and nothing can be done until this has all been removed. As large a catheter as possible should be passed, and a stream of warm water forcibly injected with a large bore syringe. At first only a very small quantity of fluid should be injected, and then allowed to flow back again; as the clot comes away more and more fluid nay be injected each time. This must be persisted with until all the clot has been washed out of the bladder, as evidenced by the absence of clots in the water coming back from it. Some styptic solution should then be injected into the bladder: for this purpose a strong solution of hazeline or Ruspini's styptic is recommended; but other styptics, such as suprarenal extract, turpentine, etc., may be used instead. Styptics having a caustic action, such as liq. ferri perchlor., etc., must not be used, as they set up cystitis.

Of course, if there is an opening into the bladder, either through the perineum or above the pubes, the clot can he washed out much more easily through it. And when there is such an opening, if the hæmorrhage will not yield to styptics and hot lotion, the bladder may be packed with strips of lint after passing a tube or tubes 


\section{Hamorrhage after Operations}

down to the openings of the ureters. The lint should be in long strips, and the ends left outside the wound. In cases of severe hæmorrhage from the prostate or trigone the bleeding can be temporarily controlled by passing one finger into the rectum and compressing the prostate and trigone against the back of the pubes, or by compressing the bladder bimanually by one hand above the pubes and a finger in the rectum.

Hemorrhage From the Rectum.--This is, fortunately, a rare occurrence with the present improved methods of operating; it still, however, occasionally follows operations for piles, etc. It is a very troublesome complication, not only on account of the difficulty of stopping it, but because a large amount of blood may be lost in to the bowel before there is any external evidence of its presence. The hæmorrhage usually takes place after the bowels have acted for the first time following the operation, and is, as a rule, due to the slipping or premature separation of a ligature. The bleeding is free, and is accompanied by a considerable amount of collapse. The bleeding may, however, occur where no ligature has been used. In a case which the author saw recently, a hamorrhage which might have been fatal and which necessitated plugging the rectum occurred three weelis after the operation and a week after all the ligatures had separated.

It is well to remember that the amount of blood lost externally is no indication of the total hæmorrhage, as the rectum and sigmoid may be filled with clot. An anæsthetic should be administered and the sphincter dilated, then, after emptying the bowel of clot with the finger and by syringing with hot water an attempt may be made to clip the bleeding-point and religature it. To facilitate this mancurre the wall of the rectum above the bleeding-point should be caught with a pair 


\section{The After-Treatment of Operations}

of pile forceps or an ordinary clip, and drawn down so as to give good access to the bleeding spot. Even then it is often by no means an easy matter to control the hicmorrhage, as the rectum tends to lie in folds, and the bleeding often comes from a surface rather than a point. If, as is not infrequently the case, it is found to be impossible to control the hæmorrhage in this way, the rectum nust be plugged.

This is best done as follows: A piece of sterilized indiarubler drainage-tube about $3 \frac{1}{2}$ inches long and $\frac{1}{2}$ inch in diameter is talien, and round one half of this

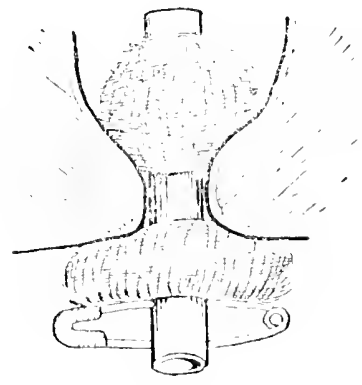

FIG. I5.

a strip of dry gauze or wool is wrapped, so as to increase its diameter by about three times. The surface of the gauze is then well greased with sterilized vaseline, and the tube is inserted into the rectum, with the big cnd upwards. The portion of the tube which projects out of the anus should then be pulled upon so as to bring the dilated part down against the bleeding surface. A large safetypin should next be passed through the end of the tube ahout $\frac{1}{2}$ inch away from the anus, and a long strip of gauze, which has been previously greased with vascline, wrapped round and round the tube between the anus and the safety-pin. Any required amount of pressure can thus be exerted upon the bleeding-point, as the gamze wrapped round outside pulls down the tuhe and retains it in place (see diagram, Firg. I5). Inother method of phigging the rectum which is uneful in cases where an 


\section{Hæmorrhage after Operations 71}

anxsthetic caunot be given is to cut a finger-stall out of an indiarubber operating-glove, and, having greased it inside and out and having inserted one's finger mto it, pass it gently into the rectum. Then withdraw the finger and plug the inside of the finger-stall with gauze, using a large safety-pin as before to prevent the plug slipping up too far into the bowel.

It is seldom necessary to leave the plug in for more than forty-eight hours. Ifter its removal a small piece of drainage tube may be left in the bowel to give warning should any further heeding occur.

In cases of secondary hæmorrhage--i.e., when bleeding occurs a week or more after the operation, and is due to sloughing-no attempt should be made to catch the bleeding-point with clips, but plugging should be resorted to at once. In women, hæmorrhage from the rectum can be temporarily controlled by passing a finger into the vagina and compressing the rectal wall against the sacrum.

Bleeding after Incision 1nto INFl..med Tissues.-It is not at all uncommon for rather free hemorrhage to occur after incisions have been made into inflamed tissues, such as for the relief of tension in cellulitis, etc. The ends of any small vessels that may have been divided do not contract, but are held open, and, in consequence, bleeding from them continues for some time. A certain amount of bleeding in these cases is advantageous, as it relieves the local congestion. If it continues for long, however, something may have to be done to stop it. It is generally useless to attempt to pick up the bleedingpoints, as the tissues are often so rotten that they give way at onces Elevation of the part and the application of a really hot fomentation and pressure will almost always suffice to stop the bleeding. Should it not do 


\section{The After-Treatment of Operations}

so, the incisions must be packed with strips of ganze or lint, and firm pressure applied with cotton-wool and bandages.

When severe hamorrharge occurs from a wounded vessel situated in rotten or gangrenous tissues, and the vessel camnot be picked up with a clip owing to the tissues tearing away, the best way to secure the ressel is to pass a hare-lip pin or needle through the tissues beneath it, and then compress the ressel by a figure of eight made with silk round the ends of the pin-i.e., secure the ressel by acupressure. This is also the best way of arresting hæmorrhage from an artery in the hase of an ulcer or ulcerating surface. The tissues should be under-pinned on the proximal side of the bleedingpoint.

Hemorrhage from the Stump after Amputations. - Recurrent hremorrhage after an amputation will usually stop if firm pressure is applied and the part elevated. Should it not do so, the wound must be reopened, and any bleeding-points clipped and ligatured.

Secondary hæmorrhage after an amputation is, fortunately, a very rare occurrence now, though it used to be common. Ligature of the main vessel above has been advised, but most authorities agree that it is better to re-amputate higher up.

\section{Constitutional Treatment of Patients suffering from Hæmolphage.}

Immediate Treatment.-This is mainly the treatment of shock, which is gone into in the next chapter.

The patient should be freely stimulated if all the bleeding-points have been properly secured. Liquoris strychnime may be given hypodermically in doses of from 5 to 


\section{Hxmorrhage after (Operations 73}

to minims. Brandy or whisky may be given; this is hest done by giving repeated doses of from $\frac{1}{2}$ to I ounce by the rectum-or mouth if there is no danger of romitingor alcohol can be given hypodermically in small doses (ro to 20 minims).

Remote Treatment. - I'atients who have suffered from severe hamorrhage are usually very anæmic, and in old or weakly patients this condition may persist for some time. In children and young arlults the blood. forming capacity is good, and they soon make up any deficiency. In order to assist the tissues in forming new blood, iron in some form or annther should be given until all signs of anæmia have disappeared. l'ort wine is an excellent remedy in these cases, and 3 to 6 ounces should be given per diem unless otherwise contra-indicated. Patients who are suffering from anæmia due to loss of blood must not be allowed to get up and about too soon; they must be made to go very gradually at first, as there is great danger of thrombosis if they are allowed to get up too quickly. Massage to the lower limbs, if carried out for a day or so previous to their getting up, will do much to prevent this danger. 


\section{CHAPTER V \\ SURGICAL SHOCK}

SURGICAL shock is a condition of exhaustion of all the vital faculties, which is liable to occur after any severe injury or surgical operation. Before the discovery of modern aseptic surgery by Lister, the two great dangers of surgical operations were sepsis and shock. Thanks to his discovery, the danger of sepsis has now been almost eliminated; but it was not until comparatively recently that any attempt was made to study, from a scientific point of view, the shock following operations, or to find out how it could be best combated. The first real scientific researches into this subject were made by G. IV. Crile in Imerica. The publication of the results of his researches in 1897 laid the foundation of our modern conception of what is really meant by surgical shock. Since that date research on this subject has been almost continuous. In Iyo5 the author of this book published the Hunterian Lectures delivered at the Royal College of Surgeons, on the l'hysiology and surgical Treatment of Shock and Collapse.' The most recent research work on the subject is a book just published, by G. W. Crile and W. L. Lower, entitled 'Anoci-Association,' in which a large amount of very valuable experimental work is recorded, and it may now be said that the physiology of surgical shock is no longer a closed book, but 


\section{Surgical Shock}

that the main factors in the causation of this curious condition are well known and unclerstood. The greatest credit is due to Dr. Crile for the careful and thorough manner in which his experimental worl has been carried out, for no stone has been left unturned and no corner uninvestigated.

It is obviously impossible to give a complete description of the physiology of shock in the present volume. The reader is, however, referred to the works mentioned at the end of this chapter for further information on this interesting subject.

The symptoms of surgical shock must be familiar to everyone who has worked in the hospital wards of a large hospital. The most typical picture that one can take is perhaps that of a man who has undergone a serious and severe operation which has resulted in shock. Previons to the operation the patient presented the ordinary appearance of a healthy human being (apart from the condition for which the operation was performed), with a good colour, normal pulse, and muscles which responded promptly to his call. If we examine this same patient after the operation, when he is in a condition of shock, we find that the skin is pale, covered with sweat, and feels cold to the exanining hand : the pulse is rapid and so slight as to be hardly perceptible except in the larger arteries; the temperature is subnormal, and the respirations rapid and shallow; the eyes have a glazed and anxious appearance; and although the patient is quite conscious, he is incapable of doing anything for himself, and is only just able to answer questions. There is generally a certain amount of restlessness, and the face expresses extreme exhaustion and a fear of impending dissolution, while the skin appears to have shrunk over the facial bones. The patient complains of thirst, and is constantly asking for something to drink. He is hardly 


\section{The After-Treatment of Operations}

able to lift his head from the pillow, and his muscles are in a condition of complete relaxation, as if he were utterly exhausted after running a long race. Food cannot be digested, and all the functions are more or less inhibited. Thus, the mouth is dry owing to a lack of salivary secretion, there is very little urine passed, and digestion has ceased owing to the lack of digestive juices; the most marked feature of this condition, however, is the great lowering of the blood-pressure. The blood-pressure of a normal man is 120 to 130 millimetres of mercury, as measured by a sphygmometer. In the condition of shock we have been describing the pressure will be found to have fallen to 60 millimetres of mercury, or even lower. The blood has accumulated in the large vessels of the abdomen, and if the patient were sat up he would, in most cases, immediately collapse and become unconscious, owing to the anæmia of the brain caused by the blood, under the force of gravity, flowing out of it to the lower parts of the body. This condition, which sometimes follows severe operation or other injuries, is a most interesting physiological problem, and the factors producing this curious condition have been very carefully investigated. The following is a brief outline of the more important factors concerned in its production.

\section{Physiology of Shock.}

In a normal human being the pressure of the blood in the vessels of the various parts of the body is maintained at, or about, a constant pressure (roughly between 120 and 130 millimetres of miercury) by the contraction or relaxation of the muscular walls of the arteries and arterioles, while the circulation through the vessels is maintained by the action of the heart. It is obvious that if there were not some means of controlling the pressure 


\section{Surgical Shock}

within the vessels, constant and disastrous changes would occur in the distrilution of the blood as the result of changes of position, owing to the force of gravity. Thus, in the erect position the llood would tend to flow to the feet and away from the brain, and so produce unconsciousness by anamia of the brain-cells. In a healthy person the pressure of the blood is maintained by means of certain centres in the brain called the vasomotor centres. These centres not only lieep the pressure within the larger vessels at a more or less constant figure, but also control the amount of blood in any one part of the hody at a time, and by so doing adapt the supply of blood to the require. ments of the particular organ which is most in need of an increased supply of blood at any one time. If these centres in the brain cease to act, the blood immediately accumulates in the splanchnic area, and a great fall in general blood-pressure occurs. Thus, experimentally, if the vasomotor centres in the brain are cocainized, a great fall in general blood-pressure results, and the animal passes into a condition similar to that of surgical shock. A similar condition results from damage to the vasomotor centres, or from section of the spinal cord. Experimental investigation has proved that the condition of surgical shock is the result of exhaustion of the great centres in the central nervous system, which control the vital functions of the body, more particularly those centres which directly control the maintenance of a normal circulation throughout the body, such as the vasomotor and the respiratory centres, although all the centres in the brain are more or less affected.

The whole of the surface of the body and some of the deeper parts are supplied with nerve-endings, or 'nociceptors,' whose function it is to send messages to the brain when they are stimulated. Stimuli are of two kinds- 


\section{The After-Treatment of Operations}

those of ordinary sensation, which might be described as messages conveying information to the brain-centres, and useful in assisting the ordinary functions of the body; and, secondly, stimuli of pain, conveying messages to the brain when damage is being done to that particular part of the body, and, if we may say so, asking for assistance. The immediate result of painful stimuli is motor activity, in order to get away from, or remove, the cause of the pain. If the person or aninal is under an anzesthetic, this motor activity cannot be manifested in movement of muscles; but there is, nevertheless, expenditure of energy within the brain. This can be seen experimentally by direct increase in the blood-pressure, increased frequency of the pulse, and increased frequency of the respiration as the result of painful stimuli.

Dr. Crile lias recently sone much further, and has been able to show that actual microscopic changes occur in the cells of the cortex of the brain as a result of stimuli reaching the centres from the nerve-endings in the slin. He bas been able to show that if stimuli of a painful character from the nerve-endings on the skin pass up the afferent nerves in sufficient quantity and severity, demonstrable lesions occur in the cells of the brain, suprarenals, and the liver, There are certain organs in the body, among which are the brain, the thyroid, the suprarenals, the liver, and the muscles, whose function is that of converting latent into linetic energy in response to adaptive stimulation. In response to environmental stimuli of any sort, these organs convert latent energy into motion, or into heat. As the result of long-continued painful stimuli, certain changes can be demonstrated to take place in the cells of these organs. Thus, if shock of a severe character is experimentally produced in a normal, anesthetized dog, changes in the cells of the brain cortex 


\section{Surgical Shock}

and cerchellum are found to talke place as a result. These changes are-(1) chromatolysis; (2) alteration in the nucleus-plasma rclation; (3) rupture of the nuclear and cell membranes ; $(4)$ in extreme cases, disintegration of the cell itself. These changes in the cortical cells occur as the result of long-continued painful stimuli, such as would be caused liy a severe and protracted operation or a severe tramatism; hut it has also been demonstrated that such emotions as fear and anger, if prolonged and intense, will likewise produce similar changes in the brain-cells which are indistinguishable from those produced by shock. Severe local infections, such as peritonitis, will also cause similar changes.

As a result of clinical experience we know, of course, the extremely important part played ly fear and terror in the production of shock when associated with trauma. It seems certain that the centres in the brain, the muscles, the liver, suprarenals, and probably many other of the internal secretory glands, act together as a system to preserve the integrity of the body as a whole. This system has been termed by Crile the 'kinetic system,' its object being to protect the body against harmful affects from outside agents. The whoie of this system suffers together in conditions such as shock, and shows demonstrable changes in its cells.

In recent years a good many theories of shock have been propounded with a view to showing that the phenomena of shock are due to changes in the contents of the blood, or to the noxious products of metabolism circulating in the blood-stream. It is obvious that the correctness or otherwise of any such theory is easily put to the proof by experiment, and for many years the author has wanted to perform such an experiment with a view to testing once and for all the correctness of 


\section{8o The After-Treatment of Operations}

such theories. Such experiments are, however, difficult to perform in this country, and he has never been able to carry out the experiment. Recently Dr. Crile has performed this experiment with complete success. The experiment consists in crossing the circulation of two dogs. It is obvious that if the circulation of two animals can be united in such a way that the blood circulates through both of them, and if one of these animals is put into a condition of shack, then, provided that the cause of shock is due to any change in the gaseous or other contents of the blood, both animals--the shocked animal and the other animal-will suffer alike; but if shock is due to damage or exhaustion of nerve-centres by repeated stimuli, as Dr. Crile and the present writer believe, then the non-shoclied animal will be quite unaffected.

Dr. Crile performed this experiment by anastomosing the proximal end of one carotid artery of Dog A with the distal end of the corresponding carotid artery of $\operatorname{Dog} B$, and one jugular vein of $\operatorname{Dog} A$ with the corresponding vein of $\operatorname{Dog} B$. The dogs were as nearly as possible alike, and were both under an equal amount of anæsthesia. Dog A was subjected to traumatism sufficient to produce shock. Both animals were then lilled, and their brains examined. It was found that the typical changes in the cells of the brain cortex were present in Dog A, while they were completely absent in Dog B. The result of this experiment proves that gaseous or other changes in the blood cannot be the primary cause of slıock, and it therefore disposes of the acapnia theory of Yendall Henderson.

It is obvious that if an operation is to he performed in such a way that no shock shall result, two factors are necessary: (1) All stimuli of a painful character must be prevented so far as possible from reaching the brain from 
the area of operation; and (2) the patient must be protected from the harmful effects of fear, terror, etc., which might be caused by the performance of the operation or its anticipation. I'urther, if these two conditions cin be fulfilled there should be no shock resulting from an operation, unless there has been severe hamorrhage.

Different parts of the body have different shock-producing properties when operated upon, and it is important that these should le known, so that special care may be taken when operating upon such parts.

The Relation between the licyion eperated upon and the Shock produced.--It appears that operations upon the abdominal contents and visceral peritoneum, and operations upon the male generative organs, produce the most profound shock as a general rule. In the abdomen the severity of the shock produced is in proportion to the distance of the part operated upon from the pelvis, the shock being most severe after operations in the neighbourhood of the stomach, pylorus, and duodenum.

In the extremities the amount of shock caused by operation is in direct proportion to the nerve-supply of the part-that is, to the area of skin and muscle injured and the relative number of nerve endings in that area. Thus, a crush of the paw of a dog will cause more pronounced shock than amputation of the limb high up. Crile states that in animals subjected to extensive removal of integument, shock was induced with a rapidity proportional to the area exposed, and its depth corresponded to the duration of the exposure.

Recent experimental work carried out by Dr. Symes and the present writer has proved that injury or interference with the parietal peritoneum or mesentery will produce shock, while similar manipulation of the risceral peritoneum has no effect. 


\section{The After-Treatment of Operations}

\section{Collapse.}

Collapse is a very similar condition to shock, but with certain marked differences. Collapse, unlike shock, occurs suddenly, and is accompanied by a great and sulden fall in blood-pressure, often with resulting anæmia of the brain and unconsciousness. It is due to a sudden paraiysis of the kinetic system, or, in other words, of the centres of the brain and cord controlling the maintenance of the blood-pressure. It differs from shock in that it may be successfully treated by means of stimulants. Since, however, the important cause of the trouble is the sudden fall in blood-pressure, the obvious indication is to support the blood-pressure, and the brain and heart, by putting the patient into a recumbent position, or with the head down, to drive the blood out of the limbs and abdomen by pressure, while at the same time stimulants are administered or the bloodvessels transfused in order to combat the lowered pressure in the ressels.

The condition following severe hicmorrhage differs from both shock and collapse in that the centres in the brain are not at first affected, the falling blood-pressure being due to an actual loss of fluid. If, however, the hæmorrhage has been severe and the lowered pressure has persisted for some time without relief, a condition of true shock may supervene, The obvious treatment for severe hamorrhage is transfusion, preferably with blood from another subject, but failing this, with a physiological salt solution.

\section{The Treatment of Shock.}

It will be obvious from the foregoing description of the physiology of shock that it is possible to prevent shocli from occurring as the result of an opcration, and 


\section{Surgical Shock}

that the best way of protecting one's patient from this condition is to so perform the operation that shock-producingr factors will be absent. In fact, post-operative shock is now, or soon will be, as much a reflection on the surgical technicue of the surgeon performing the operation as is sepsis in the wound; that is to say, that when an operation can be performed under circumstances carefully chosen and selected by the surgeon beforehand, and with the necessary proper assistance and preparation, surgical shock should not result from any operation, provided the surgeon is sufficiently shilled in the technique of operating.

\section{Methods of preventing Shock.}

The ideal method of preventing shock is so to anrsthetize the patient that no afferent impulses of a painful or harmful character can reach the brain-centres. It has been shown that in order to secure such conditions all the nerves passing from the area of operation must be tenporarily blocked by a local ancesthetic, so that no impulses can pass from the operative field, and at the same time the higher brain-centres must be further protected from ontside impulses by a prelinunary narcotic and suitable general anæsthetic to the point of unconsciousness. This method of performing shockless operations has been very carefully worked out by Dr. Crile and others, and is now interesting many surgeons. This method has proved that in most operations it is possible by means of the correct technique to be absolutely certain that no shock will follow the operation, and no doubt in time and with increased knowledge it will be possible to apply this method to all operations. The exact technique of the method cannot be described here for want of space, but it will be found in Dr. Crile's textbook. 


\section{The After-Treatment of Operations}

There are certain factors in an operation which are particularly liable to produce shock, and by taking care to avoid these, much may be done to prerent its occurrence. Thus, tearing and crushing tissues causes much more shock than cutting with a sharp knife. The rough use of retractors, dragging or pulling on the intestine, and, in fact, roughness of any kind, should be avoided. Again, certain areas require particularly careful handling, as, owing to the distribution of the nerves in these areas, shock is especially liable to result from interference with them. Such areas are the upper region of the abdomen and diaphragm, the extremities of the limbs, the neighbourhood of the anus, and the parts round the mouth and larynx.

One must also realize that emotions such as fear and terror have a powerful effect in producing shock, and in accelerating it when combined with an operation, so that patients who are highly nervous about themselves and dread an operation are much more liable to suffer from shock. For these reasons, the patient must be protected by every possible means against such influences. Careful preparatory ireatment, avoiding all details in the preparation which may tend to frighten the patient, and the administration of a preliminary narcotic, such as morphia, and atropine or scopolamine, are valuable agents. The author's practice is to administer from $\frac{1}{4}$ to $\frac{1}{3}$ of morphia combined with $\frac{1}{1^{\frac{1}{2}} \overline{0}}$ of atropine hypodermically about an hour before the operation. An important point also, which is often neglected, is to see that when the patient enters the operating-room no time is wasted in getting him immediately under the anæsthetic. To keep a patient waiting even two minutes while the anxsthetist is getting ready is of much more consequence than many people suppose. 
Complete quiet during the period of induction of ances. thesia is also an important factor.

Pain and discomfort after the operation are potent causes of shock, so that a patient who was not suffering from shock when he left the operating-table may be found deeply affected loy shock some hours later if careful means have not been taken to prevent painful impulses. Everything should be done to reliere pain, and when shock is feared a narcotic, such as morphia or heroin, should be administered at regular intervals in sufficient quantities to keep the patient free from pain and discomfort. The rapid increase in the pulse and respiration is a sign calling for the administration of a narcotic.

\section{Treatment of Shock.}

When a patient is seen who is already suffering from shock, the first thing to do is to remove the cause of this condition, if still operative-that is to say, if the patient is in pain, morphia or heroin should be administered hypo. dermically in sufficient doses to shut off immediately all painful impulses and produce rest and quiet. This should be done before any other treatment is given.

WarmTh.-The patient should be kept warm with blankets and hot bottles, but care must be taken not to overdo this; the patient should never be kept in a condition of profuse perspiration, as this will tend to greatly increase the shock. Although it is important to maintain the body temperature, at the same time much heat will cause dilation of the superficial vessels, and when this occurs it means a still greater loss of blood to the essential circulation.

Positron.-The position of the patient is of great importance in treating shock. The best position to place the patient in, is with the foot of the bed so raised that 


\section{The After-Treatment of Operations}

the abdomen is on a higher level than the thorax and head. This tends to prevent the blood from accumulating in the abdomen and lower limbs, and helps the blood to flow from the great veins into the heart. The foot of the bed should be raised on blocks a foot or more in height, and the patient should not have a pillow under the head.

Bandaging the abdomen, rapidly and effectually raises the general hlood-pressure, and may be tried if there is no serious contra-indication to its use; since it tends to embarrass the respiration care should be taken to see that the thorax is free to move, and is not pressed upon by heavy bedclothes, etc. Bandaging the extremities is also effectual in raising the blood-pressure, and is a useful way of treating shock in suitable cases. The limbs should be firmly bandaged all the way up with some elastic bandage, such as flannel or domet. The bandages must be put on carefully so that there are no creases, and must not be left on for long, or they will do harm by cutting off the blood-supply to the limbs.

Stmulants.-These are worse than useless in the treatment of shock. Nany cases of shock can easily be rendered much more serious by stimulation. It must be remembered that the cause of the condition is exhaustion of the great nerve-centres, and that stimulation increases this exhaustion and does not give the centres time to recover. Again, if the heart be stimulated while the blood-pressure is still so low that the great venous trunks passing to the right auricle contain only a small amount of blood with which to supply it, the heart will only exhaust itself by beating more forcibly without being able to raise the blood-pressure or improve the circulation, except momentarily. And to stimulate the heart to increased action when it has nothing to work on will 


\section{Surgical Shock}

only have the effect of hastening the time when it must fail. It is true that an injection of strychnine will improve the pulse for a tine, but it does so by forcing the already exhausted nerve-centres into action, and this will he followed by further exhitustion of these centres as soon as the effect of the strychnine has passed off. Again, it has been repeatedly proved by experiment, and is a well-olserved clinical fart, that stimulants administered while the patient is in a condition of shock are often not eliminated, but remain in the system, so that when the shock passes off the combined effect of all the stimulants administered will be produced, with perhaps a fatal result. This is particularly the case with strychnine.

It has recently been proved by a series of experiments upon animals that the administration of strychnine in repeated doses to a normal animal will cause shock by overstimulation of the vaso-motor centres and consequent exhaustion. In all degrees of shock the administration of strychnine caused the animals to sink into a deeper degree of shock as soon as the first effects of the administration had passed off. These facts seem to be well supported by clinical observation, and it follows that strychnine is not only useless, but absolutely harmful, in the treatment of shock. In collapse, on the other hand, strychnine may be of service, as the vaso-motor centres are not exhausted. Even in the collapse following a severe hæmorrhage, strychnine though it may do good, is not so useful as transfusion, which directly treats the cause of the collapse.

SALNE INFUSION. - The obvious indication in treating shock is to raise the blood-pressure as near as possible to the normal level, and to lieep it there until the vasomotor centres have recovered sufficiently to maintain the pres- 


\section{The After-Treatment of Operations}

sure at or about the normal. The most certain and rapid method we know of raising the blood-pressure is that of saline infusion into the bloodvessels. Unfortunately, it has been proved by experiment, and confirmed by clinical observation, that the pressure can only be maintained for a short time by this method; and although it will raise the pressure rapidly and quickly if the shock is severe, continued intravenous or subcutaneous infusion will merely result in the water-logging of the tissues, and the pressure will slowly fall back.

The only form of transfusion which is permanently effective is human blood from another patient. This method is difficult and quite inapplicable in most cases. It does not follow that infusion with physiological salt solution is useless. It of ten enables us to tide over a crisis, and gives the patient the chance of recovery that is alone necessary. It is useless, however, to repeat it for any length of time, and other methods must be found.

The fluid should not be allowed to flow in too quickly, and it should be kept warm (at blood temperature). There is generally a very marked improvement in the pulse and general condition as soon as transfusion is started; this must, however, not he talien as an indication that the transfusion can be stopped, but the fluid should be allowed to flow in slowly until about 2 or 3 pints have been injected, and then the patient should be watched for a time to see if the blood-pressure is sustained.

Method of performing Transfusion. - The best apparatus for the purpose is about 2 feet of rubber tubing, to one end of which a glass funnel is attached, and to the other a glass cannula: the cannula should taper to a narrow point, and should have a slight hend in it. The cannula must be tied into the end of the tubing before com. mencing the operation. i very good cannula can be 
made by using the ncedle of an exploring syringe; it has the advantage that it can be very rapidly introduced into a vein without even a preliminary incision being made in the skin, and, in addition, it can be introduced into a much smaller vein than the glass cannula; and this is of importance, as in some patients the veins, even such veins as the median basilic, are so small that it is almost impossible to get an ordinary glass cannula into them.

Introduing the Cannula. - A bandage should first be tied round the upper arm to make the veins prominent; then, any large vein being chosen (this will usually be the median basilic), an incision is made over it and the vein exposed. A double loop of silk or catgut is then passed beneath the vein with an aneurism needle, and the thread is divided so that there is a double ligature round the vein. The lower of these ligatures is then tied up so as to shut off the rein

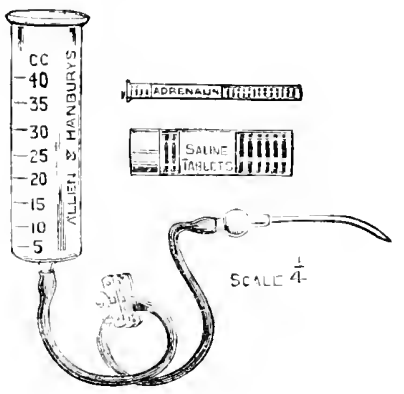

Fis. i6.-Author's Apparates For INTRaienods Infusion With AdRENALIN.

below; the other is held up by the surgeon so that the vein is steadied in the loop. Next, a longitudinal incision is made into the vein with the point of the knife, the cannula is slipped into it, and the upper ligature tied over the point so as to fix it in the vein. Before introducing the cannula, the surgeon should see that the whole of the rubber tubing and cannula are full of fluid, and that there are no air-bublles in the apparatus.

If the needle of an exploring syringe is used instead of 


\section{The After-Treatment of Operations}

the giass cannula, it can simply be stabbed through the slin into the vein in a direction towards the heart.

The best solution to use for intravenous infusion is a physiological solution such as the following:

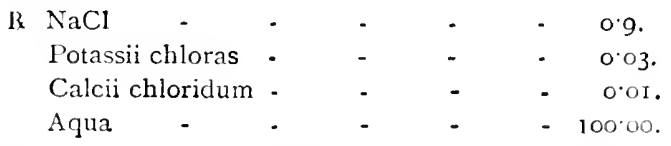

Messrs. Burrouyhs Wellcome and Co. also supply 'soloids,' which when dissolved in water make a physiological solution ('Soloid' Sal. Comp.).

When no such solution is obtainable, a fairly satisfactory solution can be made by adding a teaspoonful of common salt to I pint of water. The solution should be boiled to sterilize it, and then cooled down to about $110^{\circ} \mathrm{F}$. The right temperature may be roughly estimated in cases of emergency by the surgeon putting his fingers into the solution; he should be able to just bear his fingers in it with comfort. In an emergency also, when it is necessary to waste as little time as possible, the fluid need not be sterilized, but common tap-water may be used, to which sufficient boiling water from the kettle has been added to raise it to the desired temperature. In carrying out the transfusion, the fluid should he allowed to flow in slowly, and if there are any signs of dyspnœea at any time after the fluid has been running in, the transfusion must be stopped until this has passed off, when it can again be allowed to flow in. Some time should be occupied in introducing the fluid, and thirty minutes for the introduction of 3 pints is about the average time necessary: 2 or 3 pints of fluid should be allowed to flow in, and then the cammla may be removed and the wound sewn up; or the camnula may be left in, and the rubber tule, after heing clipped, can 


\section{Surgical Shock}

be wrapped round the arm so that it is all ready for use again. All that is then necessary in order to retransfuse is to unwrap the tube, refix the glass funnel, and remove the clip. It might be supposed that there is a danger of the blood clotting in the cannula and rein, and this clot being swept into the circulation by the next lot of fluid used for transfusion. This is, however, not the case, as the cannula and vein remain full of water. As already mentioned, the addition of adrenalin or hemesine to the infusion fluid in suitable quantities greatly increases the value of infusion.

It will be as well to mention here that rigors sometimes occur after transfusion of normal salt solution or even of water. They usually come on about twenty minutes or half an hour after the transfusion; they are not accompanied by any rise of temperature, and soon pass off without doing any harm. What the cause of them is it is very difficult to say; that they are not due to the accidental introduction of septic matter or other poison into the circulation is certain, as beyond the rigors no other bad effects follow, and they occur however carefully the solution and instruments are sterilized. They do not apparently occur if physiological solutions are used.

Rigors more commonly follow transfusion in men than in women, and do not occur except in a comparatively small number of cases. Dyspncea is said to follow transfusion occasionally; this occurs when the fluid is injected too quickly into the circulation, and is due to sudden dilution of the blood in the lungs. It does not take place if the fluid is injected slowly so that it is able to mix with the blood before passing into the lungs. If it should occur, the injection must be stopped until it has passed off, and then continued more slowly.

Rectal enemata of saline solution may be made use of instead of transfusion, but are not so effectual. In cases 


\section{The After-Treatment of Operations}

of very severe shock where the circulation has almost failed, the fluid is not absorbed fast enough to be of use, as there is not enough circulation to carry it into the great vessels. It is, however, a very useful method when the degree of shock is not very severe, and we want to prevent it from increasing.

The water used for the injection should be at a temperature of about $110^{\circ} \mathrm{F}$. As much water as possible should be allowed to flow into the bowel-as a rule not more than I pint at a time can be retained; but this depends to a large extent on the care with which it is injected. By allowing it to flow in quite slowly while the buttocks are well raised on a bolster it is often possible to get a couple of pints retained without any discomfort ; at least twenty minutes should be occupied in introducing this quantity. The best apparatus for injecting the water is a No. 8 soft rubber catheter, with a glass funnel attached to the free end ; the eye end of the catheter should be passed well up into the bowel, and then the fluid should be poured slowly into the funnel.

Another method of performing infusion is by the subcutaneous injection of normal salt solution. The injection is usually made into the subcutaneous cellular tissue of the breast. This method has, however, no advantages orer the intravenous or rectal methods, and on the other hand, it has many disadvantages.

The Use of Drugs.-There are certain drugs which have the property of causing contraction of the ressels in the peripheral circulation, and of so raising the general blood-pressure independently of the action of the rasomotor centres. It is obvious that such drugs are of the greatest value in treating a condition such as shock, in which it is necessary to maintain the circulation until such time as the brain-centres have recovered. There 


\section{Surgical Shock}

are several drugs which have this property, but only three need be mentioned here-namely, extract of the infundibular portion of the pituitary gland (usually called pituitary extract), adrenalin, and nicotine. All these drugs, if administered intravenously, will raise the blood-pressure to, or above, the normal level in the complete absence of the central nervous system. Nicotine, however, owing to its poisonous properties, is not a suitable drug for clinical administration. The most powerful drug of the three is adrenalin, which, if administered in small doses together with saline infusion intravenously, will raise the bloodpressure under any condition of shock. Unfortunately, in practice this drug is not very suitable, owing to the fact that it is rapidly oxidized in the tissues, and its effects are therefore only transitory, and frequent administration is required. Noreorer, it has to be given intravenously, owing to the fact that subcutaneous injections have no effect upon the bloodvessels. Pituitary extract, however, is a very valuable drug for clinical use in the treatment of shock. Dr. Symes and the author were able to prose by experimental work some five years ago that pituitary extract would raise the blood-pressure under any condition of shock, and would maintain it at or about the normal level for a considerable time without readministration, and, moreover, that it could be administered subcutaneously provided there was sufficient circulation to carry it into the general circulation.

It is obviously useless to administer pituitary extract or any other drug hypodermically to a patient suffering severely from shock. The circulation of the blood beneath the skin has practically ceased in such circumstances, and drugs so administered have no chance of reaching the general circulation. It is therefore necessary to inject the drug into one of the larger veins, such as the median basilic, 


\section{The After-Treatment of Operations}

or to administer it in association with an intravenous infusion of saline solution if the blood-pressure has already reached a very low level. The alternative practice in such circumstances is first of all to infuse the patient intravenously, and, after a pint of fluid has been run in, to inject I c.c. of pituitary extract into the india-rubher tube passing from the reservoir to the veins, thus insuring that the drug is carried well into the circulation. This drug may be readministered after four or five hours subcutaneously, if the pressure has not dropped back to a very low level.

Pituitary extract has now been used for a number of years, and it has been found the most effective method of treating shock. It can now be obtained in fairly standardized solutions from the leading chemical manufacturers. One peculiarity about pituitary extract is that second and third injections have far less effect than the first one. The exact reason for this has never been explained, but experimentaily it is very marked.

It must always be remembered that if a patient is rallying from a condition of shock our best method of preventing a relapse is by keeping him absolutely quiet, by administering nourishment in suitable quantities either by the mouth or rectum, by assisting the respiration with oxygen. and, ahove all, by protecting the central nervous system with narcotics, such as morphia or heroin, at suitable intervais.

Artificial Respiration. - This has of ten a remarkable effect on patients suffering from shock. It does good by drawing blood into the chest to supply the heart, and by increasing the oxygenation of the blood. It may be done gently in severe cases of shock, and may with adrantage be combined with the administration of oxygen.

When the patient remains in a condition of shock for 


\section{Surgical Shock}

many hours, it becomes most important to administer nourishment in some form, as the condition is one that gives rise to a great deal of tissue change, and the patient has probably been without food for some time previous to the operation. Some easily digested form of food must therefore be administered in the hope that some of it may be assimilated and help to keep up the vitality of the patient. Nutrient enenata of albumin or peptonized milk should be given every one or two hours, or appropriate food may be given by the mouth if the patient can swallow.

In conclusion, it must be borne in mind that the condition called shock which follows severe operations and injuries is, in a large measure, a mechanical one, in which the circulation is the main factor at fault, and that therefore it is a condition which it is possible to treat successfully in many cases, since by appropriate means the mechanical disadvantages under which the circulation is labouring can be overcome. One of the chief factors in maintaining shock is the exhaustion of the nerve centres in the cord and medulla, and although we cannot directly influence these, in most cases their recovery is only a matter of time, if meanwhile we can succeed in maintaining the circulation. Our efforts, therefore, must be exerted in maintaining the circulation in as efficient a condition as possible until such time as the exhaustion of the nerve centres has passed off.

We must not expect this to take place suddenly or quickly in bad cases, and considerable patience and perseverance will be called for. The most difficult cases to deal with successfully are those where a profound condition of sepsis or toxæmia is present in addition to the shock; it is often extremely difficult or impossible to distinguish the one condition from the other, and patients 


\section{The After-Treatment of Operations}

under such circumstances often react extremely badly, or not at all, to treatment, and when they do react, relapse again almost at once.

The best results will always be obtained by preventing shock rather than by treating it.

\section{REFERENCES.}

'Surgical Slock': G. W. Crile, New York.

'Iroblems relating to Surgical Operations' : Same author.

' Blood-Pressure in Surgery' : Same author.

'Shock in Abdominal Operations': George I Iawkins-Ambler.

'The I'hysiology and Treatment of Surrical Shock and Collapse':

Lockhart Mummery, Lancet, vol. i. I905. pp. 696, 776, 846 . 'Shock and Collapse ': Clifford Allbutt's 'System of Medicine.'

'Gynxcological Operations' : Dr. Kelly, Baltimore.

- The Specific Gravity of the Blood in Shock': Procedings of the

Physiological Socicts, July 20, 1907.

'Some Points on the Experimental Production and Control of the

Vascular Atony of Surgical Shock' : Lockhart Mummery and

W. Leggre Symes. Britisit Medicil Joumal, September 19, IgoS.

'Anoci-Association': G. W. Crile and IV. E. Lower. 


\section{CH.MPER VI}

\section{POST-ANESTHETIC COMPLICATIONS}

Owing to the sreat improvements in the methods of olministering andsthetics which have taken place recently, the after-efiects are now less imp rtant tiran formerly, and we do not so often find the results of the anasthetic complicating the after-treatment of an operation case. It is especially in the old and weakly sulyects that these after-effects are mot likely to cause twinle. The after-effects are much climinished if the patient has been properly prepared for the ana thetic betorhand. In some cases, however, and expecially in emeryency operations, time will not permit of the patient bung properly prepared for an ancesthetic, and it is in these cases that we most often see pontanasthetir complion. tions. Most of the atter-effects result more in discomfort to the patient than in any atual danger; occasionally, however, the results of the anasthetic, either alone or by complicatings some condition caused hy the operation, may give rise to symptoms of the gravest import. The nature of the anatheric used and the method of administration are of considurable inportance. Fther is undoubtedly more liable to canse unpleasant after-results than hloroform, but its other advantages suficiently ourweigh these to render it a 


\section{The After-Treatment of Operations}

preferable anosthetic in the majority of cases. The liability to, and the severity of, post-anæsthetic complications are proportionate, to a large extent, to the length of the administration.

\section{Vomiting.}

A certain amount of vomiting may be said to be the rule after ether; the vomited material is usually little else than mucus, and vomiting generally passes off before the patient regains consciousness. Occasionally, however, it is more severe, and may continue for many hours or even days. When this is the case it is very distressing to the patient, and may be dangerous, by lowering his strength and preventing the proper assimilation of nourishment.

Vomiting is more liable to occur if the patient is jolted or moved carelessty soon after the anæsthetic; care should therefore be exercised in moving the patient back to bed, both to avoid jolting and to keep him as flat as possible. The cause of the romiting has been attributed to the presence of ether in the stomach. Hess of New York, who has investigated this subject, comes to the conclusion that the drug is excreted by the gastric mucous membrane, and as it is usual for the stomach to be empty during in operation, it remains there in a concentrated form mixed with mucus; no doubt also a considerable quantity of ether finds its way into the stomach with the saliva which is swallowed. Hess considers that the bad cases of post-anxsthetic romiting are due to a sastritis set up by the ether present in the stomach, and suggests that the best way of preventing this is by diluting the stomach contents. He advises that the patient should be given a drausht of water before 
the commencement of the anesthetic, so that any ether that may find its way into the stomach will he rapidly diluted. Whether the voniting is due to any local condition of the stomach or is of central nervous origin is still somewhat doultful; that, at any rate, the romiting is not entirely due to local causes seems probalue, as romiting follows the ancethesia proinced by rectai etherization. And, again, some of the worst cases of vomiting occur after chloroform. That ether does get into the stomach during the adninistration of the and thetic there can be no doult, and draughts of water after the administration, whether retained or not, will assist in cither diluting or washing it away.

Although romiting is more common after ether than after chloroform, the worst cases of romiting are seen after the latter drus. The presence of blood in the stomach (which has been swallowed during the anæsthesia) is a common canse of subsequent romiting. In children, vomiting after ether is very much less common than with adults, in spite of the fact that, as a rule, children are sicls from very slight causes; and it seems that old people are also less liable to post-anasthetic vomiting.

The position of the patient after an anresthetic is of some importance in preventing sickness. The patient should be turned on to the right sicle if possible, so as to allow any fluid in the stomach to find its way easily into the duodenum. In cases of very intractable romiting, propping the patient up into a sitting or half-siting position will often be efficacious in stopping the sicliness. When the vomiting consists in simple regurgitation of fluids directly they are swallowed, this is all that is usually necessary to stop it and enable the putient to retain nourishment. 


\section{The After-Treatment of Operations}

Another point of great importance with regard to the posture after an anæsthetic may be referred to here-that is, that after the patient has been put back to bed, and before he has regained consciousness, the head must be kept well to one side, as if he be allowed to lie on the back with his head in the midline, should any sickness occur there is a great danger of the vomited material becoming suclied into the air-passages and obstructing respiration. This may occur even though a nurse is watching the patient, and several deaths have been recorded from this cause after the administration of ether.

When from the nature of the operation it is particu. larly advisable that the patient should not vomit after the operation is finished, or when it is known that the particular patient is liable to exceptionaily serere romiting after anæsthesia, an excellent plan is to wash out the stomach with warm water before sending the patient back to bed; this is often effectual in completely preventing vomiting.

As soon as the patient is conscious after the anæsthetic, if vomiting does not cease he may be given some quite hot water to drink (about $\frac{1}{2}$ pint may be allowed); this will sometimes have the effect of making the patient sick, but will do no harm, as it washes out the stomach and gets rid of the ether.

Another plan is to give 15 to 20 grains of bicarbonate of potash in $\frac{1}{2}$ pint of hot water; or 3 minims of tincture of iodine dissolved in $\frac{1}{2}$ pint of cold water is some times very effectual. Another way of giving iodine is I minim of iodine in I drachm of water every two hours. Strong hot coffee may be tried, or champagne is sometimes useful.

There are several drugs which enjoy a reputation for preventing vomiting after anæsthesia; thus hydrocyanic 


\section{Post-Anasthetic Complications 101}

acid in small repeated doses is said to be of value. Morphia is certainly sometimes of use, and may be given either hypodermically or by the mouth. Sir F. Iiewitt says that when there is a neurotic element in the vomiting, bromide of potassium may he given as an enema (20 grains in 2 ounces of water) with good results. Sometimes Io grains of bromide placed on the back of the tongue is effectual.

Counter-irritants to the region of the stomach are sometimes effectual. The best of these is a flannel rung out of boiling water and applied to the epigastrium; it must be applied as hot as possible and changed as soon as it has become cool. Blisters have also been used with success.

Strong essence of peppermint is sometimes very effectual; it is best given as 5 or ro drops on a lump of sugar, the latter being suclied slowly, or it may be given with a little water: it probably acts in the same way as a counter-irritant. In cases of very severe and intractable sickness the stomach should be washed out with warm water by means of a soft rubber tube, until the water comes back quite clean; this removes any decomposing or irritating material that may be present, and it is the most effectual method we possess of stopping vomiting. The repeated inhalation of oxygen has sometimes proved effectual in controlling vomiting in bad cases. Patients who have suffered from severe vomiting often complain of pain round the lower part of the chest, especially on deep inspiration, for a day or two afterwards; this is due to the muscles having been strained during the violent retching. This pain often gives rise to a great deal of discomfort, and may even give rise to a suspicion of pleurisy. It should be relieved by rubbing the skin over the painful muscles with linamentum saponis or by gentle massagre. 


\section{IO2 The After-Treatment of Operations}

\section{Lung Complications.}

The liability to lung complications after anæsthetics is prohably greater than is usually supposed. These com. plications are most commonly seen after ether, and but rarely after chloroform. The most common of these complications is bronchitis, which may go on to bronchopneumonia in bad cases. The so-called ether pneumonia, which is of the lobar type, seems to be much more rare than its name would imply.

The term 'ether pneumonia,' though commonly used, is a bad one, and 'post-operative pneumonia' would be better. That ether is not responsible for all the cases of pneunomia which occur soon after an operation is shown by the fact that pnenmonia also occurs after chloroform and infiltration anxsthesia. There is little doubt that many of the cases quoted as 'ether pneumonia' are due to infarction of the lung. This is also borne out hy the fact that pneumonia more frequently occurs after abdominal and pelvic operations, and it will he seen by reference to the chapter on Thrombosis that these are the operations after which infarction is most liable to occur.

Crouch and Comer, who investigated this subject recently at St. Thomas's Hospital, found in $2,+00$ administrations of ether, ten cases of sulserfuent lung complications which were directly attributalle to the anasthetic. Of these ten cases, three were bronchopnenmonia (one of whom died), one developed pleurisy, and the remainder bronchitis of rarying degrees of severity. It may he mentioned that in this seties of cases the anathetics were given, for the most part, by inexperienced anasthetists. The liability to these complications appears to be greater after prolonged anasthesia, 


\section{Post-Anesthetic Complications 10.3}

and especially when the patient is subjected to changes of temperature or dramohts soon after the arlministration, as is the case when he has to he conveyed aloner passages, etc., on the way from the operating-table to the hed. It is, therefore, commoner in hospital than in private practice. Tu pievent these complications sreat care should be taken not o lat the patient be subjected to any dranght or sudden thange of temperature after an anæsthetic, and if it is necessary to move a patient some distance from the optriting room, the head and mouth should be covered over with a thin hlanket. The treatment is, of course, that which is appropriate for the lung conduon present. Many cases of ' ether pneumonia' are really lobar collapse in connection whin inhibited action of the diaphragm during and atter ahdominal operations.

\section{Other Complications.}

Among other complications that may be seen are the following :

Renal Trovbles.-Some observers state that albuminuria for a day or two is very common, and is more often seen after chloroform than after ether. Two cases have recently been reported in which uræmic coma followed an anæsthetic. Disease of the lidneys was found to be present in both cases at the postmortem. Such cases show the importance of examining the urine before giving an anxsthetic.

JALxdice has been recorded as occurring after chloro. form.

Insanitr.-Several cases of this have been recorded. It is specially liable to occur in patients the sulijects of recurring attacks of insanity, the anmsthetic acting as the exciting cause in bringing on another attack.

Diabetic Cosir has been linown to be brought on by the administration of an anæsthetic. Of course, this is 


\section{The Atter-Treatiment of Operations}

best prevented by carefully dieting the patient before the operation.

I'Ararysis.-Dr. Blumfeld mentions three varietics of paralysis that may follow anxihesia: (I) Those of peripheral orisin. These are lue to the patient, while his volition is in abeyance, lemer allowed to remain for some time in a strained position, which has resulted in some nerve or nerves being pressed upon. Deltoid and uhar paralysis are examples. (2) Those of central origin. These are really apoplectic fits, resulting from the consestion due to the anxsthetic.

(3) Indeterminate.

Persistent IIIccougn.-This may occur and prove very difficult to stop. Tongue traction has sometimes been successful.

HeMATEMLSIS. - This complication is very rare, but is sometimes seen after operations, and it is loubthul how much of it is due to the anasthetic and how much to the operation itself. It seems to be commoner after cperations on the intestinal tract than after operations on other parts of the body. A case is reported in the Lamat, August 22, Igo2, where hrematemesis occurred four days after the operation, and Mr. Mayo Rohson cites sereral cases of this complication, some of which were fatal.

Hanoptrsis. - This also is a rare complication, but is occasionally seen. (i course, as a rule it is seen in fulercular patients who have caritics in the fungs, and the congestion resultins from the anasthetic acts as ilue wating cause. Sometimes, howerer, no history of any previr s lune trouble is olotanable, amel on eximination of the chest it is nut posible to discover any sisns of mischiof. It is, ats one would naturally suppose, most communty seen after ther.

Demave Chiorororn Pusonug is a condition in which the patient, usually a child, having apparently 


\section{Post- Inasthetic (omplications}

recovered from the effects of the andsthetic, hegins to romit ropeatedly. The onset is usually twelre to thitysix lours after (pperation; the romiting continuts, acetone appears in the urine, the temperatute rises, and chelinim, restlessness, and coma supervene, terminating in death. Nider forms of this complication, from which patients have recovered, have also ineen described. The most hopeful form of treatment is stated to be repeated washing out of the stomach with solutions of bicarb nate of soda ( $\vec{i}$ i. to the pint), a small puantity of the solution being left hebind in the stomach. Glucose shouid also be siven porrectum.

\section{Diet.}

As a rule, no food should he given by the mouth for from four to six hours after the anasthetic, as it will probably only cause vomiting. The first food that is griven should be something that is easily assimilated, but need not necessarily be fluid. Solids or semi-solids are often more readily retaincd, and are more satisfying to the patient. A cup of tea with some soft bread-andlutter and a lightly-boiled egrs may be given. Anything in the way of a large meal shonld not be allowed, as it will almost certainly cause sickness. When the administration has been a long one, of course the interval that must be allowed to elapse before food is given should be longer. On the day following the operation the patient nay be allowed to go back to his ordinary diet if there is no sickness and it is not otherwise contra-indicated by the isature of the operation.

\section{REFERENCES.}

'Anesthetics': Sir F. llewitt

'Vomiting after Anæshthetics': Dr. Blumfeld, Clinical Joumal, Ausust, 1901. 


\section{CHAPTER VII}

\section{THROMBOSIS FOLLOWING OPERATIONS}

THIS is, fortunately, a rare complication. It may result from two conditions: (I) After a prolonged or severe operation upon an anæmic subject; (2) as the result of sepsis in the wound. The thrombosis differs considerably, according to which of these conditions has caused it, both as to its type and its liability to give rise to infarction. In the first case, the thrombus is due to stagnation of the blood and infarction if it occurs, will do so during the period of formation of the clot, and there is very little tendency for it to do so later. In the second case, the thrombus is a septic one, and the chief period of danger is during the softening of the clot; moreover, in this case, if infarction occurs abscess will probably form at the site of the infarct, anct a condition similar to pyæmia will be set up. It is well to bear these facts in mind as it is of the utmost importance that the patient should he kept absolutely quiet during the dangerous period. There seems to be an exceptional liability to bed-sores in some of these cases, and if the case is a septic one necessitating prolonged immobility, it is best to turn the patient on to his face, lifting him on a sheet so as to disturb him as little as possible. The liability to the formation of bed sore is rinuch less in this position, as has already been pointed out. 


\section{Thromboss following Operations 107}

Thrombosis most commonly occurs about a week or ten days after the operation, though it may take place very much earlier than this, and, as in the second of the appended cases, it may occur as late as three weeks afterwards. In a résumé of forty-eight cases of crural thrombosis following surgical operations collected by Shenck, and reported in the New York IItdical Joumal, September 6, 1902, it was found that out of a total of 7,130 synacological operations there were fortyeight cases of thrombosis of the reins of the luwer extremity.

In the more recent statistics from the Nayo clinic: for the year 1913 (1)eckman, "Complications following Surgical Operations,' Joum. Sury., Gynacol., and Olsictrics, May, I $91 .+$ ) there were fourteen cases ont of a total of 6,825 cases. These figures show a very marked improvement, and are what one would expect as the result of the improved technique and greater attention to after-treatment that have been the chief features of surgical advance in the last ten years. The fourteen cases in these last statistics occurred in twelve different types of operations, although all were abdoninal operations. The conclusion arrived at from these figures is that there is no special liability for thrombosis to occur in septic cases as opposed to clean ones.

Shenck also points out that this complication is much more common after operations on the pelvis, than after operations on any other part of the body, and that injury to the large venous trunks by the too forcible use of retractors is a possible canse in some cases. Ligature of a vein close to the point at which it enters the main renous trunk may cause thrombosis in that trunk by extension of the clot, and this was thonght to be the cause in some of Shenck's cases. The most common 


\section{I08 The After-Treatment of Operations}

date for the onset of this complication was found in this series of cases to be between the twelfth and sixteenth days after the operation. It was found that the anæmia and cachexia accompanying malignant disease was a factor in many of the cases where thrombosis followed operation for the relief of this condition. An infective origin for the thrombosis was also traceable in many of the cases.

In an investigation carried out by Wright and Knapp into the cause of post-typhoid thrombosis, it was shown that there was a decrease in the coagulation time of the blood of typhoid patients during the later stages of that disease (i.c., that the blood coagulates more rapidly than normal), and that this increased coagulability is accompanied by an increase in the amount of calcium salts present in the blook. This increase in the calcium salts is attributed to the fact that typhoid patients are fed almost exclusively on a milk diet, which contains a high percentage of these salts. If this view is correct, and it seems a reasonable one, and is well backed by experimental evidence, the thrombosis following typhoid is in part due to a milk diet. And it is possible that some of the cases of thrombosis that follow operations are due to the same cause. Wright and Knapp suggest the use of citric acid to precipitate the calcium salts as a prophylactic agent.

It would seem that operations in the neighhourhood of the pelvis are those most liable to be followed by thrombosis, and that this is attributable to direct injury or infection of the main venous channels or the ligature of their inmediate branches. Anamic or cachetic conditions undouhtedly predispose to the condition.

The onset of thrombosis is usually accompanied by pain in the part or by itching. This pain is generally of 


\section{Thrombosis following Operations 109}

a dull, aching character. On examining the part there is found to be tenderness over the site of the rein, or the thrombosed vein, if superficial, may sometimes le felt like a lead pencil beneath the skin. The greatest care must, lowever, be taken in cxamining a patient in whom thrombosis is suspected, as otherwise there is mat danger of dislodging the clot. The treatment should consist in wrapping the affected parts in cotton-wool and elevating the limb. Absolute rest in hed for at least five weeks is usually necessary, and this time may have to be considerably extended. Splints should not be used, but the limb, if necessary, may be steadied ly sand-bags.

Great care must be exercised in the nursing, especialily during the period when the clot is extending, and the patient must be moved as little as possible and very carefully, otherwise there is great danger of a portion of the clot becoming detached and giving rise to an infarct in the lung; the patient should also be warned as to the danger of moving. For the same reason anything in the nature of a purge must not be given, and if there is any difficulty in getting the patient's bowels to act, enemas should be used.

Roughly speaking, it may be said that in the non-septic cases most of the danger of infarction is over in a fortnight from the commencement of the thrombosis. In the septic cases the time is longer, being roughly five or six weeks. When there is marlied anæmia, it is most important to treat this condition by careful attention to diet and the administration of iron in some form or another.

When infarction does occur and is not immediately fatal, the patient should be sat up and oxygen administered to relieve the dyspncea, which is very distressing; some stimulant is usually necessary, such as strychnine 


\section{I The After-Treatment of Operations}

or lrandy. As soon as the dyspnoea has to some extent passed off, which in most cases is in about five or ten minutes, the patient should be propped up with pillows and kept as quiet as possible. Allialies, and especially ammonium carbonate, seem to be of some value in preventing further extension of the clot, and may he given in large doses ly the mouth. In thrombosis of septic origin, if the position of the clot will permit of it, the rein on the proximal side of the clot may be cut dom and ligatured. When sudden death has occurred from infarction and the medical attendant is at hand, it is always worth while to try and restore the patient by artificial respiration, etc., as the cause of death in most cases is quite momentary.

Infarction is usually accompanied by a rise of temperature to $1_{01}^{\circ}$ or $102^{\circ} \mathrm{F}$.; the temperature falls again in twenty-four hours, as a rule, though it may remain slightly elevated for some days. In the septic cases there is, of course, the ordinary septic temperature. A careful examination of the chest on the day after infarction has taken place will sometimes reveal a patch of consolidated lung corresponding to the area cut off by the infarct.

\section{Illustrative Cases of Thrombosis and Infarction following Operations.}

Case i (Fig. i7). Thromiosis following Operation for AppexDICITIS.-A rather anamic-looking girl was admitted with symptoms of acute appendicitis. At the operation, which was performent on January 16 , a large abscess containing much foul pus was openel and drained. The case progressed favourably for the next few days, and there was free discharge of pus from the wound. On the 22nd (six days after the operation) the patient complained in the morning of some pain in the right leg, and it was discovered on examination that the right femoral vein and most of the veins of the calf were thrombosed. At 3 p.m, the same day the patient had a 


\section{Thrombosis following ()perations I I I}

cudden attack of dyspnora, faintness, and cyanosis. She was ver: bad for some few minntes, but was relieved by the inhalation of oxygen and an injection of strychnine. She had to sit nip. The respirations were 50 .

On the 23 rd the patient was still dyspncric. Respirations fo.

This condition remained practically unchanged till the 26 th. Nothing at this time was found in the lungs. The cundition now improved, but on the night of the 25 th there was another attack of dyspncea (i.e., another infarct). There was at this time some oedema of both legs, and both the femoral veins were thrombosed. The legs were dressed with leal and opium lotion, and 20 grains of ammonium carbonate was gicen three times daily by the mouth. The wound was now almost healed, and he tubes had been removed. On February 6 the patient complained of pain and stiftress of the right shoulder, and it was noticed that the superficial reins of the right side of the chest and all down the irm were dilated. All the veins of this region that could be seen or felt were found to be thrombosed, and it appeared certain that the ritht innominate vein was thrombosed.

On the IIth an eczematons rash appeared orer the legs, chin, and right hand. There vere no further infarcts, and the patien rapidly improved. The thromboses all cleared up in the course of abont ten days or a fortnight after this, and the patient left the hospital quite well on March 6 .

At first the patient was fed with albumin water, but after the ap. pearance of the thrombosis a more nourishing fluid diet was allowel.

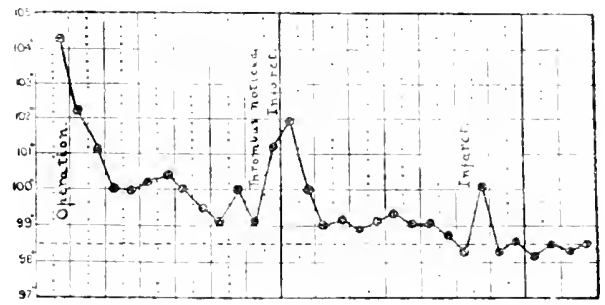

FIG. I 7 .

and iron in the form of cachets of pil. ferri ( 5 grains) was given three times a day; half a pint of stout was also given daily and port wine. For the pain and distress when the infarction took place 


\section{12 The After-Treatment of Operations}

a hyphlermic injection of morphia was administered. Large doses of alkalies, sodium bicarbonate, and ammonium carbonate were given throughout.

In what way alkalies act in the treatment of these cases is very doubtful, but they seem to have a very beneficial etfect.

Case 2 (Fig. io). Tirrombosis following an Operation for Appendicitis.--This was the case of a man, aged forty-five, who was operated on for acute appendicitis, and had a large abscess in the neighbourhood of the appendix drained. About twelve days after the operation the patient had what was described as an acute cardiac attack, accompanied by very severe dyspnoa. (This seems to have undoubtedly been an infarct in the lung.) There was at the same time cedema of the right leg, and the ferroral vein was found to he thrombused. A week later there was another attack of a similar nature to the first one. After this attack some friction was noticel

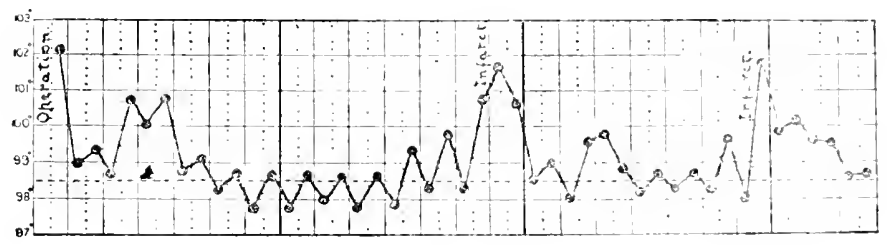

IIIG. 18 .

on listening with the stethoscope over the lower part of the left side of the chest. The thrombosis gradually cleare 1 up, and the ratient was able to go away to the country two months after the operation.

The temperature charts of both these cases are appended, and it will be noticed that there is a rise of temperature coincident with the infarction of the lung.

Case 3 (Fig. 19). Thrombosis following an Opzration fok HERNiA. - A woman, aged forty-nine, was operated upon for the radical cure of a hernia on the right side, on Nuvember 22

On the third dy after the operation there was a slirht rise in the temperature. This, however, dropped again, and remaine normal 


\section{Thrombosis following Operations 113}

till the 28th, when it again rose, and continued high. On Decernher 2, as sepsis was suspected, the wound was dressed, though the patient complained of no pain in the wound. The wound was found to be quite healthy, and almost healed On this day pain was complained of in the calf of the left leg, and on examination it was found that the iliac, femoral, and saphena veins were all thromboned. There was some cystitis present, for which she was treated by washing out the bladder.

The same afternoon, while being moved in bed, she had an infarct in the lung. There was sudden, very severe dyspnora: the puise became irregular and uncountable, and she was in great distress Oxygen and stimulants were administered, and she gradually rallied. Cn December 6 she had another pulmonary infarct, which almost proved fatal. On December 27 she had another pulmonary infarct of a severe nature, and another less severe attack on the 28th. At this time the patient was very ill indeed, and romited everything. There was much dispnea, and she was very cyanosed.
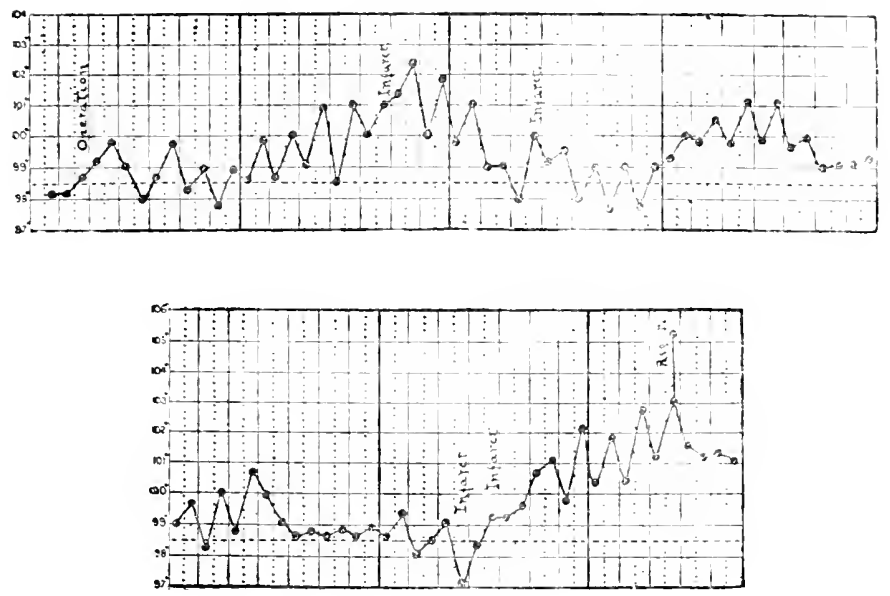

FIG. I9.

The breathing gradually improved in the course of the next few days.

On January 8 a large sloughing bed-sore formed over the sacrum. and she was accordingly turned on to her face and subsequentiy 


\section{4 The After-Treatment of Operations}

nursed in this position. The bed-sore was very septic, and con. tained much gangrenous tissue. From time to time there were rigors, and her temperature remained high.

On February 3 her temperature went up very high, and she became extremely ill.

On February I2 she had several rigors, and developed a bad cough, though no signs could be discovered in the chest.

On February 28 she coughed up a quantity of pus on two occasions.

After this the temperature gradually came back to the normal, and by April to the cough had disappeared, and she soon afterwards left the hospital for the seaside.

This case was one of septic thrombosis, though the cause of infection is somewhat doubtful. It may have been from the wound (which, however, did not break down), or from the cystitis which was present. It shows very well how much more dangerous these cases are than those of simple thrombosis, and how the danger of infarct extends for a much longer time.

There can be little doubt that the bed-sore and the abscess in the lung were due to septic emboli. There were no signs of the lung abscess for over two months from the time of the formation of the thrombus; this shows the great importance of complete rest in bed for a long time in these septic cases. Cases of pulmonary embolism are often more serious, there being no indication of anything wrong before the sudden onset of dyspnca and death. These cases are veritable tragedies, death often occurring in a few minutes without any warning, though the patient was apparently doing well. In most of these suddenly fatal cases an autopsy will reveal the presence of a clot in the right pulmonary artery and thrombosis of the femoral or pelvic veins. 


\section{Thrombosis following Operatıons 115}

\section{REFERENCES.}

'Crural Thrombosis following Surgical Operations': B. R Shench. New York Medical Jourkal, September 6, igoz.

'Post-Typhoid Thrombosis': Drs. Wright and Knapp. Lancot, December 6, 1902 .

Dr. Wright and Dr. Paramore. Lamit, October I.4, 1905.

'Pulmonary Embolism and Thrombosis after Laparotomy': L. Ficlwell. Practitioner, February, I9og.

'Complications following Surgical Operations': Beckman. Sugrem, Gynacology, and Olistincs, May, I9I. 


\section{CHAPTER VIII}

\section{POST-OPERATIVE RASHES AND DRUG-POISONING \\ Septic Rashes.}

FOR a long time great confusion has existed in the diagnosis of rashes following operations, and hitherto many of them have been called scarlet fever. Some text-books describe a form of scarlet fever called 'surgical scarlatina,' which occurs in patients with open wounds; it seems most probable that this is really a septic condition. Though undoubtedly there are from time to time cases where a genuine attack of scarlet fever follows an operation, careful investigation seems to show that these cases are rare, and that most of the cases described as scarlet fever following injury or operation are in reality septic in origin.

A septic rash generally makes its appearance at the time that other septic manifestations usually appearthat is to say, from one to four days after the operation -though the time after the operation at which the rash appears is often slightly shorter than in the case of ordinary sepsis in the wound, as the nature of the infection is more acute. The appearance of the rash is senerally accompanied by a marlied rise in temperature to $102^{\circ}$ to $103^{\circ} \mathrm{F}$, and is followed by other constitutional 
symptoms, such as malaise, rapid pulse, restlessness, etc. The rash itself is usually a scarlet erythema, which much resembles the rash of scarlet fever. It usually appears quite suddenly in the course of a few hours. Often the rash is an almost uniform injection of the skin, at other times it may be more punctate or blotchy in appearance. Occasionally it is papular. The rash often fades on pressure, lut this depends to some extent upon the intensity of the injection. The exact appearance of the rash is by no means constant. Its distribution also varies a good deal; the most common type is a uniform scarlet rash, which appears simultaneously all over the body. In some cases, however, the rash is more limited in its distribution, and may be confined to the buttocks and flexor aspects of the thighs, or to the skin over the joints of the extremities, around the ankles, knees, and wrists. Most commonly the rash only lasts for a few days, and then fades away; occasionally it may persist for a week or even longer. Desquamation often occurs, and especially if the rash has been at all severe. Slight albuminuria is sometimes present for a few days in the more severe cases.

In the worst cases all the symptoms of septicæmia develop, and the patient soon sinks into a typhoid state and dies. In the milder cases the rash lasts for a few days, accompanied by an elevated temperature, but often by very few other constitutional symptoms, and then clears up, and the patient makes a good recovery. Almost any degree may be seen between these two types of case. Septic rashes are much more often seen in children than in adults. In children a very mild degree of sepsis is often followed by a rash, and frequently the rash is almost the only symptom present. It is quite common to see a child, as the result of some septic 


\section{8 The After-Treatment of Operations}

infection, such as the opening of an abscess or the presence of an infected wound, develop a scarlatiniform rash and perhaps a temperature of $103^{\circ} \mathrm{F}$, and in twentyfour hours or forty-eight hours to see the whole of the rash disappear and the temperature come down to normal.

As regards the condition of the wound : there are often no signs of sepsis in it at the time when the rash first appears; it may be a little puffy round the edges, but often there is little more than this, and sometimes there is nothing to be seen at all. Later on the wound usually gets into a sloughy condition, or breaks down and suppurates.

The argument often used against the diagnosis of the rash as septic, that the wound does not show signs of sepsis, or only shows them slightly, is quite fallacious. It must be remembered that the appearance of a septic rash after an operation is evidence of a general septic infection in contradistincton to a local infection, and that therefore the wound itself, which is the site of infection, does not always breali down or show signs of sepsis.

General septic infection only occurs in the cases where the local resistance to septic organisms is absent or insufficient; and since pus in the wound is the result of local resistance, one would not expect to see the wound break down to any marked extent in these cases. And, in fact, it may be stated as a rule that in those cases where, after an operation, general infection of the blood occurs as manifested by the appearance of a rash or other constitutional symptoms, the wound shows little or no evidence of sepsis. And the more severe the seneral infection, and the more rapid its onset, the less likely is the wound to show marked signs of sepsis. There is, 
however, another class of case in which the wound first breaks down and suppurates, and then later on, the local resistance to the action of the septic organisms proving insufficient to protect the body from general infection, general infection takes place and a rash develops; in this class of case the rash will, of course, not appear for some time after the operation.

The diagnosis is often a matter of very considerable difficulty. The conditions under which the rash appears - that is to say, within a few days after an operationshould make one suspicious of sepsis, and cases should not be called scarlatina and removed to a fever ward without strong evidence in favour of scarlet fever and a history of possible infection. If there is much doubt as to whether the case is one of scarlet fever or sepsis, the patient should be isolated as far as possible for a few days, when the diagnosis will probably be cleared up. The so-called strawberry appearance of the tongue which is seen in scarlet fever is not seen in cases of sepsis, though the tongue is furred.

The following are some of the points which may help in distinguishing a septic from a scarlet fever rash:

I. The premonitory febrile symptoms are usually absent, the rash being the first thing noticed in most cases.

2. The distribution of the rash is irregular; it appears often simultaneously all over the body, and not, as in scarlet fever, on the neck and face first.

3. There are no throat symptoms, except in those cases where the wound is in the throat.

4. The pyrexia is high and of the septic type, with often marked intermissions.

Subsequent peeling is no proof of scarlet fever, as it not infrequently occurs in the cases of undoubtedly septic rash. 


\section{20 The After-Treatment of Operations}

The following are good illustrative cases of septic rash following operations :

A child was operated upon for curved tibiæ; the right tibia was divided on November 15, and the left on the $22 \mathrm{nd}$. On the 27 th the child developed a scarlet rash all over the body. The wound in the right leg was found to be swollen, and it subsequently broke down and suppurated. On December I the rash had cleared up, and the patient was pecling freely all over the trunk and right leg. This child was in a ward with twelve other children, none of whom developed scarlet fever, so that there could be no doubt as to the rash being septic.

A boy of sixteen had the tendons at the back of the ankle divided for talipes. Two hours after the operation he had a shivering fit. The next morning he was hot and flushed, and had a temperature of $\mathrm{IOI}^{\circ} \mathrm{F}$. The chest and limbs were covered with a mottled, rosecoloured rash, which disappeared on pressure. Forty-eight hours after the operation the rash had commenced to fade away. The temperature was $\operatorname{ror}^{\circ} \mathrm{F}$. and the pulse 126 . On the following day, three days after the operation, the rash had disappeared. The temperature was $100^{\circ} \mathrm{F}$. On examining the wound, it was found that the skin round it was red, swollen, and very tender, and the foot and ankle were œedematous. On the seventh day after the operation all the symptoms had cleared up, and the patient made a good recovery.

The following is a good example of a doubtful case, in which the diagnosis was difficult:

A boy, aged six, had an exostosis removed from the lower end of the femur. Thirty-six hours after the operation his temperature went up to $101 \cdot 2^{\circ} \mathrm{F}$. Forty-eight hours after the operation the tem. perature had risen to $104^{\circ} \mathrm{F}$., and he was in a state of high fever, with a flushed face, rapid pulse ( $5_{5} 6$ ), and quick, shallow respiration. The whole of the body and limbs were covered with a bright, scarlet, punctiform rash, fading on pressure, and not elevated or perceptible to the touch. The tongue was furred and the pharyns was congested. The wound at this time was swollen round the edges, but otherwise showed no signs of suppuration. On the fourth day a bright erythematous patch was noticed on the back of the left wrist-joint. On the fiftl day the rash was the same as 
hefore, lut there was in addition extreme hypersthesia over the whole lody, and the patient complained of pain in the wound. On the sixth day a trace of albumin was found for the first time in the urine. On the eighth day both ellow-joints were painful and swollen, and the patient complained of pain in the linees. At this time the wound was rery foul and slonghy, and contained some very fotid pus. On the tenth day the rash had faled slightly, and there was commencing desquamation on the chest and face. The inguinal glands were enlarged, and there were pyamic abscesses in several places. The patient died in the afternoon.

At the post-mortem the elbow-joints and knees were found to contain pus, and there were other signs of pyamia.

Scarlet Fever following Operations.-There have been a considerable number of cases reported from time to time of scarlet fever following an operation. Many of these cases are certainly not scarlet ferer, but cases of sepsis which have been mistaken for scarlet ferer. It is sometimes extremely difficult or even impossible to distinguish between a genuine attacli of scarlet fever following an operation and a septic rash. In some of the cases, however, other persons who have heen in attendance on, or in contact with, the patient lave subsequently developed scarlet ferer, and thus the infective nature of the rash has been conclusively proved.

Operations upon the nose and throat-such as for the removal of adenoids, tonsils, etc., and operations for cleft palate-seem to be those most commonly followed by an attacli of scarlet fever. Quite a large number of cases seem to have followed the operation for adenoids. The source of infection has not always been clear. In some cases it has afterwards been found that the room or house was infected, or that the patient had come into contact with infected persons just prior to the operation, or even that the operator was the source of infection, as in a case quoted by Sir James Paget. 


\section{22 The After-Treatment of Operations}

The late Dr. Washbourne, in an article on this subject, in which he quoted several cases, stated that he thought the organism or infective virus of scarlet fever remained dormant in the mouth, and that the traumatism caused by the operation allowed of its entry and development. This is a similar view to that of the late Sir James Paget, who said that the operation, by lowering the patient's resisting power, allowed of the development of an otherwise dormant virus.

Another view which would seem a very probable one in many cases is that the virus of scarlet fever finds an entrance by the wound at the time of the operation in the same way that septic infection occurs. This view will account for the very short incubation period in these cases of post-operative scarlatina, owing to the more direct method of entry of the virus into the system. That this view is the correct one-in some cases, at any rate-is supported by the fact that occasionally the rash starts in the neighbourhood of the wound, and then spreads over the rest of the body.

The type of scarlet fever which follows operations seems to vary somewhat from that seen under ordinary circumstances, the characters of the attack being apparently modified by the conditions under which it occurs. Thus the incubation period is often very short. In a series of sixty-three cases collected by Edward C. Stirling the commonest time for the appearance of the rash was two days after the operation. The value of this series of cases is, however, very doubtful, as there are a great many cases included in the series, if not the majority, that are really septic cases. An analysis of the undoubtedly scarlatina cases, however, shows that the time at which the rash appears is often very short-two or three days in many cases, and as short as twenty-four 
hours in a few. Most of the other variations that have been described seem to be the result of the inclusion of septic cases among those of genuine scarlet fever, and therefore but little value can be attached to them.

Rashes due to Enemata.-These are not at all un. common, and it is most important that they should be recognised, as otherwise they may be confused with septic or scarlatinal rashes, and cause considerable confusion. The practice of giving an enema just before an operation is now so usual that it is not uncommon to see a rash follow an operation, and be mistaken for the onset of septicæmia or scarlet fever, when it is really due to the enema that was given before the operation. The rash generally makes its appearance very shortly after the injection, usually in from three to twenty-four hours. The most common time seems to be about twelve hours. The rash lasts from two to four days, and then gradually fades away.

The distribution of the rash is very variable; it may be evenly distributed over almost the whole body, or it may be confined to certain parts. The buttocks and thighs-especially about the inner aspects-and over the sacrum are perhaps the most common places for the rash to appear, and it is here that it is usually best marked and thickest. The rash often appears on the face, and sometimes on the arms and upper part of the chest.

The type of the eruption also varies a good deal. Dr. Monro describes three types of rash from enemata : (I) The scarlatiniform ; (2) the measly; and (3) the urticarious. More than one of these types may, however, be present at once, or the rash may start as one type and subsequently change to another.

There is usually no itching in the first two types, but the urticarious form is, as a rule, accompanied by very 


\section{The After-Treatment of Operations}

severe itching. Very rarely desquamation follows the rash. The rash most commonly seen is a bright erythema, which fades on pressure. It is usually patchy, and often much more distinct in some places than others. The spots are sometimes raised, and the similarity to measles may be close. As a rule, the rash is not accompanied by any pyrexia, but occasionally the temperature is raised for a time. In some of the recorded cases the onset of the rash has been accompanied by sicliness and vomiting. The diagnosis is often very difficult when the rash first makes its appearance. The cause may, however, be suspected when a rash appears within twentyfour hours of the administration of an enema, and is not accompanied by pyrexia and other constitutional symptoms.

The cause of enema rashes is somewhat doubtful. It appears to occur only after large injections, and is not seen after the use of suppositories or small enemata. Soap enemata, and especially enemata made from hard soap, seem to be the most common cause of the rash. Soft soap, when used to malie enemata, seems to be much less liable to give rise to a rash. Turpentine enemata also occasionally cause a rash. It has been supposed that the cause of the rash is the absorption of fæcal matter by the intestinal wall as the result of solution by the enema. It appears more probable, however, that the material composing the enema is the responsible agent. No treatment is, as a rule, called for. Subsequent enemata may cause a reappearance of the rash, or they may be quite unaccompanied by any further trouble. When there is severe itching, as is often the case in the "nrticarious form of the rash, a weal lotion of carbolic acid should be used to bathe the slin. This will generally relieve the itching. 
Illustrative Cascs,-. E G, a woman, aged thirty, was operated on for the removal of a lipoma on January 15. She had been given an enema of hard soap and water ( 16 ounces) five hours before the operation. Three hours after the operation she was seen to be very flushed, and on examination it was found that she bad a bright erythematous rash on the face and limbs and a large part of the trunk. There was no itching, and there wcre no symptoms except the rash. The temperature was normal. The rash lasted for two days and then faded away, having entirely disappeared by the igth.

Miss M. was given an enema consisting of 2 pints of soap and water at $9 \mathrm{a.m}$. on November 23. At 12.30 chloroform was administered, but no operation was performed. At $7 \mathrm{p}$. m. the same evening she complained of headache, and had a shivering fit The temperature was normal. During the evening she dereloped a red rash on the neck and greater part of the trunk, which was accompanied by itching. During the night the patient vomited. On the following day there was a profuse red eruption all over the body. The temperature in the morning was $994^{\circ} \mathrm{F}$., and in the evening it rose to $99^{\circ} 8^{\circ} \mathrm{F}$. The pulse was also rapid (102). On the $25^{\text {th }}$ the temperature was normai, and did not again rise, and the patient feit quite well. The rash was still present, though fading. On the 26th the patient was quite well, and the rash had almost gone.

Salicylic Rash.--There is a peculiar rash sometimes seen when salicylic wool has been used as a dressing. This rash only occurs on those parts of the skin with which the wool has come into direct contact, and its distribution, therefore, corresponds to the area of the dressing, and thus renders its nature immediately apparent. The rash usually consists of numbers of small clear vesicles, which may have an inflamed base. The rash is not accompanied by itching. It soon disappears if the salicylic wool is changed for sal alembroth or plain wool.

Herpes following Operations.-Several cases have been recorded where an attack of herpes, accompanied by a high temperature, has followed an operation or even the passage of instruments into the bladder. In most of 


\section{26 The After-Treatment of Operations}

the cases the herpes made its appearance in crops of vesicles on the neck and face, and around the mouth. In many of the cases there appears to have been some septic infection.

Ether Rash.-This rash often makes its appearance during the administration of ether. It is a bright roseolous rash, and best seen on the face and chest, though often also present on the limbs. It usually disappears very quickly.

Erysipelas.-This is now a very rare sequel to operations, but is still sometimes seen.

\section{Drug-Poisoning.}

Cases of poisoning from the excessive use of antiseptics have been recorded from time to time, and the possibility of such an occurrence should be borne in mind. These cases often give rise to a great deal of difficulty in diagnosis, as the symptoms are often put down at first to some complication of the operation, and poisoning is not suspected. Many of the cases follow the use of dressings saturated with strong antiseptics and kept damp by placing oil-silk or jaconet over them, such, for instance, as may be used for preparing the skin previous to operation. Of course, the larger the area of skin so covered, and the longer the time that the slin is subjected to the action of the antiseptic, the more pronounced will be the result.

Poisonous symptoms may follow the packing of large cavities with antiseptic gauze or washing out large cavities with strong antiseptic solutions, especially if care is not taken to remove the antiseptic afterwards. Poisonous symptoms are much more liable to follow the use of antiseptics in children than in aclults, and patients whose kidneys are not working properly are more prone 


$$
\text { Drug-Poisoning }
$$

to develop symptoms from comparatively small quantities of antiseptics than those whose renal organs are sound. Again, some individuals seem much more susceptille to certain drugs than others.

Iodine Solution. - This also causes blistering of the slin, resulting in the epidermis peeling off over most of the area to which the iodine has been applied. Iodine should not be applied to the sciotum or to areas, such as the axiliæ, where the slin is very loose. Where blistering has occurred, the best dressing is sterilized stearate of zinc powder or sterilized vaseline.

IODOFORM PoIsoning. - This may follow the packing of a large cavity with iodoform gauze or the use of iodoform emulsion in the treatment of tubercular joint affections. The chief symptoms in the acute cases are a very high temperature ( $104^{\circ}$ to $107^{\circ} \mathrm{F}$.), accompanied by cerebral disturbance, either in the form of delirium, mania, or coma. The pulse is rapid, and in the fatal cases the patient soon passes into a condition of collapse, followed by coma and death. In addition, the pupils are generally contracted, and there may be hæmorrhage from the rectum. The symptoms usually come on within twentyfour hours. In the chronic cases there is disturbance of digestion, loss of appetite, insomnia, vertigo, with a rapid pulse and a raised temperature.

As soon as the symptoms show themselves, any iodoform-gauze packing, if present, should be renoved and the cavity washed out with a solution of bicarbonate of potash, which is said to act as an antidote. The same drug may also be given by the mouth.

Illustrative Case.-F. W., aged fifty-two, was operated upon for a large hydronephrosis of the right kidney. The kidney, or what was left of it, was shelled out of its capsule as the intestines and other viscera were firmly adherent to the latter. The walls of the cavity 


\section{28 The After-Treatment of Operations}

were stitched to the edges of the abdominal wound, and the cavity itself was packed with ioloform gauze. A very large quantity of the gauze had to be used. The operation was a very severe one, but the patient rallied as well as could be expected, after being transfused with normal saline and having an injection of strychnine. Next day she was comfortable, and her condition was good. Her urine was normal, containing no albumin, and being normal in quantity as far as could be estimated.

At II.30 p.m. her pupils were noticed to be contracted. Up to this time she had had no morphia. Later in the evening an injection of $\frac{1}{8}$ grain of morphia was given to secure sleep and allay the restlessness which was present. She slept all night, but at $5 \mathrm{a}$.m. her temperature was found to be $105^{\circ} \mathrm{F}$, and she was drowsy and could not be aroused. The pulse was very rapid, and there was some twitching of the muscles of the face. The pippils were still more contracted than on the previous evening. At 7 a.m. the temperature was $107^{\circ} \mathrm{F}$. This was reduced by sponging to $102^{\circ} \mathrm{F}$. She was very hot and perspiring freely. Tlie pulse was almost imperceptible, and very fast. There was marked twitching of the fingers and facial muscles. She had some hamorrhage from the rectum. The case was thought to be one of iodoform poisoning. and the gauze was all removed from the wound, and the cavity washed out with a solution of potassium bicarbonate (20 grains to the ounce). She also had 20 grains by the mouth. The temperature again went up to $104^{\circ} \mathrm{F}$., and remained up till death, which took place a few hours later from heart failure.

Carbolic Acid Poisoning.-The symptoms usually come on within a few hours of the application of the dressing or compress; the initial symptoms are commonly drowsiness and pallor. The respirations are markedly affected as a rule, there may be dyspncea, or the breath. ing may be laboured or stertorous - the chief symptoms seem to be due to the action of the drug on the central nervous system-sooner or later there is complete coma with muscular relaxation: the pupils may be contracted or normal. The urine is turned a darli olive-green colour, and its specific gravity is increased. It is said that a premonitory sign of poisoning is the disappearance of 


\section{Drug-Poisoning}

sulphates from the urine, the atsence of all sulphates being a sign of danger. The prognosis is favourable, the symptoms usually passing off, after the cause has been removed, in the course of a diay or two.

Lysol, if used too strong, may also cause symptoms of carbolic acid poisoning, and I have lnown it produce these symptoms when used as an enema.

Illustrative Case. The putent was a chldd, aged four years. An operation was guing to lie perforned to stet rid of the delornuty of genn valgum, and to propare fur this the skin of both legs was thoroughly cleaned up and a compress of $I$ in 40 carbolic acid applied to most of the skin of the lower extremities. Six hours luwer it was noticed that the chill? was rather sleepy, but nothing was thought of it. Soon after this it was found that the chitd was in a comatose condition. She could not be aroused, and the inuscles were relaxed. There was, however, slight response to stimulation. The skin was cold and very pale. Tespiration was rather rapid-about 36 . Thic pulse was 180 . The knec-jerks were absent. The pupils were normal in size, and reacted to light. Some urine which was drawn off was found to be of a greenish colour and of a specific gravity of 1,022 .

Carbolic acid poisoning was diagnosed, and the compresses removed. Saline purgatives were administerer and stimulants given. Recovery took place slowly in the course of abont two days, but the urine remained green and the pulse rapid lor a day or so.

Perchloride and Biniodide of Mercury Poisoning. - The symptoms are the ordinary ones of ptyalism. There is generally marlied gastro-intestinal disturbance, especially diarrhcea; vomiting may also be present. Salivation is often a marked symptom. Suppression of urine sometimes occurs, and is a rery dangerous complication. The pulse is feeble and quick. The symptoms often vary very considerably in different cases, but if the condition is thought of, there is seldom any great difficulty in arriving at a correct diagnosis. The treatment should 


\section{30 The After-Treatment of Operations}

be directed to washing the drug out of the system by the use of saline purgatives and large draughts of fluids:

Poisoning from Strycmine or Nux Vumbi. This may occur if large repeated doses of strychnine have been used to treat shock. As the patient recovers from the shock the cirug begins to act, and, having a cumulative action, produces poisoning symptonis. Apart from overdosage, however, there are certain individuals who are peculiarly susceptible to even small doses of nux romica. Such individuals get violent purging and other alarming symptoms if this drug is administered. I remember the case of a man who had been operated upon for piles, in whom a single dose of a tonic containing 5 minims of tincture of nux romica produced violent purging and severe constitutional symptoms. A minute dose of strychnine given to this patient on atother occasion caused the same result. I have also seen other similar cases.

It is, of course, not possible to prevent this, but when a patient after an operation develops inexplicable symptoms, one of which is purging, it is adrisable to inquire if strychnine in any form is being given.

The remedy is, of course, to stop the drug and give morphia.

\section{REIERENCES}

- Observations on Certain Eruptions of the Skin which occur after recent Operations or Injuries ': Edward C. Stirling, St Georgi's Hospital Reforts, I\$79.

'Six Cases of Rash after Enemata': T. R. Monro, Glasgow Mcdical Jounul, ISg9.

'Scarlet Fever following Operations': Dr. Mashlourne, Clinical Joumal, October I5, 1902.

'Sir James l'dyet's Lectures and Essays,' p. 349. 


\section{CIIAPTER IX}

\section{OPERATIONS ON THE MOUTH, NOSE, AND PHARYNX}

\section{Removal of fidenoids.}

Complications.-(I) Severe sepsis, followed occasionally by septic pneumonia; (2) severe septic throat due to diphtheria or scarlet fever; (3) septic rash; (4) acute otitis media.

Complications after an operation for the removal of adenoids are but rarely seen, but when they occur they are often grave; this is all the more unfortunate, as the operation is usually considered to be a very simple one. In order to aroid these complications as far as possible, it is particularly desirable that the patient should not be operated upon unless the throat is in good condition at the time, and the patient has not recently been exposed to the bad effects of unhealthy surroundings, or is likely to be exposed to them afterwards. With this object in view it is an excellent plan to have any bad and especially septic teeth removed before the operation, and to let the patient have the throat sprayed with some suitable antiseptic for a day or two previous to the operation. The greatest care should always be taken to see that the patient has not recently been subjected to any risk of catching scarlet fever, diphtheria, or any 


\section{32 The After-Treatment of Operations}

other fever. After the operation is over the patient should be kept in bed for twenty-four hours, and provided with plenty of clean pocket-handkerchiefs on which to blow his nose. It is adrisable in private cases to warn the parents that the child may romit some blood occasionally for the first twenty-four hours, as otherwise this may give rise to the idea that the child is bleeding, and cause considerable alarm. Care must be taken to see that the patient is not put in a draught; a stuffy room is, however, to be particularly aroided. Some light food may be given in about two hours after the operation. No particular diet is necessary, but, as a rule, semisolids, such as custard, bread-and-milk (boiled), thick soups, etc., are more easily swallowed than fluids. On the day following the operation the throat should be sprayed with some suitable antiseptic, such as one of the following:

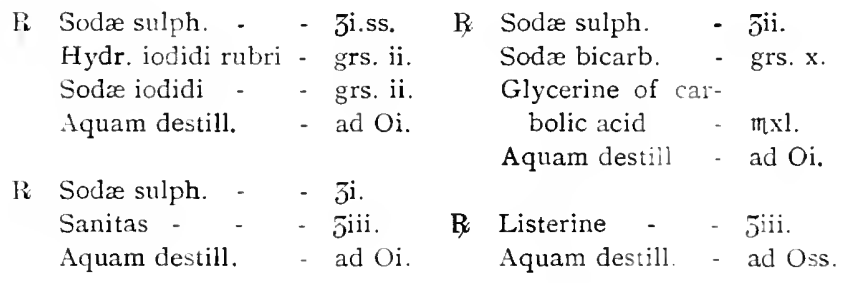

or, if the patient is old enough, he should be made to use the same solution as a gargle; this helps to get rid of any accumulated blood or mucus at the back of the throat, and at the same time tends to keep the latter free from infective material. The throat should be sprayed or gargled before and after each meal hr the first week after the operation. Anything in the way of syringing or spraying the naso-pharyn is generally better avoided, as it increases the danger of midile-ear trouble. 
If it is thought advisalle to syringe the naso-pharynx. care must be takin that the fluid is not injected forcibly, and that a free exit is allowed for its esrape. Mr. Sheild advises that a syringe of about 5 -nunce capacity should be uscd, with a piece of rubber tubing of small diameter attached to its end. The tubing should he passed along the floor of the nose, and should fit the nares quite loosely. He also recommends allowing the patient to inhale the vapour of creosote, iodine, or carbolic acid from one of the usual forms of apparatus, two or three times a day, after an operation on the nose or throat.

A saline purge should be administered on the day following the operation, and repeated, if necessary. The patient may be allowed to get up on the day after the operation in uncomplicated cases, but should be confined to one room, if possible, for two or three days. For the first day or so, and sometines for a week after the operation, the symptoms of nasal obstruction often persist. owing to the swelling of the mucous membrane which takes place. At the end of this time, however, it is of great importance to make the child do regular respiratory exercises, so that he may get accustomed to breathing properly through the nose. The child should be made to close the mouth and breathe entirely through the nose for five or ten minutes at a time; this should be done two or three times a day, and the child encouraged to breathe as much as possible through the nose at all times.

In cases where it is difficult to get the patient to do this properly, owing to lack of intelligence, etc., a good plan is to fix a piece of oil-silk over the mouth by tapes round the head, for an hour or so daily, so as to oblige the child to breathe through the nose. These exercises 


\section{34 The After-Treatment of Operations}

must be continued until the child has got into the way of carrying out normal respiration with the mouth shut. If previous to the operation the child has got into the habit of pronouncing words in a nasal manner, as is almost always the case when there is pronounced olstiuction, he must be carefully taught to pronounce these words properly, repeating them over and over again until the proper sound is obtained. The importance of these exercises of breathing and speaking must not be underestimated; children who have suffered from adenoids for any length of time have contracted the habit of breathing through the mouth and spealing in an incorrect manner, and it is not to be expected that the mere removal of the growths will remedy all this unless care and paticnce are exercised in breaking the child of the habit. And, moreover, it is only by carefully teaching the child nasal breathing and stopping habitual mouth breathing that any guarantee against a recurrence of the adenoids can be secured.

If the naso-pharynx becomes septic, accompanied by foul-smelling breath, and perhaps a high temperature, the naso-pharynx should be irrigated with a nasal douche two or three times a day, warm water, or water to which a little hicarbonate of soda has been added, being used for the purpose; the fluid must not be allowed to flow in under pressure, but should flow gently in at one nostril and out at the other, the patient being instructed to breathe through the mouth meanwhile. A purge should, of course, be administered at once, and small doses of quinine and iron are sometimes useful.

If symptoms of otitis media develop after the operation, a blister or leeches should be at once applied behind the affected ear, or hot fomentations repeatedly applied to that side of the head. The naso-pharynx must also be 
irrigated. If suppuration occurs in the ear, the case must be treated as an ordinary case of otitis media.

Children who have just unlergone the op ration for adenoids secm especially liathle to catch diphtheria or scarlet fever if they are subjected to any infection, and when they contract one of these diseases under such circumstances it is a very serious matter. Care must, therefore, be exercised to prevent as far as possible any chance of the child contracting them. An attack of influenza may supervene upon an operation for adenoids, and when this occurs there may le considerable difficulty in correctly diasnosine the symptoms, which may be very alarming at first.

The appearance of a rash after in operation for the removal of adenoids or tonsils seens to be commoner than is generally supposed. In an analysis of sixty such cases made by Dr. Wyatt Wingrave, ${ }^{*}$ he found that a rash appeared in about 2 per cent. of all cases of operation for tonsils or adenoids. In only four out of the sixty cases was the rash proved to be scarlet fever, in one case it was diphtheritic, and in the remainder it appears to have been septic in origin. In a large number of the cases the rash was not accompanied by any other constitutional symptoms of sepsis. The rash generaily appears on the second or third day, and lasts about fonr days. In four out of the sixty cases the rash was followed by acute inflammation of the cervical glands.

On the fourth or fifth day after the operation the Eustachian tube should be irflated by means of Politzer's bars: and this should be repeated daily for three or four days, and for longer in cases where there is any marked deafness associated with the adencids. Or, if the child is old and inteliigent enough to linderstand, he

* Medical Press and Civiulur, January 27, 1904. 


\section{The After-Traament of Operations}

may be shown how to inflate the Eustachian tubes for himself by holding his nose and furcing the air into his pharynx. Of course, if there is any sepsis after the operation, the use of the l'olitzer's lag must be deferred. In all bad cases of adenoids it is a grood thing to insist on the child doing daily respiratory cxercises, with deep breathing, for some months after the operation.

\section{Removal of Tonsils.}

The complications are practically the same as in the case of adenoids, except that otitis media does not occur. The after-treatment is also the same. As in the case of adenoids, the throat should be sprayed for the first few days after the operation at frequent intervals. Gargling is usually impossille, as the throat is too sore. On this account also swallowing is more painful, and while this is the case the patient should be given such things as jellies, custard, bread-and-mill, etc., as these are often swallowed more easily than fluids. A condition very closely resembling ordinary follicular tonsilitis sometimes occurs on the raw surface after the removal of the tonsils. It should be treated as for that affection ly chlorate of potash, gargles, etc. Chlorate of potash internally is often very useful in these cases:

$\begin{array}{lllll}\text { B I'ot. chlor. } & - & - & - & -g r . v \\ \text { Aquam menth. } & - & - & - & -\end{array}$

Sig.: Three times a day.

or the following mouth-wash may be used, and some of it swallowed:

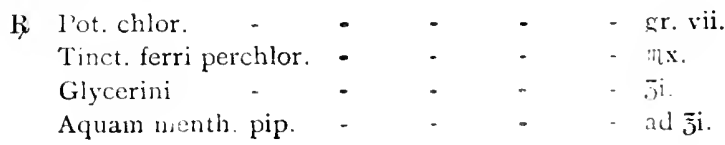


There is one point of considerable importance in the after-treatment of hoth adenwids and ton ils which must be kept in mind: the patients are often in weak health, and the enlargenent of their tonsils, etc., is largely the result of their constitutional condition, and therefore care must be talien after the operation to improve their gemeral health. If possille, they should le sent away for a change of air, preferably to the seaside, as soon as they have recovered from the operation-i.e., in about a week or ten day's' time.

\section{Tooth Extraction, etc.}

It is not usually considered necessary to pay any attention to the wound after the extraction of teeth, except in the event of himorrhage proving troublesome. This carelessness is not, bowever, justified; sepsis not infrequently occurs, and there are many recorded cases where the most serious results have followed from this cause. Lately, considerable attention has been paid to oral sepsis and its results, and it seems probable that it is answerable for many more diseases than had previously been supposed. Some attempt, therefore, shonld be made, by the constant use of mouth-washes, etc., to keep the mouth clean for the first two or three days after teeth have been extracted. One of the hest preparations for this purpose is phenate of soda (about I drachm to the pint). This has the double advantage of keeping the mouth clean and relieving the pain after extraction. A solution of tincture of arnica, which is very popular, can also be used, but is not so efficacious as phenate of soda. A very excellent mouth-wash in all septic conditions of the mouth, and one which can be used after extraction, is the following: 
? 9 The After-Treatment of Operations

\begin{tabular}{|c|c|c|c|c|c|}
\hline Alcohol & - & - & - & & roo parts \\
\hline Tinct. rhatany & - & - & - & . & $40 \quad$. \\
\hline Acid benzoic. & $\cdot$ & - & - & - & 8, \\
\hline Saccharine - & - & - & - & - & 4 \\
\hline Olei menth. pip. & - & - & - & - & $\frac{1}{2}$ part \\
\hline Olei cinammomi & - & - & - & - & $\frac{1}{2}$ \\
\hline
\end{tabular}

Sig. : Fifty drops to half a pint of water.

\section{Operations on the Tongue, ete.}

Complications.-(I) Sloughing and hæmorrhage; (2) septic pnenmonia; (3) redema of the glottis; (4) cellulitis, etc.

A certain amount of sepsis often accompanies these operations, and is quite unavoidable; but much may be done to reduce it. It is very important that before the operation any decayed or septic teeth should be removed, and the mouth and throat well washed out with some suitahle mouth-wash for several days prior to the operation. The most effectual way of keeping the mouth clean after operations upon the tongue is to make the patient lie right over on his side, so that the fluid cannot get into his throat, and then to gently inigate the oral cavity with warm borwic, or other suitahle solution. (Mr. Jacobson advises I in to or so carbolic to be used.) If this is done with care, the mouth and stump of the tongue can be very effecinally cleansed without any liscomfort to the patient, and without causing conghing. The irrigator should be prosided with a glass nozzle, and very little pressure should be used. A syringe may be used instead, if desired. The mouth should be frequently irrigated ont in this way during the first few days after the operation. After this the patient may rinse the mouth out for himself in the ordinary way. The alcoholic mouth-wash already mentioned (under 'Extrac(ion') is a very good one in these cases. Mr. Jacobson 
arlvises painting the stump over every two or thee houls with a solution of formalin. The patient should he nursed in a sitting position, well propped up with pillows. This position tends to prevent congestion of the lungs, and also prevents the stump of the tongue falling back and obstructing the air-passage, which, if it has been freely cut away from the floor of the mouth, it is apt to do in the prone position.

The patient should be fed after the operation by means of a feeder with about 3 or 4 inches of indiarubber tube attachert to the nozzle. The end of the tube is passed to the back of the throat, and the feeder gently tilted up. For the first day or so the diet has to be fluid only, but after that semi-solids can usually be taken. A calomel or saline purge should usually be given on the day following the operation. For hæmorrhage after operations on the tongue, see p.

\section{Operations on the Nose.}

All that has been said in connection with adenoids also applies here. The treatment of hæmorrhage after operations on the nose has already been descrilied in the chapter on hemorrhage. A piece of gauze kept over the nose, and damped occasionally with some volatile antiseptic, is of assistance in preventing sepsis in some cases, especially after removal of the turbinates. Persistent sneezing is a curious complication that sometimes occurs after operations on the nose. This may prove extremely troublesome. If it continues for any length of time, the best way of treating it is to paint the nasal cavity with a solution of cocaine, ui cocaine and suprarenal extract. It may also often be stopped by simply syringing out the nose with wain 


\section{The After-Treatment of Operations}

water. As a rule, after operations on the nose. one or both nostrils are left plugged. The plugs will either consist of gauze or pieces of rubber sponge. The plugs are generally removed in forty-eight hours, and after this the patient is allowed to breathe through the nose. The patient should be told on no account to attempt to blow his nose during the first day or two. If crusts form in the nostrils and obstruct the passage, they should be carefully removed by soaking them till they are soft, and then sponged away. 


\section{CHAPTER X \\ OPERATIONS ON THE HEAD}

\section{Operations on the Brain: Trephining, ete.}

Complications,--(1) Hernia cerehri; (2) wedema of the brain.

After any operation on the brain, the patient must be kept as quiet as possible, preferably in a darkened room, and anything that may tend to excite the patient, such as visits from friends, etc., prevented. The bowels should be kept acting freely by the administration of calomel. The use of alcohol in any form must be avoided. In cases of trephining for hæmorrhage on to the dura mater, the patient need not be subjected to so much restraint, and, as a rule, he may be allowed to sit up soon after the operation; in these cases it may be assumed that the patient is well as soon as the wound has healed. Inflammation, if it occurs after these operations, will usually show itself by a high temperature and symptoms of increased intercranial tension on or alout the third day after the operation.

After operations in which the dura has been opened, drainage is generally provided for by means of flat pieces of thin rubber. These drains can usually be removed in twenty-four hours after operation, unless sepsis was present in the first instance. 


\section{42 The After-Treatment of Operations}

If shock occurs after an operation on the brain, it is best treated by small repeated doses of morphia rather than by stimulants.

After any operation on the brain-tissue, it is most important to insist on the patient abstaining from any form of mental strain for some months after the operation. At first reading should be forbidden, and later only allowed in moderation. I complete change and rest for some months is rery important in most of these cases.

Hernia cerebri is caused by unrelieved tension in the brain, and is generally the result of sepsis; the cause of the tension should therefore be investigated, and, if possille, removed, when the hernia will probably disappear. Not infrequently pus will be found in the interior of the hernia, or a superficial abscess will be found beneath it. The hernia itself consists mainly of granulation tissue, and contains very little brain substance, so that there need be no hesitation in scraping it away and applying pure carbolic acid to the stump. This requires no anæsthetic, as the protrusion is insensitive. The hemia may be treated by applying pressure over a piece of sterilized tin-foil.

\section{Hare-lip Operations.}

Complications. - (I) Bronchitis and pneumonia : (2) diarrhœa ; (3) sepsis; (4) dyspnoea and asphyxia.

A low form of sepsis sometimes occurs after these operations, especially when it has been necessary to interfere with the bone in any way. Care must be taken to keep up the strength of the patient under these circumstances, and to keep the mouth as clean as possible. In very young infants who have had a large cleft closed by operation there is danger of sudden death from asphyxia 
soon after the operation, and this should be forne in mind The nasal passare in youm infants is often ton small to be used efficiently for respiration, and it asily becomes blocked up with secretion; the sudden sireat dinninution in the size of the oral cavity may result in sudden dyspncea some hours after the operation. Mr. Jacolson cites three cases in which fatal dyspmoci occurred from chis cause. The nurse should be instructed to watch for any difficulty in the breathing, and to depress the lower lip of the infant from the to time so as to allow a free entry of air, or the lower lip may be held down ly apply. ing a piece of plaster unit the child has had time to become accustomed to the new comditions.

If hare-lip pins have been mate use of, they slonld be temoved on the second day after the operation; if fish-gut or silver wire has been used for the supporting sutures, one of them should be removed on the third day and the other left for a day or so longer. The fine sutures used for approximating the edges of the wound should not be removed for a week. unless they are causing stitch abscess, when they must be removed at once. While examining or removing stitches, the chet is

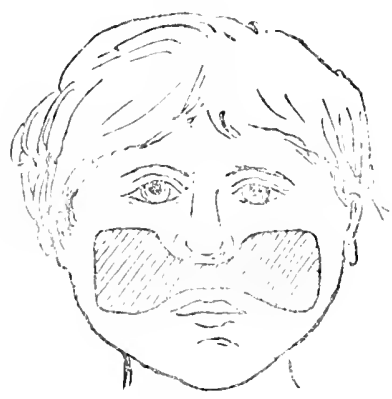

Fis. 20 . must be held together so as to prevent the wound being subjected to any tension. After the stitches or pins are removed, a piece of adhesive plaster, cut with a narrow bridge to go over the upper lip, and expanded ends to fit on to the cheeks, must be put on firmly so as to bring the cheeks together and prevent any tension coming on the wound (Fig. 20). 


\section{The After-Treatment of Operations}

\section{Cleft Palate.}

Complications.-(I) Whooping-cough; (2) exanthematous fevers; (3) diarrhcea.

After the operation the child's hands should be secured either by applying splints or by wristlets attached to a broad piece of wellbing fixed across the bed; if the child can be constantly watched by a competent attendant, it is better to dispense with this restraint, as it tends to make the child restless, and may lead to crying. Nothing should be given by the mouth for thres or four hours after the operation, and for the first fortyeight hours only barley-water and albumin-water or milk allowed; rectal feeding may be added if necessary after this, and for the first week the diet should be confined to soups, broth, egg and milk, etc., and then jellies, light puddings, and food which does not need mastication for a week more. If the child is old enough to understand and do what it is told, the mouth should be syringed out or sprayed with some mild antiseptic lotion several times a day. If this procedure leads to any struggling, or the child is too young to keep quiet during the process, it must be discontinued. Everything possible in the way of careful nursing must be done to prevent the child trom crying or being sick. If old enough to talk, the child must be prevented from doing so. In three or four days after the operation, if the weather is fine, the patient should be got out into the open air for an hour or two every day. It is best not to inspect the stitches at all till the time arrives for their removal. As a rule, some of the stitches may be removed at the end of a week or ten days, and the remainder at the end of a fortnight; but unless the stitches are causing sloughing or ulceration, it is well to leave them as long as possible. It is usually about three weeks after the operation before the wound is firmly united. 


\section{Operations on the Ilead}

If the operation has been successfui and the grap in the palate has been closed, the next thing that calls for attention, and which is of the greatest importance, is to teach the child to pronounce its words properly, and this is of still greater importance if the child has already learnt to talk and has got into the habit of pronouncing words wrongly. A great deal of care and patience is often necessary; the patient should be made to sit on a chair facing the teacher and pronounce words, and especially those words which he has got into the habit of pronouncing badly, after him, and at the same time watch the way in which the teacher mores his lips and tongue. The teacher should exaggerate these movements, so as to malie them more obvious. Words with sibilants and labials in them should especially be taught with great care, as these words are the ones most likely to be pronounced badly as the result of the cleft-palate. Nasal breathing exercises should also be carried out daily to get the child used to breathing properly through the nose when the mouth is shut (see under Adenoids). After the Davies-Colley operation at least three weeks and often more should be allowed to elapse before the stitches in the mouth are removed; those in the deep flap must be left to come out in the best way they can. Sloughing of the large flap need not be apprehended in this operation.

\section{Artificial Appliances.}

For the Relief of Cleft-Palate. - An obturator should only be fitted in those cases where no operation is possible, as, for instance, after repeated operations have failed to close the gap, when there is not enough tissue to close it, or when the hard palate has been successfully operated upon, but owing to lack of tissue or scar contraction it is not possible to close the gap in the 


\section{I $\{6$ The After-Treatment of Operations}

soft palate. In such cases a properly fitting obturator is necessary. There are two principles of fitting obturators - the Kingsley method, in which an ordinary vulcanite or gold plate is fitted to the hard palate, and to the back of this is attached a soft rubber vellum, which fits into the gap in the soft palate and moves with the palate muscles; and the Seursen method, in which there is a fixed vulcanite obturator taling the place of the hard palate. In the Seursen method the fixed obturator fits in between the pharyngeal muscles, and passes backwards to within $\frac{1}{4}$ inch of the posterior. pharyngeal wall; when the patient swallows or phonates, the muscles close round it and shut off the naso-pharynx from the buccal cavity. It is fixed in place by a dental plate fastened by bands round some of the upper teeth. The Seursen method is particularly adapted to cases where the gap in the soft palate is very wide. Very good phonation can be obtained by means of these instruments, but to obtain good results it is of the utmost importance that the patient should be carefully taught to speak after the instrument has been fitted.

After the Removal of the Upper Jaw. - The instrument usually fitted in these cases consists of a gold or vulcanite plate, to the upper surface of which is attached a hollow obturator, made so as to fit into the gap left by the removal of the jaw; the plate takes its purchase from the opposite teeth and the remains of the hard palate. Artificial teeth are fixed to the plate, so as to complete the upper set on the side on which the jaw has been removed. These obturators are made of gold or vulcanite, and should be very smooth, so as not to cause any irritation; the chief value of them is in preventing the fallingrin of the cheels, which is such a 


\section{Artificial Applances}

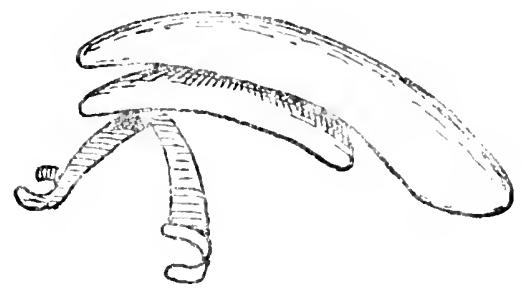

Fig. 2i,-Kingsley Obterator for Cleft Palate: Made of Sofr Kubber.

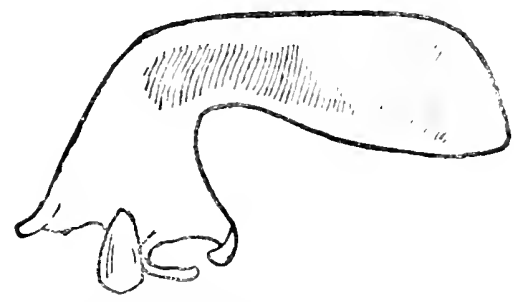

Fig. 22.-Sedrsen Obturator for Cleft Palate: made OF VULCANITE.

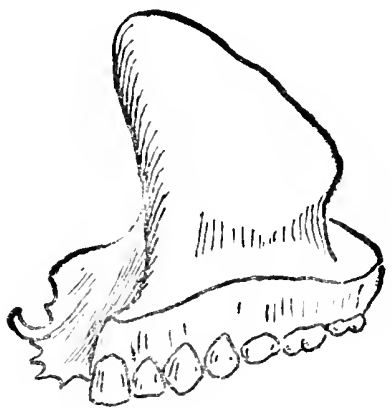

Fig. 23.-Obiorator For Repair of the Hard Palate and Alveolar Arch after Removal of 3 he Left Upper Jaw. 
148 The After-Treatment of Operations

distressing after-result in many of these cases. By restoring the roof of the mouth they also help phonation, and prevent food from getting into the nasal carities. They should be fitted as soon as the wound has healed, and before the parts have had time to contract and cause deformity. 


\section{CHAPTER XI}

\section{OPERATIONS ON THE NECK}

\section{Tracheotomy and Laryngotomy.}

Complications.-(I) Surgical emphysema; (2) ulceration of the trachea; (3) sloughing of the wound.

Surgical emphysema is either the result of a fanlty operation, or is due to the tube not being in the trachea. If the tube is properly in the trachea and the air-way free, emphysema cannot occur. When it occurs, the tube must be removed and carefully reinserted, or a better fitting one substituted. Ulceration of the trachea is due either to the tube not fitting or to its being worn for too long a time. A metal tube should not he left in for more than a week without being changed; at the end of that time, if the tube cannot be dispensed with, a rubher one, such as Morant Baker's, should be substituted. Many tubes are made with too great a curve on them, and the lower end in consequence presses on the anterior wall of the trachea and causes ulceration. The necks of different individuals differ very considerably, and it may be necessary to try several different tuhes before one can be found to fit well. In young children especially it is most necessary to get a properly fitting tube, as their tissues will not stand pressure in the same way as adults, and ulceration is very liable to occur from a badly-fiting tube. 


\section{I $5^{\circ}$ The After-Treatment of Operations}

Sloughing of the wound may be diphtheritic or may result from the tube pressing too tightly against the wonnd. The tapes should be relaxed, and the wound dressed frequently with ointment or gauze, a collar of which should be kept beneath the tube. If the sloughing tends to spread, the wound should be well painted with carbolic acid or nitrate of silver.

After the operation the patient must be put back to hed, and made as warm as possible. Most surgeons have a steam-tent put round the bed, so as to keep the atmosphere warm and moist. The value of this is, however, somewhat doubtful, as the steam seldom gets anywhere near the tube, and usually expends itself in damping the tent. Fresh air is of the utmost importance, and if the temperature of the air round the cot can be kept up to about $60^{\circ} \mathrm{F}$. and the child kept free from draughts without the use of the tent, it is much better not to use one. Whether a steam-tent is used or not, the temperature of the room must be kept up to $60^{\circ}$ or $65^{\circ} \mathrm{F}$., and all draughts avoided; a double fold of gauze should be placed over the mouth of the tube, and it is a good plan to drop a few drops of eucalyptus oil on to the gauze from time to time. If, however, this causes coughing, it must be discontinued. The child should be encouraged to go to sleep after the operation. After the difficulty of breathing has been relieved by the operation many children naturally fall asleep for a few hours, and they should on no account be awakened, as it is the best thing possible for them. Sleep is of the greatest importance, as in most cases the child is rery exhausted from the previous difficulty of respiration. The inner tube must at first be removed every two hours, or oftener if necessary, lut the child should not he awakened for this purpose. The imner tuhe must he cleaned in wak 


\section{Operations on the Neck}

carbolic solution ( $\mathrm{I}$ in 200) and replaced. Any mucus or membrane that is coughed up should be wiped away at once with a clean piece of turkey-sponge dipped in the carbolic solution. If the tube becomes blocked with any mucus that will not come out, a soft feather may be used to remove it. The feather should, if possible, have been sterilized by immersion in some strong carbolic solution for an hour or more, and then the carbolic washed away with sterile water, or the feathers may be sterilized by boiling. Several of these feathers should be kept at hand immersed in a weak carbolic solution. The feather should be gently inserted into the tube, and then turned round before being removed, so as to catch the mucus, etc. If the breathing becomes harsh and whistling, and there seems to be lifficulty in bringing up the secretion, the opening of the tube must be sprayed with a solution of bicarbonate of soda (20 grains to the ounce) for five or ten minutes at a time. This will loosen the secretion or membrane, and allow of its being easily coughed up, or, if desired, the solution can be applied to the trachea with one of the feathers. Careful nursing is of the utmost importance in these cases; it must not, however, be meddlesome. Especially, the child must not be prevented from sleeping.

The old adage of 'leaving well alone' is very applicable to these cases, and the too free use of the feather is particularly to be avoided. If the breathing at any time becomes very difficult owing to the accumulation of mucus, etc., in the trachea and tube, this can be quickly relieved by sitting the patient up, and propping him in that position with pillows. Feeding the patient is usually a difficult matter, and must be undertaken with care. If possible, the patient should be propped up in a sitting position for this purpose, and ted by means of a feedur 


\section{The After-Treatment of Operations}

with a piece of rubber tube attached to its spout, the end of which is passed to the back of the throat. The feeding must be at frequent intervals, and if there is much difficulty in getting the patient to swallow, nasal feeding must be resorted to at once.

At the end of the first twenty-four or thirty-six hours the outer tube must be removed and cleaned, or a new one introduced. This is usually an easy matter, but it is well to have a director or tracheal dilator at hand in case of any difficulty arising in reintroducing the tube. If the original tube has not got a hole at the bend so as to allow a free air-way by the mouth, one of these tubes should be introduced at this stage if obtainable, or a bivalve tube may be used. If the inner tube of a bivalve tube is removed, the patient can breathe through the mouth if there is no obstruction. On the second day after the operation the mouth of the tube should be blocked up either with a wooden plug or with a piece of wet lint for ten or fifteen minutes at a time, so as to get the patient accustomed to breathing through the mouth again. (For this purpose it is, of course, necessary to have a tube with an upper opening.) Unless the cause of the obstruction is a permanent one, an attempt should be made to remove the tube altogether on the third or fourth day.

Removal of the Tube.-As stated, this should be done at the earliest possible date. A great deal of trouble will be saved if the patient has been gradually accustomed to breathe through the mouth hy plugging up the opening of the tube from time to time. When the tube is removed, a pair of tracheal dilators should be at hand, so that should any difficulty with the breathing occur, the wound can be quickly opened. If on remoring the tube spasm occurs, the tule must be reinserted; an attempt should 


\section{Operations on the Neck}

then be made to remove the tube while the patient is sitting up; this will sometimes be successful. The surgeon should not leave the patient after the tube has been removed until he is satisfied that the patient is able to breathe comfortably through the month.

If the tube has to be retained for more than a week, an indiarubber tube should be substituted for the metal one; this may be one of Morant Baker's tubes, or a very grood tube can be constructed ont of a piece of drainage-tube (see Fig. 20). In infants especially a metal tube should never be retained for more than a iveek. The author once saw a ease in an infant under two years of age where a metal tube had been worn for a fortnight, and in which the end of the tube ulcerated into the innominate artery. and the child bled to death in three minutes. In most cases where there is any difficulty in the removal of the tube, this is chiefly due to nervousness or habit on the part of the child, and is not due to any actual obstruction in the larynx; care and patience, therefore, is all that is called for. Occasionally, however, there is some actual obstruction in the larynx from ad.

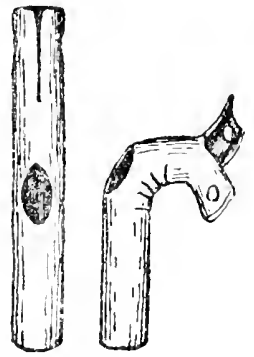

Fig 24.--1)RaWING TO SHOW THE IIETHOD OF MAKING A TRACHEOTOMS-TEBE OUT OF A PIECE OF DRAINAGE-TUBE hesion or granulations, and it hecomes necessary to dilate the trachea above the tube; this is, however, very rarely the case. A plan which is sometimes useful when there is considerable difficulty in getting the patient to breathe through the mouth is to intube the larynx, and then remove the tracheotomy-tube, the laryngeal-tube being removed at the end of twenty-four or forty-eight hours. 


\section{54 The After-Treatment of Operations}

Dilating the Larynx.-A little chloroform is administered, and after dilating the wound a soft catheter is passed up from it, and the end drawn through the mouth with a clip; several catheters of increasing sizes may be in this way passed through the larynx until it is sufficiently dilated, or by means of the catheter a silk thread can be passed through from the wound to the mouth, and a small picce of fine Turkey sponge tied on to the end of the thread and drawn up through the larynx so as to clear it or break down any adhesions; or a Nacewen's tube can be made use of.

Artificial LARYNx.-This is an apparatus designed with the object of enabling a patient after his larynx has been removed to swallow without danger of food getting into the trachea, and at the same time, by means of a reed fitted into the exit-tubc, enabling him to speak. There are several varieties of artificial larynx, of which probably Gussenbauer's, or Dr. Foulis's modification of it, are the best. They are much too complicated for description here. Some patients can use them with considerable success, but a great muny find that they can get on better without; the great difficulty connected with them is that they are very liable to get blocked with mucus.

\section{Esophagotomy.}

The chief difficulty in these cases is the feeding; if possible, this should be done by nutrient enemata for the first three or four days, and the patient not allowed to swallow anything by the mouth during this time. If, however, this cannot be managed, a soft rubber tube must he passed down the esophagus either from the mouth or nose, and the patient fed through it. This tube can either be inserted each time the patient is fed, or, if possible, it should be retained, at any rate during the daytime. At the end of the first werk or earlier, if the wound is healing well, the patient may be allowed to 


\section{Operations on the Neck}

swallow liquids in small quantities at a time. These wounds are practically always septic, owing to organisms getting into them from the wound, and it is necessary to see that there is free drainage at the most dependent part of the wound.

\section{Operations on the Thyroid Gland.}

Complications.-(1) Aphonia; (2) cellulitis of the neck ; (3) thyroidism? : (4) tetany.

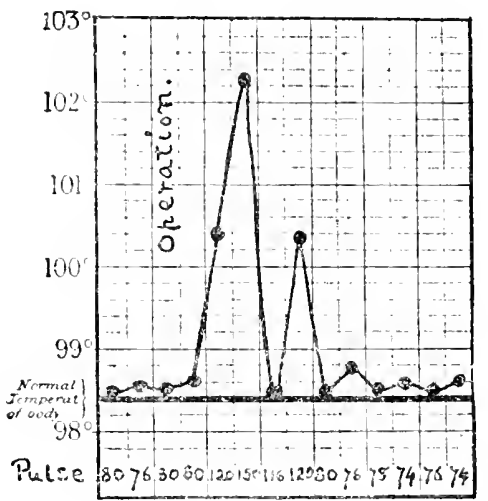

Fig. 25.-Chart of a Case of Thyroidism.

A phonia results from wounding the recurrent laryngeal nerve, or from its becoming involved in the cicatrix. In the first case, the aphonia will come on immediately after the operation, and in the second, some time afterwards.

Cellulitis of the neck is a very serious complication, and should, of course, not occur; if it does, the wound must at once be freely opened up and drainage prorided for. The possibility of thyroidism occurring after operations on the gland must be borne in mind. The 


\section{The After-Treatment of Operations}

symptoms are similar to those of exophthalmic goitre (without the exophthalmus), but are acute. They come on, as a rule, at the end of the first twenty-four or fortyeight hours after the operation; the temperature goes up, often to a great height $\left(103^{\circ}\right.$ to $105^{\circ} \mathrm{F}$ ), and remains intermittent ( $\mathrm{Fig} .25$ ); the patient becomes very flushed and uncomfortable; the pulse is quick and bounding, and there is often marked tachycardia; the symptoms are very alarming, and may easily be mistaken for the onset of acute sepsis. The pulse and tachycardia are, however, characteristic, and this mistalie should not be made. The symptoms, as a rule, subside in the course of a day or two, and no harm results. Should they, however, be serious, as is sometimes the case, the wound must be opened and washed out thoroughly with sterilized water, and then drained or packed with gauze to prevent the secretion of the gland getting into the tissues of the wound and being absorbed by the lymphatics. In very bad cases transfusion may be tried. This condition of thyroidism is rarely serious, but one or two cases of a fatal issue have been recorded. The best method of preventing toxic symptoms after partial thyroidectomy is by giving the patient plenty of water and lieeping the tissues well flushed ont. The practice at the Mayo clinic, where large numbers of these operations are performed, is to administer I quart of saline slowly fer retum immediately after operation, and to repeat this twice within the next twelve hours. If the patient cannot retain these salines, the fluid should he given subcutaneously. In the earlier days of the operation, when it was the practice to remove as much as possible of the gland, symptoms like those of myxadema not infequently occurred. In these days, howerer, as a rule, only one lobe is removed, and this danger is consequently absent. It may happen, however, that tor much of the gland is 
removed, or that the part left is not functional, and then symptoms due to absence of thyroid secretion may develop. The symptoms usually come on a few days after the operation, and often take the form of muscular spasm. Laryngeal spasm may occur, and cause acute dyspncea. There may be tetany of the hands and feet, and there is usually progressive emaciation. The best treatment is large doses of thyroid extract, which may have to be continued indefinitely.

Tctany may develop after an operation for thyroidectomy, and will show itself by attaclis of tonic flexion, generally in the muscles of the hands. There may be general convulsions and high fever. The condition, though alarming, is not fatal. It is due to removal of the parathyroid glands. The best treatment is administration by the mouth of parathyroid extract, or the surgical implantation of a parathyroid gland from an animal into the abdominal cavity.

\section{Operation for the Removal of Enlarged Glands.}

After the operation the patient should be prevented as far as possible from moving his head, and if the wound is large, sand-bags should be placed for this purpose on both sides of the head and neck. In order that the scar may not be unsightly, the stitches should be removed in three or four days, and the edges of the wound supported by strips of adhesive plaster. If a tube has been put in, it should be removed in twenty-four hours. If, as is usually the case, the glands are tubercular, the patient should be sent to the seaside or to a bracing climate as soon as the wound has healed, and should be kept there for some months. Plenty of fresh air and good food are most important, or more serious tubercular lesions may supervene. 


\section{CHAPTER XII \\ OPERATIONS ON THE THORAX}

\section{Amputation of the Breast.}

Complications.-(I) Lung affections; (2) sloughing of the skin ; (3) sepsis; (4) fixation of the arm ; (5) venous stasis and œdema of the arm ; (6) lymphadenoma.

If no drainage-tube has been used, the patient should be made to lie as much as possible on the sound side for the first twenty-four hours to prevent blood, etc., from accumulating in the loose cellular tissue at the axillary end of the wound. Of course, if a drainage-tube has been brought out through the skin in this situation, there will not be the same necessity for this position. If there is much pain after the operation, a hypodermic injection of morphia should be given ( $\frac{1}{4}$ grain). A good deal of pain is not uncommon at first from the tension of the sutures, especially if much skin has been removed.

There is frequently a little oozing of blood through the dressings during the first twenty-four hours; this should be looked for by the nurse from time to time, and when noticed, more wool must be packed on over the part of the dressings where it is taking place. It is better not to redress the wound unless the oozing is considerable. It is a very good plan for the first two or three days to keep large pads of clean wool under the affected side 
between the dressings and the bandages. On the day following the operation the patient should be propped up into the half-sitting position with a bed-rest and pillows in order to prevent any tendency to lung complications.

Lung complications are very liable to occur after removal of the breast, especially in elderly patients, and as carcinoma is a disease which is most common towards the later period of life, many of the patients are elderly. This tendency to lung complications is to be accounted for by the limitation of the thoracic movements, which must of necessity result from the presence of a large wound on the chest. Any deep respiration causes pain, and, as a result, the respirations are shallow and almost entirely diaphragmatic; respiration is also impeded by the chest being tightly bound up with bandages, etc. It is well to bear this in mind, as otherwise what would have been a successful operation may result in the death of the patient from an intercurrent bronchitis.

If a tube has been used for drainace, it should be removed on the first or second day after the operation and the wound dressed; the skin at the axillary end of the wound should be carefully cleaned at the same time.

In those cases where a large amount of skin has been removed and the axilla freely cleared out, the arm should be fixed after the operation in a position of abduction from the trunk, so as to avoid the formation of adhesions, which will prevent free morement of the arm after the wound has healed. After the first three or four days the arm should be gently moved each day to prevent the formation of adhesions between the skin and deeper structures. These movements must be very slight for the first fortnight, but after this they may be increased in range daily, and the patient encouraged to move the arnı freely berself. A certain amount of limitation of 


\section{I60 The After-Treatment of Operations}

movement in the shoulder on the affected side not infre. quently results after this operation oring to the extensive removal of skin, which is often necessary; but much can be done by early morements to overcome this tendency. Some of the stitches may be removed at the end of the first week, and the remainder at the end of a fortnisht. After the wound has healed it is a good plan to have the skin gently moved on the deeper tissues each day to prevent the scar from beconing adherent. It is hardly necessary to mention that the patient should be kept under close observation for several years after the operation, so that should recurrence take place, it may be detected and dealt with at the earliest possible date.

When an extensive area of skin has been renoved with the breast, and a considerable amount of tension has in consequence been necessary to bring the edges together, sloughing of parts of the skin-edges may result. When this is seen to be imminent, the tension must be at once relieved by dividing the sutures. If in consequence of sloughing a large granulating area remains, this area should be covered in by Thiersch's skin-grafting, so as to prevent the contraction that will otherwise result.

Sepsis after removal of the breast is a very serious complication, owing to the large wound and the extensive lymphatic area opened up. Septicamia is very liahle to follow, and may prove fatal. Pleural effusion on the same side as the wound may also result, and become purulent.

\section{Operations for Empyema.}

Complications.-(I) Non-expansion of the lung; (2) persistent sinus; (3) empyema occurring in the oppo- 
site side of the chest ; (4) cerebral abscess ; (5) curvature of the spine.

After the operation there is not infrequently-and especially is this the case with children-a grood cleal of respiratory embarrassment from the altered conditions of respiration; slight blueness of the lips may often be noticed, and is evidence of insufficient aeration of the blood in the lungs. This is hest met by oxygen inhalation. The patient should be allowed to breathe oxygen from an indiarubber-tube attached to an oxygen cylindes whenever the breathing seems difficult or there is

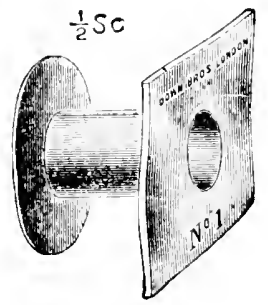

Fir. 26. - Pollard's Empyema Tube.

The square flange should go inside the chest.

cyanosis; this helps to tide over the period until the circulation becomes accustomed to the new respiratory conditions. The dressings must be changed frequently if there is much discharge, and the same care should be taken as in dealing with a sterile wound, as it is most important that fresh infection should not be engrafted on to that already present. After the first few days it is usually sufficient to change the uressings once daily. It is most important that the wound in the chest should be kept sufficiently open to allow of free drainage. If after the fluid has drained away the ribs come together and narrow the opening, there slould be no hesitation in 


\section{I62 The Aiter-Treatment of Operations}

enlarging the wound, and, if necessary, taking away more rib. The drainage-tube should be removed each day and cleaned before being reinserted, otherwise it is very liable to become blocked by pieces of pyogenic membrane, etc.

As the discharge diminishes in amount the tube may be removed and a smaller one substituted for it. A very good tube for use in these cases is Mr. Bilton Pollard's (see Fig. 22). It is easily inserted, and has the advantage of being self-retaining. It is best to keep the patient in bed for the first week or ten days, and then if his condition is satisfactory he may be allowed to get up for some part of the day, and allowed to get out of doors for a short time if the weather is favourable. There is no fixed time for which the tube should be retained, but, as a general rule, it may be said that the tube should be removed as soon as the discharge has diminished to a drachm or two of clear fluid. After the tube has been left out, the sinus should be packed with gauze daily so as to insure it healing from the bottom. In children it is often possible to remove the tube in two or three days after the operation. When the dressing is changed, the patient should be turned well over on to the bad side so as to allow any pus to run out, and the patient should be instructed to cough. This will often help to get rid of any pyogenic membrane or pus that is not able to drain away. Occasionally, after an empyema has been opened, there are still symptoms of retained pus, such as high temperatures, fever, etc, even though free drainage has apparently been established. This is generally due to the empyema being loculated, and pus still remaining encysted in some cavity other than that opened. This pus must be sought for and evacuated. The best way of doing this is to push a large catheter in different direc- 


\section{Operations on the Thorax I6.3}

tions until the pus is found, or the finger may be used if the extemal opening will admit of it.

Non-expansion of the lung after operations for empyema is a very serious complication, as it usually leads to deformity of the chest with secondary lateral curvature of the spine, and results in a persistent discharging sinus, which is a continuous source of troulle and inconvenience to the patient. A sreat deal can be done to assist the lung to expand by sul alle respiratory exercises. The exercises that are subile for hastening and facilitating expansion of the lung after empyema may, with advantage, be divided into two classes:

(1) Those suitable while there is still an opening into the pleural cavity.

(2) Those suitable after this opening has closed. (By an opening is meant one which establishes a condition of pneumothorax, and not a sinus shut off by adhesions from the pleural cavity.)

In (I) we have to deal with a condition of pneumothorax, and, consequently, since expansion of the chest will no longer give rise to negative pressure in the pleural cavity on that side, we cannot avail ourselves of the ordinary breathing exercises, and we must make use of the positive pressure produced by the sound lung during expiration to expand the affected one. The patient should be made to expire forcibly against resistance. The simplest way of doing this is to make the patient blow forcibly through a small tube held in the mouth, such as a piece of glass tubing. In the case of a child, a good plan is to give it a whistle or trumpet which will not make a noise unless blown hard. The exercise may be modified by telling the patient to make a forcible expiratory effort with the glottis closed, and then to let the air escape slowly through the partly closed lips. 


\section{I64 The After-Treatment of Operations}

These exercises are done with the object of causing positive pressure in the affected lung, and so expanding it. They should be carried out regularly from the first

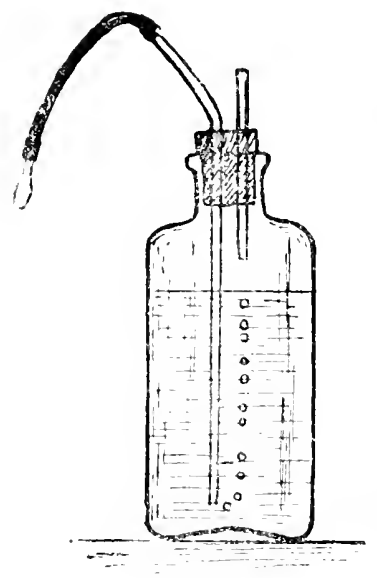

Fig. 27. day, and gradually increased from day to day. A very simple form of apparatus for assisting in expansion of the lung is shown in Fig. 2\%. It consists of a large quart bottle with a wide neck, with two glass tubes inserted into it, one of which reaches to the bottom, and the other only just through the cork. To the longer tube a rubber connection is made to a glass mouthpiece. The bottle is nearly filled with water, and the patient is instructed to blow steadily through the tube against the resistance of the water. Cireater resistance can le obtained by using narrow tubing.

In (2) our object is to obtain expansion of the lung by negative pressure in the pleural cavity as in normat respiration. This can only be done when the pleura as a cavity is closed by the healing of the wolnd or by the formation of adhesions between the visceral and parietal layers of the pleura. As adhesions are almost always present to some extent, these exercises can usually be commenced before the wound has healed. The following exercises are taken from Dr. H. Camphell's book on respiratory exercises: 


\section{Operations on the Thorax 165}

- Breathing Exercises for One or Both Lungs.

' 1 . Exercise for one lung only, in this case to be applied to the attected lung.

' One hand is plecel in the axilla of the sound side of the chest, and pressed firmly against the chest wall, so as to check its movements as far as posible. The opposite arm is then raised from the side until the wrist rests on the head. While the movement of this arm is in progress, an attempt is made to expand to the utmost the corresponding sicle of the thorax at the same time that the body and head are inclined to the opposite side.

'2. Take the fullest possible thoracic inspiration, followed by an ordinary expiration.

3. Expire to the utmost, hending the hody somewhat forward; then take an ordinary inspiration, resuming the vertical position.

' 4 . Take the fullest possible thoracic inspiration, then expire to the utmost, bending the body forward.

'5. The patient stands erect, and then blows quickly through a small opening produced by pursing the lips. At the same time he bends the head and then the dorsal portion of the spine, whilst with the outspread fingers he compresses the sides of the thorax. Having done this, the fingers are enlaced bebind the neck, the mouth is closed, and a very slow and prolonged inspiration taken through the nostrils, whilst at the same time the spine is slowly extended.

- Breathing Exercises combined with Active Exercises.-6. The arms, held stiff, are swung round as far as possible in the sagittal direc. tion. Inspiration accompanies the upward movement, expiration the downward.

47. The arms, held stiff, are moved from the side of the body outwards in a lateral plane to the vertical, and then returned to the original position. Inspiration accompanies the upward movement, expiration the downward.

'8. The arms, held horizontally in front of the body in the sagittal plane, are swung backwards in the horizontal plane as far as they will go, and then returned to the original position. Inspiration accompanies the former movement, expiration the latter.

49. The arms are made to swing in the lateral plane and in the same direction, so as to reach the highest possible point on either side, and are then returned to the original position. Inspiration is taken with the ascending movement. 


\section{66 The After-Treatment of Operations}

'Passive Ritspiratory Eivicises. - Io. The operator stands behind the patient's head, which should project slightly beyond the couch. The upper arms are then grasped by the assistant, his thumbs looking upwards. The alms are then brought above the head, so as to form a $\mathbf{Y}$ with the buly, and strong traction made upon them, $z$ the patient meanwhile taking a deep inspiraton. They are then brought towards the thorax, and firmly pressed against it, while the patient takes the deep expiration.

' $I$. The operator stands at the side of the patient, and grasps the arms as they rest at each side of the body just above the elbows, his thumbs being uppermost and looking towards the patient. He then moves the limbs in a horizontal plane until the hands meet behind the head of the patient, who meanwhile takes a deep inspration. This is followed by a deep expiration while the limbs are moved back to the original position, the elbows being firmly pressed against the sides.

'12. The patient lies on the sound side of the chest, with the arms above the head, and the uperator, standing behind, places the palm of each hand over the uppermost part of the thorax, so that the roots of the fingers correspond with the axillary line. The side of the thorax is thus grasped hetween the tingers and thumbs. With every expiration the operator makes firm pressure on the thorax, and endeavours to make the fingers and thumbs meet.'

Persistent sinus maly be due to several different causes, one of which will, of course, be non-expansion of the lung. If the lung has expanded properly, and yet there is persistent septic clischarge from the wound, the presence of dead bone must be suspected and looked for hy exploring the sinus with a probe. A portion of the rib is often found to be necrosed, the necrosis being most commonly along the lower border of the rib above the sinus. When this is the case, all the necrosed portions of rib must be removed before the sinus will close. Insufficient drainage from the chest is a not unfequent cause of persistent smus, and when the discharge is intermittent from the sinus-that is to say, when the wound keeps healing up and breaking down again-this cause must especially be suspected; the 
wound under these circumstances should be freely opened, and if a large cavity is found inside the chest, it must be well drained until it has almost closed up, and then made to heal from the bottom by plugging. Other and rarer causes of persistent sinus are tubercular disease of the pleura ; caries of the spine, to which the empyema was secondary; and the development of calcareous plates in the pleura.

When empyema occurs on the opposite side, it is probably safer to be content with aspirating the chest for a few days to allow time for the formation of adhesions, so that complete collapse of the lung does not take place when the chest is opened.

With regard to washing out the pleural cavity after making an opening into the chest, this procedure has been proved to be dangerous, however carefully practised. In many cases no harm results, but in a few, dangerous collapse symptoms and even sudden death have followed after the most careful washing out of the carity. It is therefore safer to be content, as a rule, with simple drainage. Should it, however, be thought desirable to irrigate the cavity, as is sometimes the case in very foul or purulent empyemata that resist treatment by drainage alone, the patient should be placed in the recumbent position while this is being done, and a free exit must be allowed for the fluid so that there is no possibility of the irrigating fluid causing tension in the pleural cavity while the irrigation is in progress.

The constitutional treatment of these patients is of the utmost importance; fresh air and an early change to the seaside are of the greatest benefit in restoring the patient to health. Breathing exercises should be carried out from the first to help the expansion of the lung, and later on proper gymnastic muscular exercises should be 


\section{I68 The After-Treatment of Operations}

enforced to prevent the tendency to contraction of the chest and curvature of the spine. This is particularly important in children who are liable, as the result of empyema, to develop marked deformity of the chest and lateral curvature of the spine. In some cases curvature of the spine after empyema may be loolied upon as a beneficial condition; that is to say, when the lung has not expanded the lateral curvature of the spine allows the chest on the affected side to fall in and close the gap. When the deformity is very marked, however, an attempt should always be made to get rid of it by suitable exercises, as the condition is apt to be progressive. 


\section{OPERATIONS ON THE ABDOMEN : GENERAL TREAT MENT AND COMPLICATIONS}

\section{The After-Treatment of Laparotomy.}

A GREAT deal depends in these cases on the way in which the after treatment is managed-more so, indeed, than after almost any other class of case. The treatment, however, must be carried out with intelligence, and must be based upon careful observation of the individual case, as these cases vary very much, and hardly two of them are quite alike. Anything in the way of routine management is to be particularly aroided, and the line of treatment adopted should, so far as possible, be based upon physiological facts, the medical attendant trying to form a mental picture of the condition of the abdomen, and treating the case accordingly. It should be his object to prevent complications as far as possible, as it is much easier to prevent the complications that are liable to arise than to treat them after they have once become well established. Meddlesome interference must, however, be avoided, and especially the too free use of drugs. When complications do arise the treatment must be vigorous, as, once well established, there may be great difficulty in combating them. 


\section{70 The After-Treatment of Operations}

After the operation the patient should be carried carefully back to bed, and jolting must be avoided, as it is very liable to increase the vomiting. The flannel gown which the patient has worn during the operation should be changed for a clean one, which has been warmed, and hot-water bottles should be applied to the feet and elsewhere if necessary. This should not be overdone, as it is not desirable to make the patient break into a profuse perspiration, which is often the case if the use of hot-water bottles, etc., is carricd to excess. Care must be taken also in the use of hot bottles not to burn the patient. Persons who are under the influence of an anxsthetic burn extremely easily, and it is not at all uncommon to see quite extensive burns from this cause in hospital practice.

A warm nutrient enema should be administered soon after the patient has been got back to bed, and it is a very good plan, if there is any sign of shock, to administer an enema of warm water I pint and brandy. I ounce. This may cither be combined with a nutrient enema, or given separately. Mr. Watson Cheyne advises an enema containing hot coffee (2 ounces), brandy (I ounce), beef-tea (I ounce), and liquor strychnina (1o minins).

If there is vomiting, and it does not stop in a short time, hot flannels may be applied to the epigastric region, and the patient can be allowed to drink some hot water with some bicarbonate of soda dissolved in it (see under Post-Inaesthetic Complications).

In cases where there is constant regurgitation of fluid from the mouth rather than actual vomiting, as is not uncommonly seen in cases of intestinal olstruction and peritonitis, this can often be stopped by just propping the patient up a little so as to allow gravity to act. 


\section{Operations on the Abtomen 171}

This is not advisable, however, when there is shock present. A better method of preventing this type of regurgitant romiting is by washing out the stomach. This should be done before the patient leaves the operating table. If there is much pain after the patient regains consciousness, it may sometimes be relieved by flexing the patient's knees over a pillow, so as to relax the abdominal muscles. A saline enema containing io to $1 j$ grains of aspirin administered directly after the operation will often relieve pain and avoid the necessity of giving morphia. If very serere, an injection of morphia must be given, but it is as well to aroid the use of opium if possible, as it increases the liability to meteorism. If there is much restlessness, morphia is indicated. It should be given in a dose of from $\frac{1}{4}$ to $\frac{1}{3}$ grain hypodermically, according to circumstances. Heroin (1) to $\frac{1}{32}$ grain) may be used instead of morphia with advantage. With regard to position, the patient should, as a rule, be allowed to lie in the most comfortable position, and this will usually be found to be upon the side (see Introductory Chapter).

Relief of Distexsion.-In order to prevent the possibility of meteorism, an excellent plan is to pass a small tube, such as the ivory nozzle of an ordinary Higginson's syringe, through the sphincters twice in the twenty-four hours, and leave it in for one hour at a time. It does not cause the least discomfort, and allows of the escape of flatus. When the patient is elderly it is always advisable to pass a catheter once a day for the first few days to make certain that the bladder is being properly emptied. On the second or third day after the operation, and earlier if the patient's howels have not been well opened prerious to the operation, a soap-and-water enema should be administered, and repeated in an hour if there is no 


\section{The After-Treatment of Operations}

action of the bowels. If this fails to act, an oil enema may be given, or a dose of castor-oil ( 1 ounce) given by the mouth, or calomel, $\frac{1}{4}$ grain every hour for eight hours, or until the bowels act, may be used instead of the oil, or salts in repeated doses every two hours are preferred $b y$ some surgeons. In cases where there is uncomfortable distension of the abdomen after laparotomy the author adopts the following procedure: A turpentine enema, consisting of turpentine $\vec{j} s \mathrm{~s}$. and thin sruel $\mathrm{I}+$ ounces, is first given; if this fails to give relief, a hypodermic injection of I c.c. of pituitary extract is given, followed at once by an enema consisting of fels bovinum, i drachm in $1 \frac{1}{2}$ pints of water. This results in immediate and complete relief of the distension in most cases. Eserine may also be used hypodermically for the same purpose. This question of aperients is a very important one, and surgeons differ very much as to the exact procedure; but it may be stated as a general principle that the sooner a proper evacuation of the bowels has been obtained, the sooner is the patient out of danger. The importance of getting the bowels to act early after abdominal operations is well shown by the following figures, for which I am indebted to Dr. Darwall Smith, who has investigated this subject in an analysis of +2 consecutive cases of abdominal section.

Of these +2 cases, I 3 developed complications in the form of vomiting or distension, or both.

In 1 I cases the bowels were opened by aperients or enemata on the second or third day, and of these 2 devele ped complications.

In 20 cases the bowels were similarly opened on the fourth or fiftl day, and of these 5 developed complications.

In I I cases the bowels were left to nature, and of these 6 developed complications. 


\section{Operations on the Abdomen 173}

The generally accepted ricw among surgeons now is that meteorism or paralytic distension is due to sepsis; in other words, is a mild form of peritonitis. It any rate, it does not occur if strict aseptic conditions are secured, and the interior of the abdomen is not hamdled roughly. This complication should not occur now as the result of laparotomies, unless there are septic lesions.

Our object must he to get, if pussible, a natural action, unaccompanied by viotent peristalsis. The best way of doing this is by the use of enemata, which are probably the least irritating form of aperient and at the same time produce their effect with the least amount of peristalsis. With regard to the use of aperient drugs, salts, especially in small repeated doses, are probably the least irritating to the intestine, and take effect without giving rise to much muscular action of the intestinal wall; but, unfortunately, they are very liable in some cases to caluse romiting, which it is often particularly desirable to avoid. One of the best ways of administering salts for the evacuation of the bowels in these cases is in small loses dissolved in a large quantity of water, as, for instance-

$\begin{array}{llllll}\text { Pi Mag. sulph. } & - & * & - & - & 5 \text { ss. i. } \\ \text { Sodæe sulph. } & - & - & - & - & 5 \text { ss. i. } \\ \text { Aquam } & - & - & - & - & \text { ad } \\ \text { jwi. }\end{array}$

Sig. : Every hour till the bowels act.

The value of saline purgation in the treatment of insipient peritonitis has been repeatedly proved, and there can be no doubt of its usefulness in appropriate cases. The late Mr. Lawson Tait was one of the first surgeons to revive the practice, and he used to speak very highly of the value of saline purgation in the aftertreatment of ovariotomy cases. 


\section{The After-Treatment of Operations}

It has recently been pointed out by McCullum that most of the saline aperients act even more readily if administered hypodermically than if given by the mouth. This method of administration may he tried in cases where salts cause romiting when given in the ordinary way.

Castor oil is certainly one of the most reliable and most valuable aperient drugs that we possess, and, when it can he taken, is in many caes preferable to the use of salts. In ounce of the oil may be given on the morning of the third day after the operation. Calomel, especially in small repeated doses, is very uselul in some cases, and should be made use of in preference to salts or oil in cases where there is peri tonitis present or suspected: but as calomel acts largely by virtue of its irritating qualities, causing peristalsis, it must be used with caution. Great judgment and care is necessary in the enployment of aperients after laparotomy, and careful observation of cases combined with a linowledge of the physiology of the intestine will be of more service in the treatment of cases than any amount of reading.

()ne warning must, however, be given. In the aged and in wealily subjects, too active purgation, especially by irritant drugs, like calomel, etc., should be aroided, as it is liable to set up an intractable diarrhoea which may prove fatal from exhaustion. After the bowels have been opened a mild aperient should be given daily so as to insure a sufficient daily action. For this purpose a teaspoonful of liquid cascara or liquorice powder is as grood as anything.

TreaTMext of THE WOUND. - When the abdominal wall has been sewn up in layers, the superficial stitches should be removed in a weel, the deep ones, of course, 
being left. After the stitches have been removed, the wound should be supported with broad pieces of strapping so as to present any strain being thrown upon the newly-minited wound edges, and a firm flannel binder should be worn over this.

If the abdominal wall has been sewn up with nonabsorbable stitches passing through all the layers of the abdominal wall, the stitches should he left in for ten days. If a drainage-tuhe has been inserted into the wound, it should be removed in twenty-four hours unless there is pus draining away, in which case it should be retained. Drainage of the ahdominal cavity is not efficient after twenty'-four hours, as the tuhe is shut off by adhesions.

The period of recumbency necessary after laparotomy depends on several factors. The way in which the incision has been made and closed, the size of the incision, and the condition of the abdominal wall, have to be considered. In the case of a short incision made through the rectus sheath or by separating the muscles and subsequently closed-in layers, there is no risk of hernia: the patient may be got up as soon as the wound has firmly healed, which will be in about ten days, and a belt is quite unnecessary.

In cases where the wo nnd is large, and has not been made by splitting muscles, it is advisalle to keep the patient in bed for a period of three weels before allowing him to assume the erect position. It is better to err on the side of keeping the patient recumbent a little too long than to run the risk of a hernia.

In the case of women it is generally advisable to fit a belt, which should be worn for some months after the operation. This is not so much to prevent the formation of a hernia as to enable the patient to get 


\section{The After-Treatment of Operations}

about without becoming exhausted In many women the abdominal muscles are rather poorly developed, and as a result of the operation or the consequent rest in bed, they are often very weak for some time after. A properly fitting belt will do much to diminish this feeling of weakness, and will be found of great advantage.

No active exercise or any exertion, such as lifting heavy weights, should be indulged in for at least two months after the operation.

DiET.-This is one of the most important parts of the after-treatment of abdominal cases, and we must be graided largely by the nature of the case in the selection of a suitable diet. When there is a lesion in any portion of the alimentary tract, our object must be to avoid the use of any diet which will need digestion or necessitate peristalsis by that portion of the intestine. Thus, in stomach cases we should avoid the use of foods which are normally digested by that organ, and in the case of lesions of the small intestine we should make use of foods which can, to a large extent, be digested by the stomach, and so on. One thing must especially be avoided - that is, the use of any diet which, in the process of digestion or otherwise, is liable to cause the formation of gas, and so flatulence and distension.

At the time when the first edition of this book appeared it was the practice to put all laparotomy patients upon special "slop" diets; considerable importance was attached to the particular kind of diet, and much care was taken in the preparation of diet sheets. Any complications which arose were frequently ascribed to the patient's being allowed solid diet too soon. Surgeons have now, for the most part, come to hold a view which is more in accordance with common sense, and only withhold those articles of diet which they beliere may do 
harm. The author has for some years given up the ue of so-called "slop" diets, except in special cases. His practice is to allow no food until the anusthetic siekness has stopped, and then to give the patien in moderate quantity an ordinary diet such an he has been acoustomed to. Thus, if there has been no sieliness during the night after oporation, the patient is allowed a light breakfast consisting of a little bacon, a lightly boiled egg, and bread and butter; and for luncheon chicken or fish, followed by a milli pudding or a little stewed fruit and custard.

The author argues that after an operation on the abdomen, or indeed after any operation, it is most desirable that the patient should not have indigestion or flatulence added to his other discomfort, and that to put a man or woman who has for years been living on an ordinary diet on to a "slop" chiet is a certain way of producing indigestion. Anyone who doubts this lias only to put himself on a "slop" diet for a couple of days to prove it. He will find that he is suffering from flatulence and indigestion within a very short time. The atuthor has found that since adopting his present method of dieting patients after laparotony, discomfort from wind and flatulence has practically disappeared altogether, and with this many other troub'es that used to be all too common, such as insominia, heartburn, and loss of appetite. The above remarks do not, of course, apply to patients who previous to the operation were on a special diet, as the object should be to aroid an alteration of the patient's diet. When, too, the alimentary canal has been seriously interfered :rith, as in the case of anastomosis, etc., some modification and restriction of diet is advisable, though not to the extent often supposed. One must always remember that it is not the condition (of solidity, 


\section{The After-Treatment of Operations}

etc.) of the food when eaten that is important, but its condition during and after digestion. Ease of digestion is important, but it should be obvious that the most readily digested diet is that to which the individual is accustomed.

When a very severe operation has been performed, such as one involving surgical shock, or, more particularly, one for the relief of peritonitis or some serious inflammatory condition of the abdomen, the case is different, and special diet is advisable until normal conditions are re-established.

It must he remembered that the alimentary tract under these circumstances is not in a normal condition, that digestion is often not complete, and fermentation and other abnormal processes are very liable to take place. Milk, which is a very commonly used diet in these cases, is particularly unfortunate in this respect, as it is very liable not to be properiy digested and to undergo fermentation, and give rise to the formation of gas, etc. It is probably one of the worst forms of dietary in many. of these cases: and although peptonizing it does anay to some extent with this disadvantage, it does not do so altogether, as it is even then liable to undergo fermentation in the stomach and intestines, and, in addition, the peptones used to peptonize it are irritating. One of the safest and most reliable diets is albumin-water. This is made by beating up the white of three or four eggs in a pint of water, lemon and sugar or other flavouring materials being added according to taste. This is very easily digested, is unirritating, and at the same time is not liable to give rise to the formation of gas during the process of digestion; 2 pints of albumin-water given during the twenty-four hours represents a fair amount of 


\section{Operations on the Abdomen r\%e}

nutritive material, and, as a rule, is ail that is necessary during the first two or three days. Ahont 2 ounces should be given by the month every two or thrce hours: while the patient is awake. If clesircd, the alluminwater may be combined with peptonized milk, hut it is better to avoid the nse of milk altogether till after the howels have acted. Inother preparation which may be used, and which is very similar to the albumin-water, is plasmon.

Plasmon* is a pure allumin prepared from the caseinogen of milk. It is a fine white granular powder, which is readily soluble and free from taste or smell. It can be added to almost any form of diet, and, as it contains a very high percentage of albumin, forms a very useful method of administering proteid. It has the advantage of being the cheapest form of pure albumin obtainable, as it is prepared from butter-milk, a byproduct in the preparation of butter. It is a very easily assimilated form of albumin, and, owing to its method of manufacture, is free from chemicals. In abdominal cases it is best given either as a beverage or as jelly:

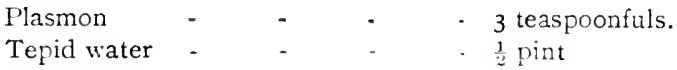

A little water should be added to the plasmon, and then stirred into a thick paste; the remainder of the water should then be added, and the whole boiled for two minutes. This will give $\frac{1}{2}$ pint of the liquid. About 2 ounces of this should be given to the patient every two or three hours, with more water and some suitable flavouring added according to taste. As a change the

* There are now many substitutes for Plasmon, such as ovaltine, sanatogen, etc. 


\section{The After-Treatment of Operations}

plasmon may be given as jeliy or cocoa. and later, when solid foods are begun, it is a very good plan to combine a certain amount of plasmon each day with the diet. The amount of plasmon whict it is advisable to give in the twenty-four hours must, of course. vary a good deal with circumstances, but roughly it should be from three to six teaspoonfuls of the powder.

A very useful diet for many of these cases, which was first drawn attention to by Mr. H. Gilford (British Medical Joumal, Norember I6, Igor), is grape-sugar. To quote his own words :

'In my opinion one of the best of these foods is grapesugar. Grape-sugar by itself is too nauseous, but combined with a flarour, such as that of raisins, it is nearly always palatable. I find, in fact, that it is, as a rule. preferred to nearly all other forms of liquid diet, and patients will often by preference continue taking their "raisin-tea" long after they have become tired of milk and slops. It is made by pouring boiling water on to half its hull: of chopped raisins. This is stewed for about two hours and then filtered. The filtrate may be given either with water or without, and either hot or cold according to the wishes of the patient. Though it doubt. less contains other substances than grape-sugar, these are apparently present in such small quantities that they may be neglected. Given at first in small doses and afterwards more freely, it is undoubtedly of value. When one remembers the important place which sugar takes among the foods, it seems strange that it should not be more utilized as an article of sick diet. This applies with peculiar force to grape-sugar, seeing that it requires no digestion.'

A combination of egg-albumin or plasmon with grape. sugar in the form of 'raisin-tea' is a most excellent diet 
for these cases during the frrst few days. It combines a maximum of nutrition in an easily assinilated form with a minimmm of bulk and residue; it contains both proteid and carbohydrate-the former in an easily digested form, and the latter in a form which requires no dicrestion at all.

Beef-tea, which is still so popular as a form of invalids' diet, is practically useless except as a stimulant, and there are many better stimulants than beef-tea. A recent chemical analysis made of the leef-tea in one of the big hospitals revealed the fact that the best beef-tea only contained $3^{*}$ t per cent. of proteid, so that beef-tea and the numerous other beef extracts are quite useless as a diet. A recent writer on the suliject says: "All the bloodshed caused by the warlike ambition of Napoleon is as nothing compared to the myriads of persons who have sunk into their graves from a misplaced confidence in the food value of beef-tea.'

When stimulants are necessary or advisable, brandy and whisky are the best, and it is better to give them in small repeated doses either separately or combined with the fluid diet than to give them in large doses. Champagne is sometimes valuable, hut, as a rule, it is better to aroid the use of gaseous drinks, as they often cause flatulence.

For the first four or five hours after the operation it is advisable not to give anything by the mouth except water. If the patient is thirsty, some lemon-juice may be added to the water with advantage, or peppermintwater is sometimes very comforting. About a tea-cupful of fluid should be allowed at a time. There is no advantage in only giving the fluid in small sips; such small quantities of water are just as liable as larger quantities to cause vomiting, and the latter will hate the advantige 


\section{The After-Treatment of Operations}

of laving the stomach if it is romited. It is correct in these cases to assume that thirst is the physiological call of the hody for more fluid, and therefore it ought to be satisfied as far as possible. Large quantities of fluid at a time are, howerer, not advisable, as they are liable to cause vomiting by distending the stomach; but giving water only in teaspoonfuls is neither reasonable nor does it answer any real purpose. A cup of tea with a little sugrar hut no milli is often very much appreciated when the vomiting has passed off. It should be made weak, and must not he allowed to stand before being drunk.

Complations of Laparotony-(i) Shocl: ; vomiting ; (3) meteorism; (4) peritonitis; (5) stitch suppuration : (6) facal fistula; ( $/$ ) parotitis; (S) weak scar : (9) intestinal obstruction; (IO) adhesions; (I I) rentral hernia: (I 2) acute dilatation of the stomach.

I. Shock.-.This condition has already been treated of in a separate chapter, and will not be further considered here.

2. Fomiting.-.'This has also been considered, but it may be mentioned here that in very bad cases of persistent romiting, which will not yicld to the ordinary treatment, washing out the stomach with warm water should be tried and repeated at intervals of two or three hours if necessary. Propping the patient up into a semi-sitting position is also sometimes of use. It should be our object to remove the cause of romiting rather than to check it (-ee p. gs).

3. Mctiorism.-This is the most dangerous complication that is commonly met with after laparotomy. A good deal has been writen on this subject under the name of 'pseudo-ileus,' a new name which seems to hare little to recommend it. Tympanites is also another name which has heen used to describe this condition. Whatever the exact plyssological calles of the cundition may 
be, whether it is due to paralysis of the intestinal musculature or to some other cause, it is a condition which is not uncommonly scen, and when once well established, it is often extremely difficult to treat. It usually first shows itself about twenty-four to forty eight hours after the operation by distension of the abdomen accompanied by some discomfort. 'The patient's breath is often foul.

In the fatal cases this distension steadily increases, and is accompanied by constipation, which nay become absolute, the patient dying either from a kind of toxamia, due, no doubt, to the alsorption of poisons from the intestine, or, in some cases, from a variety of peritonitis. A certain amount of flatulence after laparotomy is quite common, especially when the operation has been undertaken for the relief of some septic condition, as, for instance, in the case of appendicitis.

The modern view of post-operative meteorism is that it is due to sepsis and peritonitis, and that consequently the best way of preventing it is care in operating as regards careful aseptic technique, and especially the aroidance of rough and unnecessary handling of the ab 'ominal contents.

Our object must be to prevent the onset of this troublesome complication by appropriate means. The method of passing a tube through the sphincters and leaving it there is certainly one of the best means of securing this end. The late Mr. Herbert Allingham pointed out that it is necessary, for the expulsion of flatus, that the abdominal muscles should contract, and that after a wound has been made in the abdominal wall the patient is unable, or unwilling, to contract these muscles, on account of the pain which it causes him, and in consequence flatus tends to accumulate in the intestines. When the tube is in position, however, there is a free 


\section{84 The After-Treatment of Operations}

way through the sphincters, and wind is able to pass unaided.

As soon as distension has made its appearance, steps must at once be taken for its relief. An enema should be administered, and probably one of the best enemas for the purpose is a turpentine one, such as that in the old Lritish Pharmacopuia:

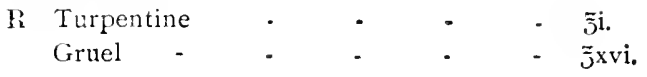

or a rue enema may be used, as:

$\begin{array}{lllll}\text { Ii Confectionis rutx } & - & - & - & \text { 亏iii. } \\ \text { Infusum anthemidis } & - & - & - & \text { ad } \tilde{\tilde{J}} \times r i . *\end{array}$

After the enema has been given, the rectal tube should be passed through the sphincters and left there for an hour, so as to allow of the escape of wind. It is a good plan to let the tube be kept in for one hour out of every six when there is any distension. An excellent plan which the author has used for some years and has hardly ever known to fail in giring instant relief is as follows: If the first enema fails to relieve the distension, a second is given, either of turpentine or, better still, of fels bovinum (B.P.), 2 drachms to warm water, 2 pints, and immodiately after the enema a hypodermic unjection of pituitary extract, I c.c. This usually results in a free passarre of flatus, and may be repeated if the distension shows signs of returning in a few hours. If these measures do not prove effectual in reliering the distension, large oil enemata should he used, or castor oil, calomel, or salts griven in repeated doses by the mouth until the bowels are open.

As a rule, the condition will yield to the ahore treat-

* St. George's Hospital Phamacopceia. 


\section{Operations on the Abdomen 185}

ment if it is commenced early and carried out rigorously. In very had cases powerful enemata, containing large doses of rlycerine, or mycerine and manesium sulphate, are some imes successful:

\begin{tabular}{|c|c|c|c|}
\hline Glycerini &. & .. & . \\
\hline Mag. sulph. & - & - & - \\
\hline Aquam - & . & . & - \\
\hline
\end{tabular}

Recently subcutaneous injections of physostigmin hwe heen used to stimulate peristalsis in these cases, and good results are claimed for this method of treatment. The dose is in wrain, and the injection should be followed in half an hour by a glycerine enema. The injection may be repeated in six hours if unsuccessful. With the same object the author has used hypodermic injections of pituitary extract, I c.c., with very good resuli:.

Lastly, in very bal cases the advisability of reopening the abdomen and incising the lowel may be considered.

4. Putonitis. - The question of reopening the abdomen will have to be consiclered. If this is not done, our only hope is in getting the bowels to act. Calomel in repeated doses is probably the hest way of securing this in these cases.

5. Stitch Suppuration. This should not occur with proper aseptic technique. lut is sometimes the result of too much tension on a stitch. When this is the case, the offending stitch should be divided, so as to relieve the tension. The stitch should not he removed, for fear of carrying septic material into the deeper parts of the wound. When the abdominal wall has been sewn up in layers, suppuration of the deep stiches is a very troublesome complication. This is the great oljection to all buried sutures. That it is not always the result 


\section{86 The After-Treatment of Operations}

of the suture material being septic is certain, as occasionally a sinus will form, leading down to the deep sutures, months after the wound has healed up. When this is the case, the oid wound must be opened and all the stitches removed.

Any persistent sinus which refuses to heal should he carefully investigated for the presence of a foreign body, such as a stitch, pjece of drainage-tube, lost swab, etc., as this is Ly far the most common cause of such sinuses.

6. Facal ifistula.- Fifcal fistula is most commonly seen after operations for appendicitis, and is then due to an opening either in the remains of the appendix or in the cacum. The first thing to do is to make sure that there is free drainage from the sinus, and that there is no danger of pocketing. For this purpose a drainage-tube should be kept in, and the fistula kept as clean as possible. The majority of these fæcal sinuses close spontaneously in the course of a month or six weeks, and often in much less time than this. If there is any tendency to the formation of a bottle shaped carity, the external opening should be carefully dilated or enlarged by cutting, and the wound drained from the bottom. The diet should be recrulater so that it may be easily digested, and the patient should be kept in bed, and, if possible, in such a position that the intestinal contents do not tend to flow into the listula, but rather to pass by the natural channel. When, in spite of these measures, the listulit will not close, it generally means that there is some obstruction to the flow of faces from the part of the intestine above the fistula into that helow it: and this should be investigated, and, if an obstruction is found, an operation must be performed to remove it, or to anastomose the intestine ahore and heluw the fistula, on whatever else may seem most suitable. 


\section{Operations on the Aldomen $\quad 187$}

As these fistular, however, often close of themselves after existing for several months, it is as weth to wat for some time before trying to close them by operation, unless there is obvious obstruction and all the fxcal material is passing by the wound. In cases of freal fistula not connected with the appendix or operations for its removal, the same remarlis apply, but the cause of the persistence of the fistula may then be the formation of a spur, and steps must he taken for its removal."

7. Parotitis.-.This curious complication may occur after any operation, lut it is most commonly seen after laparotony and operations on the pelvic organs. It seems to occur more often in women than in men. Excluding operations on the pelvic organs, it is most commonly seen after operations on the stomach, such as for the treatment of perforated gastric ulcer, etc. Out of 100 cases collected by Mr. Stephen Paget, $\uparrow$ the following primary causes were noted: Injury or disease of the alimentary canal, injury or disease of the urinary tract, ditto of the abdominal wall, peritoneum, or pelvic cellular tissue, a blow on the testicle, the introduction of a pessary, menstruation, and parturition. In 93 per cent. of the cases it occurred as an isolated lesion, no other complication being present. There was evidence of a primary septic focus in only fifteen cases. The period at which it comes on after the operation seems to vary very considerably. The commonest time seems to be from a week to ten days after the operation. In sume cases the submaxillary glands are affected as well as the parotids. The condition comes on with great swelling of

* Foret's treatment of fæcal fistulæ. See the author's book on 'Surgical Diseases of the Colon ' (Baillère, Tindall and Cox)

†'Parotilis following Injury or Disease': Stephen Paget, British

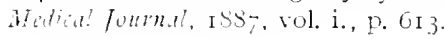




\section{88 The After-Treatment of Operations}

the parotid glands, accompanied by the usual signs of inflammation. It closely resembles mumps. There is often pain, and there may be a high temperature. The temperature, however, does not as a rule exceed $100^{\circ} \mathrm{F}$. or $\mathrm{IO}^{\circ} \mathrm{F}$., except in the septic cases.

The condition often sugrgests that an abscess is forming; as a rule, however, the inflammation subsides in the course of a day or so. Suppuration, however, may take place, and the best evidence of this will be the temperature chart. The pus tends to burrow into the external auditory meatus or the pharynx. The cause of the condition is very doubtful. That there is some curious association between the parotid gland and the genital organs is certain, but what this depends upon we do not yet know. The best way of treating the parotitis is by hot fomentations or lead lotions, and a smart purge should be administered. If suppuration takes place, incisions must at once be made into the gland, care being taken not to wound the iranches of the facial nerve.

The exact cause of this curious condition is still uncertain, but there is some reason to suppose that it results from an infection of Sitenson's duct consequent upon a septic condition of the luccal carity. Careful attention to the cleanliness of the patient's mouth is advised as a preventative meastire.

The following curious case of this complication is reported by Fislie . Jones (Boston . inilical and Surgicu? Journal, Novemb.r 20, I9:2):

A girl, aged nineteen, had a first attack of appendicitis in $\mathrm{I} S 97$. An abscess developed, spreading ir to the pelvis, which was opened and drained on the tenth day. Frny-eight hours atter lhe operation the right parutik gland began to ache and swell. Two days later the left vecame similarly affectel Within a weets the pain and swell- 
ing began to subsile. One rear afterwards a second attark of appendicitis occurred. An ahscess was opened and drained fortyeight hours after the onset of the symptoms, and wo days later the right parotid became intiamed, the oppusite gland being involved forty eight hours after its fellow. In November, I syp, two years and a half subsequent to the first seizure, a third attack occurred; the appendix was removel, and the pelvis drained once more the right and then the left parotid hecame inflamed. There was no rigor, and the symptoms were comparatively mild.

S. Wcak Scar.- Stretching of the scar, and the formation of a weak spot in the aldominal wall, is most commoniy seen when the wound is in the area below the umbilicus, as it is more subject to pressure in this situation. A reali scar is most often seen after operiations for the drainase of a septic carity, and especially after operations for tubercular peritonitis or tubercular lesions of the appendix. It must he treated hy strapping the sides of the scar firmly together with alhesive plaster, and making the patient wear a properly-titting abdominal belt. There must on no account be a pad on the belt to press on the scar, as such pressure is liable to cause atrophy of the tissues, and will tend to still further weaken the scar. In some cases, especially in children, it is better to keep the patients in bed for a time until the scar has to some extent consolidated, and then to let them get up with a belt, which should be worn for six months or more.

9. Intestinal Obstmotion.-Intestinal obstruction is an accident that may follow any abdominal operation, but it is most common after operations on the pelvic organs. It is also not infrequently seen after operations upon the appendix. The symptoms generally commence with colichy pains in the abdomen, accompanied by distension and sicliness. There is also increasing difficulty in getting the bowels to act. The patient may have been 


\section{Ino The After-Treatment of Operations}

going on quite satisfactorily for the first three or four days after the operation, and the bowels have been opened on the third day by means of enemata, and then something appears to go wrong. There is constipation, accompanied by colicky pains, and great difficulty is experienced in getting the bowels to act. This difficulty increases, until in a very short time there is absolute obstruction, and the ordinary symptoms of acute intestinal obstruction are developed. The condition is most commonly seen about five or six days after the operation. Although the symptoms develop slowly, the condition when once established is usually that of an acute obstruction. The patholory of the obstruction in these cases is probably, that a coil of intestine becomes adherent to some portion of the field of operation, and kinking takes place in consequence. At first only slight narrowing of the intestinal lumen results, but as the intestine above gets more and more distended, the obstruction increases, until often it becomes absolute.

As soon as ever the symptoms show themselves, and this condition is suspected, prompt measures must be taken for its relief. It first an attempt should be made to stretch or detach the adhesions by causing peristalsis of the intestine. Large doses of salines may be administered by the mouth, and turpentine enemata administered by the rectum. Sir VIatson Cheyne* draws attention to the value of position in the treatment of this condition. He advises that the patient should be placed in such a position that a certain amount of dragring is produced upon the adherent coil of intestine. Thus, the buttocks should be raised, and, in fact, the patient placed in a modified Trendelenburg position. Should these measures not prove effectual in gretting rid of the obstruction, time * 'Surgical Trealment': Cheyne and Burghard, vol, vi. 


\section{Operations on the Abdomen IO)!}

must not be wasted, hut the aldomen should be at once reopened, and the adherent coil detached from the part to which it has become atherent. Once the diannosis of secondary obstruction has been made, the best treatment is, undoubtedly, to at once reopen the abdomen throush the original incision. The cause is most likely to be some athesion of bowel to the incision or its strangulation in a stitch. The patient should not he exhausted by drastic attempts at purgation before operation is resorted to.

The following list show the causes found in 26 cases of post-operative intestinal obstruction collected by G. M. T. Finney: * Kinking, 7 cases; adhesions alone, 7 ; bands, 3 ; volvulus, 2 ; loop caught beneath adherent loop, I ; cicatricial stenosis, 1 : gastro-mesenteric ileus, I ; adynamic ileus, I ; cause unknown, 3. Ten of the patients died, the remainder recovering as the result of a secondary operation.

The following cases well illustrate the importance of prompt surgical interference :

Case.-S. W. was operated upon for colotomy on June 6 , and on the second day after the operation the bowel was opered and castor-oil administered by the mouth. No action of the brwels took place, and romiting began twenty-four hours later, and became severe. Further attempts at purgation only increased the vomiting without relieving the howels. (In June ro the abdomen was reopened, when it was found that a piece of omentum was cauglit in the spur stitch, and the drag on this was causing an acute kink in the transverse colon. This was released, but the patient died on the operating table. The operation should have been done earlier.

CASE.-A. M. was operated upon for chronic appendicitis, the appendix being removed, and the abdomen closed without drainage. Two deep stitches of fish-gut were put through all the thicknesses of the abdominal wall, as well as supporting stitches. The patient

* Anuls of Surgiry, June, igo6. 


\section{I92 The After-Treatment of Operations}

did well for twenty four hours, but then began to get much dis. tended, and all efforts to open the bowels failed. The ablomen was reopened on the third day through the original incision, when it was found that a piece of the wall of the small bowel was caught under one of the deep stitches and strangulated. This was released, and the damaged patch of bowel inverted by stitches. The patient made a good recovery.

Io. Adhesions.-Adhesions, though they may not cause actual intestinal obstruction, are not infrequently the cause of very considerable trouble after some abdominal operations, more especially those which have been done for some inflammatory mischief. After the convalescent period following the operation has passed, the patient begins to gret vague pains in the abdomen. These pains are often accentuated by walking and exercise. There is increasing difficulty in getting the bowels to act, and aperient medicines have to be constantly taken. Colichy pains often accompany any action of the bowels, and in some cases the patient gets considerable pain in the lower part of the abdomen if the bladder is allowed to become distended. These symptoms often increase in severity and may make the patient a chronic invalid. The symptoms are due to adhesions between different portions of the intestine or between the intestines and other organs.

Sometimes the symptoms can be cured by massage and suitable exercises in a gymnasium, and considerable relief usually follows this line of treatment.

In some of the old-standing cases however it may be necessary to open the abdomen and divide the adhesions.

Illustrative Casc. - A woman, aged thirty, was operated upon for perforating appendicitis with a small abscess in the right iliac fossa. She had had three previous attacks of appendicitis of less severity. She recovered from the operation perfectly well, and had no com- 


\section{Operations on the Abdomen 193}

plications. She made, in lac:, an uninterrupted recovery, and for a time was lost sight of. When hearl of two years later, she said she had had increasing difficulty witl the bowels since the opera. tion, and that she had constantly to take medicine before she was relieved. She was unable to stand fur more than one or two hours without getting severe pain; in the atdominal region, and hat frequently to go and lie down. She was also unable to hold her urine for any length of time willout pain. $1 / l$ her symptoms pointed to adhesions in the neighbourhood of the right iliac fossa careful regulation of the bowels and suitable massage and exercises were effectual in getting rid of all her symptoms.

I I. Ventral Hemia.-A hernia through the scar is a possibility after any laparotony if a large incision has been made. The modern practice of opening the abdomen by splitting the muscles and closing it in layers has done much to prevent the occurrence of this complication. It was a not uncommon complication when the usual practice was to close the abdominal wound with a single row of sutures. It is particularly liable to occur if the wound does not close by first intention. When a hernia occurs the effect of a properly fitting belt should be tried for a time, and if no improvement follows, an operation to close the defect shotild be undertalien.

12. Post-operative Acute Dilatation of the Stomach.-This most serious complication may occur after any operation involving the abdominal cavity. It may come on at once or after some days. Vomiting is usual, but not invariable. The distension is very great, and the patient rapidly becomes very ill.

In many cases death occurs in the course of two or three days, but cases of recovery are known. There is usually no obstruction found post mortem, though in one or two instances internal herniæ have been found.

The best treatment would seem to be lavage $r f$ the 


\section{The After-Treatment of Operations}

stomach with a stomach-tube two or three times a day till the distension passes off, and subcutaneous infusion with saline solution.

Operation is not indicated as a rule, but gastroenterostomy has been done successfully in one or two cases.

Illustrative Case. - A man aged fifty-eight was operated on for a reft inguinal hernia after forty-eight hours careful preparation for operation. The Trendelenburg position was used for about twenty minutes during the operation. After operation gastric distension came on rapidly. There was no vomiting. Relief followed the use of the stomach-tube, and it was used about twice daily for some days.

The patient recovered. Six months later he was again operated on for a right inguinal hernia, and the same symptoms occurred, though on this nccasion local anxsthesia with cocaine was used.

13. Foreign Bodies left in the Abdomen.-Leaving a foreign body inside the abdomen after an operation is a most unfortunate accident, and one which should never occur. As long, however, as it is human to err, such accidents will occasionally take place, and it is only by the adoption of systematic methods that they can be prevented.

The foreign hodies which have been left behind are various, and include clips, scissors, sponges, swabs, pieces of rubber-tubing, etc. Sponges and swabs have been known to become encysted, and to have remained for long periods in the ablominal cavity withont causing any symptoms, and have sometimes been mistaken for tumours at a later date. This is, however, by no means always the case, and very serious complications may follow the leaving of such foreign bodies in the abdomen. Ulceration into the bowel or some other hollow viscus may follow, and may prove fital; or an abscess may form beneath the slin, and a sinus develop down to the foreign body. There are a few cases on record where 
such forcign bodies have been spontanteously discharged from an abscess. Instruments left behind are certain to give rise to very serious complications.

The best way of preventing an accident of this lind is to adopt a form of operative technique that does not allow the possibility of any mistalie.

The mere counting of sponges and swabs after an operation is not by itself sufficient. A potent cause of such accidents is the practice of cutting in half sponges or swabs during the operation, or of cutting off pieces of gauze to pack round a stump or to arrest hæmorrhage. This should never be done. It is very liabie to result in something being left hehind, and counting the sponges or swabs afterwards will not prevent this if the numler has been changed in the course of operation.

The best plan, if sponges are used, is to use only three or six, and, if more are necessary, to have them in multiples of three; then, if at the eral of the operation the sponges are still in multiples of thrce, none can ba left behind. The surgeon should himself be responsille for counting the sponges.

Another and safer plan is to use square sterilized cloths instead of sponges, with a piece of tape sewn to one corner. The end of the tape is clipped and left hanging down outside the wound. These sterilized cloths are better than sponges for packing off the ficld of operation, and if used in this way cannot be left behind.

Another very good plan is to use the end of at roll $\mathrm{s}$ sterilized gauze to pack round the site of operation, the roll itself bcing kept on the towels, and more gauze unwound as it is needed, but the gauze never cut. The portion of gauze at the edge of the wound can be used for swabbing. As the whole of the gauze in use is in one 


\section{The After-Treatment of Operations}

continuous piece, it is quite impossible for any of it to be ieft behind so long as it is not cut.

The clips used in the operation should be in dozens or half-dozens, and should be counted before and after the operation by the surgeon himself. The plan of using a porcelain rack with numbered holes for the clips, as suggested by Mr. Marmaduke Sheild (Lancet, June I I, I904), is an excellent method of preventing this untowar? accident.

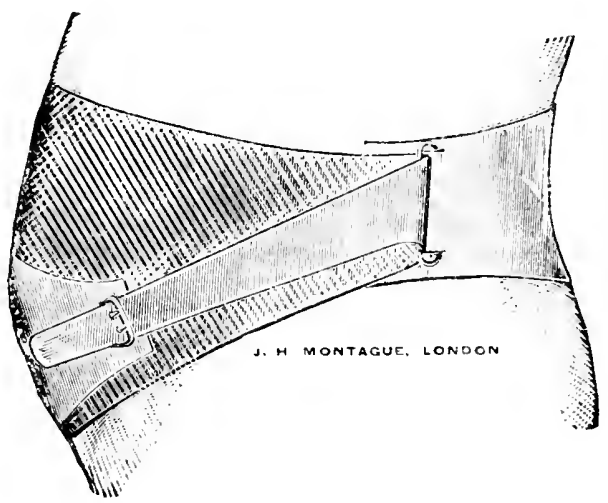

FIG. 28.

Abdominal Belts for Use after Laparotomy.There are many different hinds of belts, and the exact form is not of much importance. The principal points of a good belt are an accurate fit and a good support to the lower part of the abdomen immediately over the pelvic brim. A belt which constricts the abdomen without supporting it is bad, and will do more harm than grood. A good form of belt is shown in Fig. 23 . 


\section{CHAPTER XIV}

\section{OPERATIONS ON THE ABDOMEN (continucd)}

\section{Cases of Acute General Peritonitis.}

THE modern method of treating such cases is to deat with the cause of the infection as rapidly and effectually as possible, and to drain, by means of tubes, those portions of the abdominal cavity in which pus tends to collect. Everything, however, depends on the aftertreatment in these cases. The patient should from the first be nursed in what has been called the Fowler position - that is to say, in the semi-sitting position shown on p. $f$. In this position the pus and serous discharge will gravitate into the pelvis, where they can escape, and away from the upper and more dangerous areas of the abdomen. The patient should be kept in this position throughout, and must not be allowed to assume the horizontal position until the peritonitis has subsided.

The other important point is to administer large quantities of saline solution by the rectum. The best plan is to arrange continuous rectal irrigation. This is done by means of an ordinary irrigator or douche with a vaginal nozzle, which is passed into the rectum. The top of the fluid in the irrigator should not be more than 6 inches above the level of the anus, so that the fluid runs in slowly. The irrigator must be kept full of warm 


\section{The After-Treatment of Operations}

saline solution. From to to 20 pints should be allowed to absorb from the bowel during the first twenty-four hours, and continued, if necessary. This is a most valuable means of treating acute peritonitis, as it washes out the poisons in the blood and tissues and helps their elimination.

The dressings should be changed frequently, and the drainage-tubes shortened and ultimately removed as soon as the discharge from them gets less or ceases.

It seems certain that the drainarge of the peritoneal cavity by means of tubes is not effective for more than about twenty-four or forty-eight hours, and there is, therefore: nothing to be gained by leaving the tubes in for more than two or three days.

Very little, if any, food should be given by the mouth for the first two days, but nutrient liquids may be added to the rectal irrigating fluid from time to time.

'The bowels should be moved as soon as possible by means of castor-oil or calomel, and should be liept acting freely during convalescence, so as to prevent, as far as possible, the formation of adhesions.

\section{Operations on tha Stcmach.}

Special Complications. - (I) l'nemonia; (2) regurgitant vomiting; (3) hæmatemesis.

I. Pnemmonia.-. One of the commonest causes of dath after operations on the stomach, and more especially operations undertalien for the relief of pyloric stenosis, is pneumonia. The reason for this is that the patients are often old or enfeebled subjects, and that the free morement of the upper abdominal muscles and, to some extent. the diaphragm are interfered with owing to the incision. The respirations in consequence are shallow, as the patient is afraid of the pain caused by a deep inspiration, 
Coughing is for the same reason prevented, and, as a result, mucus collects in the most dependent parts of the lungs and sets up hypostatic pneumonia. The best way of preventing this is to nurse the patient as far as possible in a sitting position; the linees should he flexed over a cushion or bolster, and the back and head supported with a bed-rest and pillows.

A good way of preventing pulmonary trouble after operations on the abdomen is to instruct the nurse to get the patient to take a few deep breaths so as to com. pletely fill the chest every few hours.

2. Regurgitant Vomiting.-This sometimes follows the operation of gastro-enterostomy. When it comes on about two or three days after the operation and there are no signs of peritonitis, it is usually due to the formation of the so-called 'vicious circle'- that is to say, a kink has formed in the intestinal loop, and the contents of the stomach, instead of passing into the distal portion of the intestine, are passing into the proximal or duodenal portion, and so back into the stomach (Figs. 29 and 30). This should be especially suspected if there is much bile present in the vomit. It used to be supposed that the presence of bile in the stomach was the cause of the romiting, but it has now been shown that this is not the case. The vomiting is probably always due to some blockage in the new anastomotic opening, which may be of either a temporary or permanent nature. The voniting may be but slight, occurring only a few times and then ceasing altogether, or it may be so serious as to quickly cause a fatal issue. When regurgitant vomiting occurs, the stomach should be washed out, and all feeding by the mouth stopped for a time. Changing the patient's position is sometimes effectual in freeing the bowel. Thus, if the patient has been propped up he should be made to lie down 


\section{The After-Treatment of Operations}

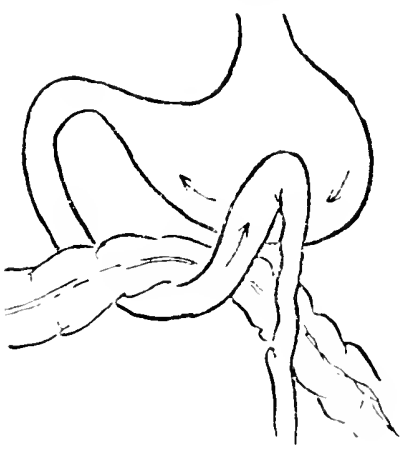

Fig. 29.-Formation of A Viciocs Circle' after Anterior GasTRO-ENTEROSTOHY, DUE TO A Fallty Operation and PeriSTALSIS OCCURRING IN OPPOSITE DIRECTIONS IN THE STUMACII AND INTESTINE.

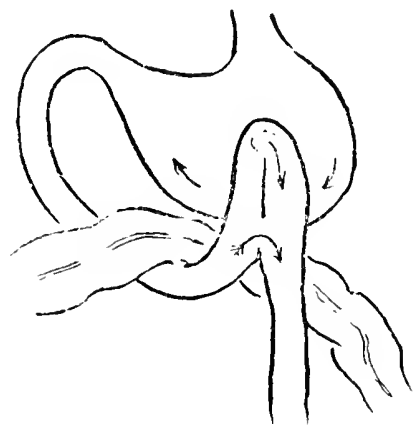

Fig. 3I.-Method OF Curing a 'Vicious Circle' by ANastoMosis BETWEen tHE AFFERENT AND EFFERENT LoOpS OF IntesTINE. THIS IS THE BEST OPERA. t TON IN CASES WHERE A 'VICIOU'S CirCle' IIAS FORMED AND A SECONDARy OpERATION has BECOME NECESSARY FUR ITE RELIEF.

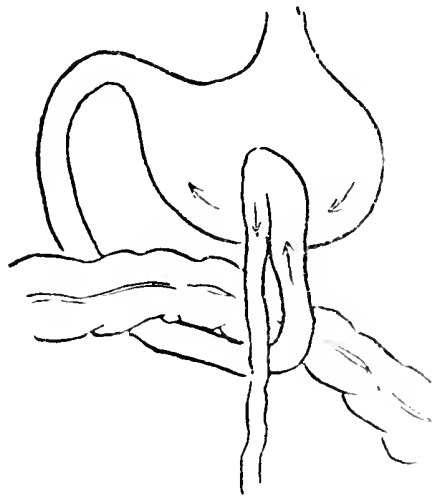

Fig 30.-ForMation OF a 'Viciots Circle' after Anterior Gas. TRO-ENTEROSTOMY, DUE TO THE Formation OF A SPCR BY THE Drag of THE INTESTINE.

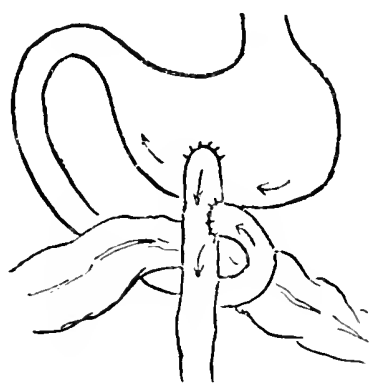

Fig. 32.-Another Method of CuRING OR PreventiNg A 'Viciocs Circle.' The Y OLLRATLN. 


\section{Operations on the Abdomen 201}

flat on his back so as to prevent the drag on the loop of intestine. Giving the patient large draughts of water to drink has occasionally stopped the vomiting. 'The bowels should also be got to act well. If these measures fail to stop the vomiting, another operation should at once be performed to make a free exit for the stomach contents into the bowel. I'robably the best operation to perform under these circunstames is to anastomose the loop between the pylorus and stomach to the distal portion of the intestine lower down (Fir. 31). In slight cases of regurgitant voniting, lavage of the stomach every twenty-four hours will give relief; in bad cases operation must be at once resorted to. When persistent vomiting follows other operations on the stomach than gastro-enterostony, it is probably due to acute gastritis or peritonitis, and must be treated accordingly.

3. Hamatemesis.-Vomiting of blood after operations on the stomach is not at all uncommon for the first twenty-four or forty-eight hours. It is generally, however, only the blood which has got into the stomach at the time of the operation, and need not cause alarm. When, however, the blood is bright in colour, and there is reason to suppose that it is the result of oozing from the stomach wound, a little hot water may be given to drink with a view to stopping it, or the stomach may be gently irrigated with warm boracic lotion by means of a soft tube. It is seldom that the bleeding is of any consequence.

Position after Operations on the Stomach.-The best position in most cases is the half-sitting position already mentioned, but the exact position must depend upon the nature of the lesion and its site in the stomach. Thus, in many cases our object should be to keep the patient in that position which will allow of fluids, etc., 


\section{The After-Treatment of Operations}

most easily finding an exit from the stomach into the intestines. Since the pylorus is to the right side, the right lateral position is, in many cases, adrisable, and is always to be preferred to the left lateral or supine positions. The power of the stomach to expel its contents is usually very feeble after any operation upon its walls, and we must try to assist it, as far as possible, by means of gravity.

It is an excellent plan when patients are being nursed in the sitting position to allow them to sleep at night in the right lateral recumbent position. They not only sleep better in this position, but it prevents the accumulation of fluids in the stomach, and insures free drainage from that organ into the intestine during the night. Moving the patient's position from time to time also tends to prevent the formation of bed-sores, which are otherwise very liable to form in the case of old and emaciated subjects.

Igain, in the case of ulcers which have been treated surgically, we must try to keep the patient in such a position that the wound will not be in a dependent part of the stomach, and so will not be constantly in contact with the contents, be it food or mucus.

As in these cases it is particularly desirable that there shoutd not be any vomiting after the operation, owing to the strain which it might throw upon the stitches in the wall of the stomach, it is best not to give anything by the mouth for the first twenty-four or forty-eight hours, and rectal feeding should be adopted. Patients often complain of great thirst; this must be appeased by giving warm water enemata, and sometimes a thin slice of lemon to suck will malie the patient more comfortable. When the patient is old or much enfeebled as the result of his condition previous to the operation, it is often not 
wise to depend entirely on rectal fecding even for the first two days, and he should be given small quantities of fluid diet, such as albumin-water every two or three hours, as soon as the results of the anrsthetic have passed off. The diet should he entirely fluid for the first five clays or a week after the operation. The sugar diet already mentioned is a very stritable one in stomach cases, and may be combined with albumin-water. The wound in the stomach wall is probably healed at the end of a week or ten days. Mr. Barker* recommends that when the paticnt after an operation on the stomach complains of a feeling of weight and distension in the region of the stomach, a soft tube should be passed and the fluids contained in the stomach siphoned off. He says that very marked relief from pain and discomfort often follows this procedure; it may be employed during the first twenty-four hours, and repeated if necessary.

\section{Operations on the Gall-Bladder and Biliary Ducts.}

Special Conplications. - (i) I Ixmorrhage; biliary fistula; (3) broncho-pneumonia and pleurisy; (4) acute dilatation of the stomach ; (5) vomiting.

I. Hamorrhage.-Many of these operations have of necessity to be performed upon patients who are suffering from jaundice, and the coagulability of the blood under these conditions seems to be altered in much the same way as is the case in patients the subject of hæmophilia. Oozing from all parts of the wound takes place, and if not stopped often proves fatal. This oozing may not come on for two or three days after the

* Laniot, Augrusi 22, ijoz. 


\section{The Atter-Treatment of Operations}

operation. The value of calcium salts by mouth or rectum as a means of preventing hæmorrhage in these cases seems very loubtful, and many surgeons have given it up. Moynihan now advises the use of horse or rabbit serum, of which 20 c.c. are injected subcutaneously five or six hours before operation. Thyroid extract has also been used to shorten the blood coagulability time in these cases with success.

2. Biliary Fistula.-This is an extremely troublesome affection, which occasionally follows operations on the gall-bladder. As a rule, these fistulæ close spontaneously in the course of a month or two. When, however, this is not the case, it is generally due to there being a block in the common duct, either from an impacted stone, malignant disease of the head of the pancreas, or as the result of adhesions, and, if possible, a further operation should be performed for its relief.

When the biliary fistula is accompanied by absence of bile in the stools, as shown by clay-coloured freces, it is practically certain that the cause of the fistula is a block lower down in the biliary passages, and a second operation must be performed. When, however, there is a certain amount of lile in the fæces, it is better to wait for some time, to see whether the fistula will close spontaneously.

3. Broncho-fueumonia and Pleurisy. - These complications often result from the interference with the movements of the diaphragm caused by the operation. They are best guarded against by nursing the patient in a semi-recumbent position.

4. Acute Dilatation of the Stomach.-This is said to have followed the operation of choledochotony in some cases. It is best treated by gastric lavage and rectal feeding.

5. Vomiting.-It may be mentioned here that persistent 


\section{Operations on the Abdomen}

vomiting may occur after these operations when a large gauze plug has been inserted. 'The vomitingr often ceases after removal of the plug.

\section{Operations for Appendicitis.}

Compracations. - (1) Peritonitis: (2) meteorism; (3) faccal tistula: (4) empyema: (5) thrombosis; (0) infarction of the lung; (7) loculation of pus; (8) adhesions.

The treatment of the wound is the same as for any other abscess, but it is very important that the drainagetube should not be left out until all the deeper parts of the wound have healed, as otherwise the opening in the skin is rery liable to contract and allow the pus to pocket. Sometimes a weeli or ten days after the operation, when the patient is apparently almost well again, there is a rise in temperature and pain at the site of the wound-in fact, a recurrence of the original symptoms. This usually means that another abscess has formed in the deeper parts of the wound carity ; in other words, some pus has pocketed, and got shut of from the rest of the wound. Under these circumstances the wound should be carefully dilated and explored with the finger or a director until the pus is found. and given a free exit. Great caution must, however, be exercised in doing this, or there will be danger of opening the general peritoneal cavity and setting up peritonitis.

The rectal tube should alway be used after the operation as a precautionary measure against distension. It is particularly in these cases that distension and meteorism are liable to occur. The patient should have the tube placed through the sphincters, and left in for one hour in six hours, commencing soon after the opera. tion (see page I $7 \mathrm{I}$ ). 


\section{The After-Treatment of Operations}

It is most important, after all operations for appendi. citis, to get the bowels to act as soon as possible. An enema should be administered on the day after the operation, and, if it fails to act, should be followed by a dose of salts or castor oil.

In cases where there is a large foul abscess carity left after the operation, it should be irrigated daily or twice daily. Care must be talien, however, to irrigate gently and to allow a free exit for the fluid, as otherwise there is some risk of forcing the fluid into the general peritoneal cavity, and so perhaps causing general peritonitis. There is no advantage, as a rule, in using antiseptic solutions for irrigating the abscess cavity. In most cases the best fluid for the purpose is normal saline solution; in cases where the abscess cavity is very foul and sloughy, hydrogen peroxide is often very useful in cleaning up the wound; it should be used of a strength of 5 volumes. Other solutions which may be used under the same circumstances are chlorine-water and lysoform in weak solution.

The author has recently analyzed the after-history in Ioo consecutive cases of operation for appendicitis in one of the London hospitals, for the purpose of ascertaining the percentage of complications and the after-results that may follow this operation.

In this series the mortality was 8 per cent.; of these 3 cases died from meteorism and peritonitis, 2 from other forms of sepsis, 2 from bronchitis, and I from infarction of the lung.

Complications, including several cases of stitch suppuration, occurred in 48 per cent. of the cases.

In 4 per cent. the patient developed a secondary empyema on the right side. and in 1 per cent. a right plenrisy. Infarction of the lung occurred in 5 per cent. of the cases, the infarction occurring in $I$ case on the first 


\section{Operations on the Abdomen 207}

day, in 2 cases on the ninth day, in I case on the tenth day, and in I case on the twelfth day; and of these 5 cases, thrombosis in the lower extremities wats detected in 3.

Loculation of the pus with recurrence of some of the symptoms, and necessitating reopening the wound occurred in 15 per cent. of cases.

A farcal fistula formed in y per cent. Meteorism occurred as a complication in 7 per cent. of the cases.

The percentage of complications in this series seems high, but this is accounted for by the fact that, as in all hospital statistics, many cases are included which were in a desperate state when operated tupon.

These statistics were made in Iyo3, and would not apply to-day, as with the great improvements in technique and in aseptic methods which have occurred since then, combined with the fact that cases of acute appendicitis are now operated upon much earlier than was then the case, complications of all sorts have been enormously diminished, so that the mortality is now less than i per cent. in the best practices, and complications generally correspondingly less frequent.

A certain amount of trouble may be experienced in getting the bowels to act for the first few weeks after the operation, owing to the formation of adhesions between the coils of intestine. This is particularly liable to occur if the alsceess has tracted down into the pelvis. It can, however, be orercome by the proper use of salts, and in most cases the adhesions will soon stretch and disappear.

When an abscess has been opened, or there has been much inflammatory mischief around the appendix, adhesions are apt to form in the neighbourhood of the wound, and as time elapses, and these adhesions contract, they may cause a considerable amount of discomfort and 


\section{The After-Treatment of Operations}

pain. In the cases analyzed by the author, symptoms which appeared to be caused iny adhesions were present from one to two years after the operation in is per cent. (see also p. 192).

The different complications and the methods of dealing with them have already been referred to in the previous ciapter.

Ventral hernia sometimes follows the operation for removal of the appendix, and it is a peculiar fact about these hernix that they are often very painful. When this is the case, a further operation should be performed for the cure of the hernia.

\section{Radical Cure of Hernia.}

Special Complications.-(i) Epididymo-orchitis; (2) retention of urine; (3) separation of the deep sutures; (4) persistent vomiting; (5) recurrence.

In order to keep the dressings dry it is advisable, in the inale, to piace a piece of jaconet with a hole in it over the dressings, the penis being made to emerge through the bole. In young children it is so difficult to keep the dressings dry that it is advisable to apply a collodion dressing to the wound in the first instance, and to place a large pad of wool over this, which can be changed constantly. The best way of nursing quite young children after operations for the radical cure of hernia is to sling their legs up to a cross-bar over the bed, in the same way as is done in Bryant's method of treating fracture of the femur. This not only enables the small patient to be kept much cleaner than would otherwise be the case, but the flexed position of the thigh acts as a protection to the inguinal rings, and prevents undue pressure being exerted on them, during the period of healing of the wound, from crying, etc. 
The usual time during which the patient should be liept in bed after these operations is from three weeks to a month. Three weeks is, however, all that is usually necessary. When the patient is first allowed to get up after the operation, a pad of wool held on by a firm spica bandage should be applied over the inguinal canal. This should be worn for the first week. After that all support to the canal can usually be dispensed with. The use of a truss after the radical cure of hernia is inadvisable, as the continuous pressure exerted by a truss tends to weaken the scar and surrounding tissues, and therefore tends towards the recurrence of the affection. Of course, when the operation has been undertaken for the purpose of enabling the patient to wear a truss-that is to say, when, owing to the nature of the case, a real radical cure of the condition was not to be expected, and the operation was undertaken with the object of so improving the local conditions as to allow of a truss keeping up the hernia - the case is different : a light truss, therefore, should be ordered in these cases. The patient after the operation for hernia should be warned against the danger of lifting heavy weights, or exerting himself in any way, for the first two months or so afterwards, as the parts are not thoroughly consolidated for that time, and any violent exertion is liable to cause the hernia to come down again.

I. Epididymo-orchitis.-It is not at all uncommon after operations for hernia to find a few days after the operation that there is some swelling and tenderness of the epididymis and testicle on the same side. This is most probably due to the interference with the veins of the cord at the time of the operation, or to the cord being constricted by the ring having been sewn up a little too tightly. The swelling is often considerable, but it is of no 


\section{The After-Treatment of Operations}

consequence, and all subsides in the course of a day or two. If there is much pain or discomfort, the testicle should be supported by a small cushion or slung up well on to the abdomen by means of a bandage, and evaporating lotions applied to relieve the pain. Occasionally this swelling and enlargement of the testis, etc., persists for a week or two, but invariably subsides without any harm resulting.

2. Retcntion of Urine.-This is not uncommon for the first twenty-four hours after the operation. Loosening the bandages is sometimes all that is necessary to enable the patient to pass his water. If simple means fail, a catheter should be passed and the urine drawn off, the usual precautions being, of course, taken to prevent the introduction of organisms into the bladder.

3. Separation of the Deep Suturcs.-This has already been referred to under the head of 'Laparotomy.' It is a particularly annoying complication in these cases, as it may render the operation ineffectual.

4. Persistont Vomiting.-Leaving out of account the vomiting due to the anæsthetic, peritonitis, or meteorism, which have already been referred to, this complication is usually seen after operations for the cure of large scrotal hernia when portions of the omentum have been ligatured and cut away. The vomiting generally comes on about a week or ten days after the operation, and is accompanied by some tenderness of the abdomen and symptoms which at first are easily mistaken for those of peritonitis. The condition is either due to some sloughing of the omental stump or to the formation of adhesions between it and the surrounding coils of intestine. The condition is not common, but is seen occasionally; the symptoms generally pass off in the course of a few days, and no harm results to the patient. The patient should 
be put on a fluid diet again if solids have been allowed, and the bowels should be well opened with saline aperients. The symptoms usually subside after the bowels bave been well opened. Pain often accompanies the symptoms, and is best treated by hot fomentations, and, if necessary, by the use of morphia.

5. Recurrence. - The question of recurrence hardly conses within the $\mathrm{sco}_{\mathrm{e}} \mathrm{e}$ of this work. Fortunately, with the present improved methods of operating it is not very often seen now, but even after the best operations cases will occasionally occur. In the case of hospital patients, many of whom are navvies, whose work entails the lifting of heavy weights, often with the knees bent, and who can seldom afford to keep away from their work for a sufficient time after the operation to insure the best results from it, it is not surprising that recurrence is sometimes seen; indeed, it is a matter of surprise that the results under these circumstances are as good as they are.

\section{Operations on the Kidney.}

Special Complications. - (I) Uræmia; (2) severe pain ; (3) vomiting; (4) high temperature ; (5) pulmonary embolism; (6) hæmaturia; (7) renal colic.

The after-treatment of these cases is practically the same as for laparotomy. When a drain has been placed in the loin, frequent changing of the dressings will be necessary to keep the patient dry, and if there is a tendency for the skin round the wound to become sore from the constant irritation of the discharge, a little ointment should be smeared over the skin to prevent this. After nephrectomy everything that is possible should be done to diminish the work of the remaining kidney until it has 


\section{I 2 The After-Treatment of Operations}

become accustomed to the new conditions. The diet should be bland, and all highly nitrogenous diets are best avoided, as they will give the kidney more work to do in excreting wea than would less nitrogenous diets. Morphia or opium in any form is best avoided, as it tends to diminish urinary secretion. The slin and bowels should be liept acting, so as to relieve the work of the remaining kidney. The amount of urine passed per diem should be measured and charted, so that any diminution in the quantity may be noticed at once.

I. Uramia.- When the excretion of urine diminislies and uramia threatens, the case should be treated in the same way as for an ordinary case of uræmia-that is to say, the skin must be made to act by the use of hot-air baths or pilocarpine, and the bowels must be kept acting freely. The application of hot fomentations over the healthy kidney is often useful.

2. Pain does not always occur, but may be very severe. it is generally of a shooting character, running down into the groin and inner side of the thigh on the same side. Sir William Bennett has pointed out that when this pain is present in a marked degree after the kidney has been stitched into the loin (nephrorrhaphy), a nerve has probably been included in the suture. On one occasion, when the pain was especially severe, he found this to be the case. The advisability in such a case of opening the wound and dividing the suture will have to be considered.

Slight renal colic may occur after some operations on the lidney, especially nephrotomy, and is due to the passage of blood-clots down the ureter. This is best treated by hot fomentations, etc. Morphia must not be given if there is any uncertainty as to the condition of the other kidney. If, however, it is known that the other 
lidney is healthy, and there has been no dimmution in the amount of urine excreted since the operation, it nuay be given with safety.

3. Persistent Vomiting after operations on the kidney, and especially after nephrorrhaphy, sometimes occurs, and may accompany the high temperature mentioned below. It is probably due to the same cause. The patient often vomits on and off for some diass; the condition is not, as a rule, serious. It is as well to remember the possibility of this complication occurring after operations on the kidney, as otherwise the symptoms may gire rise to serious fears of peritonitis.

4. High Temferature.-A high temperature is not at all uncommon after the kidney has been much interfered with. After nephrorrhaphy a high temperature may persist for a week or longer, the temperature often varying from $100^{\circ}$ to $103^{\circ} \mathrm{F}$. This is probably due to interference with the sympathetic nerves. It need not give rise to alarm, and it is not accompanied by any inflammatory condition. The temperature rises directly after the operation, and remains up. Should the temperature, however, be normal or sulmornal for the first few days and then rise, it will not be due to this cause, and sepsis must be suspected and the wound examined, and, if necessary, opened. The patient may, while the temperature persists, feel flushed and uncomfortable.

5. Pulmonary Embolism.-This is, fortunately, a rare complication. For treatment, see Chapter VII.

6. Hamaturia. - This not infrequently occurs after operations in which the kidney has been explored. It is due to oozing from the kidney substance, and, as a rule, stops within forty-eight hours of the operation. If severe, it should be treated by an ice-bag applied to the loin, and calcium chloride by the mouth or rectum, in 


\section{The After-Treatment of Operations}

large doses. It should never be treated by administer. ing adrenalin or ergot internally, as these drugs raise the general blood-pressure without constricting the renal vessels, and so tend to increase the hæmorrhage.

7. Renal Colic. - This may occur after nephrotomy. It may be due to-(a) the passage of a blood-clot down the ureter; (b) a portion of stone which has become detached from the main stone during its removal from the renal pelvis, or even to a small stone which has been overlooked at the operation.

The best treatment under such circumstances is to relieve the pain by morphia and hot stupes to the loin and abdomen, and at the same time to give the patient plenty of fluid to drink so as to wash out the clot or fragment in the ureter. 


\section{CHAPTER SI}

\section{OPERATIONS ON THE GENITO-URINARY TRACT}

ONE of the most important things to be attended to in the alter-treatment of operations on the genito-urinary tract is to keep the patient as dry as possible. There is a great tendency for the dressings to become soaked with urine, and if such dressings remain long in contact with the skin, especially of old men, it is very liable to get raw and inflamed. And quite apart from this, the constant state of smell and dampness which the patient is in cannot but cause him considerable misery and discomfort. To prevent this the dressings should be frequently changed, and mackintosh sheets should be arranged round the ends of the tubes, etc., to prevent, as far as possible, the urine getting on to the dressings. It is well to licep the skin powdered with starch or boracic powder.

Most wounds resulting from operations on the bladder or urethra are left open, and have to heal by granulation. Consequently it is necessary to frequently change the dressings and to keep the wound clean by irrisation. These cases require constant attention and slilled nursing. It is important to see that the patient has a suitable bed. This should be a good height, as a low bed is a great inconvenience; and it should also have a mattress which does not form a hollow in the middle. 


\section{6 The After-Treatment of Operations}

A pneumatic ring-pillow with a removable linen cover should be placed under the patient's sacrum.

The best way to alleviate pain after these operations is by means of suppositories of morphia and belladonna, though the use of opium in any form is best avoided in cases where the kidneys have been interfered with or where they are thought to be diseased. The bowels should always be kept acting loosely for some time after the operation. One of the most important things to assure success in these operations is to keep the urine sweet and to prevent acidity. For this purpose some drug should be given which is excreted in the urine as an antiseptic. Of these there are several. Boracic acid or salol, given in 10-grain doses three times daily, may be used, or urotropine, in 5 to ro grain doses in an ounce of water, three times daily; free diuresis is more important than drugs, and to secure this the patient should be encouraged to drink plenty of barley-water or other fluids. Where the urine, in spite of these precautions, remains foul, and cystitis is present, the bladder should be washed out twice a day witl some mild antiseptic, such as boracic lotion.

The use of stronger antiseptics than this is not advisable, as they often give rise to a considerable amount of pain, and are liable to make the cystitis worse. Where the cystitis will not improve with this treatment, solutions of protargol or argyrol ( $\frac{1}{2}$ to I per cent.) may be used with advantage. In washing out the bladder, only 2 or 3 ounces of fluid must be injected at a time and allowed to run out again, this being repeated until the solution comes back quite clear. The solution should be at a temperature of about $100^{\circ} \mathrm{F}$. The best apparatus for washing out the bladder is a sott rubber catheter on the end of a glass funnel. 


\section{Genito-Urinary Tract Operations 217}

When the urine is very alkaline, benzoate of ammonium can be combined with the boric acid in ro-grain doses three times a day by the mouth, or urotropine may be used. When the urine is very acid, bicarbonate of soda, in Io or 20 grain doses, should be given by the mouth, either alone or combined with one of the other drugs mentioned above until the urine is rendered neutral.

Catheter Fever. - After any operation on the urethral tract, or after the passage of instruments, etc., the so-called condition of catheter or urethral fever is liable to occur. It usually comes on during the first thirty-six hours, though it sometimes occurs after the removal of an instrument that has been tied in at the operation, and it is well to be on the look-out for this. It often follows the first act of micturition after the operation. The patient shivers, and has a rigor, followed by a hot stage and profuse sweating; this condition soon passes off in the majority of cases, and is not dangerous unless followed by suppression of urine, which is very rarely seen, and practically only occurs when the kidneys are diseased-Io grains of Dover's powder, administered before the operation, will usually prevent the occurrence of these unpleasant symptoms. If a large catheter has been tied in after the operation, the same powder, given that night, will often facilitate its removal next day, and add to the comfort of the patient; or an excellent plan is to remove the instrument while the patient is sitting in a hot bath. This is a good plan whenever large instruments have to be passed or withdrawn from irritable urethras. In order to prevent the occurrence of this complication after operations on the urethral tract, Mr. Freyer * recommends that a draught containing

\footnotetext{
- 'Operations on the Urethra and Prostate.'
} 


\section{The After-Treatment of Operations}

quinine ( 5 grains) and liquor opii sedativus ( 5 minims) should be administered on recovery from the anxsthetic, and quinine (10 grains) sriven daily for two or three days afterwards.

Occasionally a much more severe condition of this fever is seen. There are repeated attacks of fever, accompanied by high temperature and rigors, or the fever is more or less sustained, and the patient gradually sinks into a low state, with feeble pulse, etc. This is more common in old patients and those who have had a cystitis previous to the operation, or some other septic focus in or near the field of operation. The condition is probably a septic one, and must be treated on those lines. The great danger is suppression of urine and uræmia. When this occurs, it must be treated by purgation and sweating, and, of course, opium in any form must be absolutely avoided.

The best way of treating this severe type of urinary fever is by preventing its occurrence, and it ought to be very rare if proper care is taken. Unfortunately, the whole genito-urinary tract is in a septic condition in some of these cases, especially when dealing with old and neglected prostatic trouble, and it is in such cases that it is most commonly seen.

Diet.-The main object in dieting is to keep the urine neutral and prevent acidity; therefore it is well to avoid nitrogenous foods as far as possible, and starchy foods should be given. For the first few days after the operation the diet should be a light one, and plenty of fluids may be allowed with advantage, as this helps to wash out the genito-urinary tract. In old and debilitated subjects it is so important to keep up their strength that a low diet is not adrisable, and it should be sustaining from the first, and combined with stimulants of a suitable nature. 


\section{Genito-Urinary Tract Operations 2 I 9}

\section{Suprapubic Cystotomy.}

Compricatrons.--(I) Severe cystitis; (2) pelvic cellulitis; (3) suppression of urine; (4) epididymitis.

For the first twenty-four or forty-eight hours the wound is best dressed with absorbent dressings, which must be changed as soon as they become soaked with urine. It is important to remember that because the wound is open and primary union is not amed at the

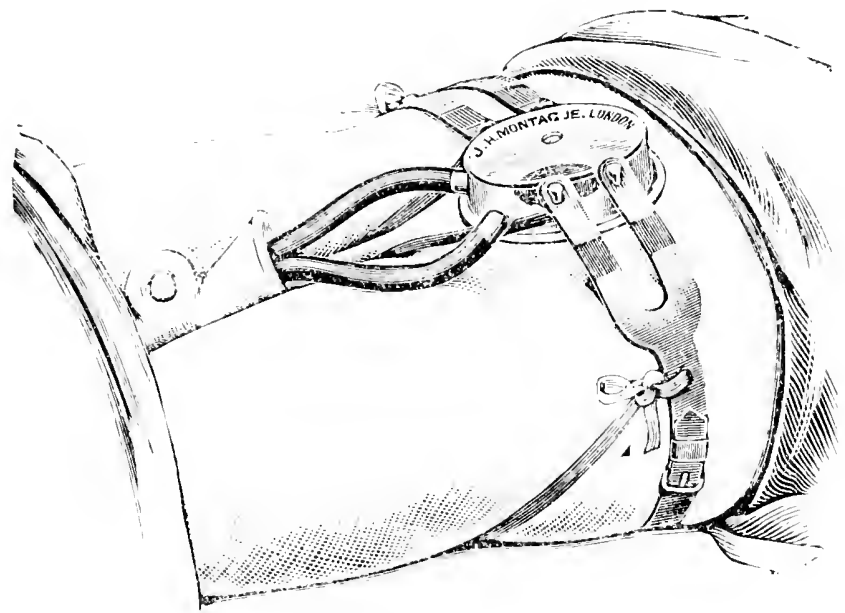

FIG. 33.

necessity for careful aseptic precautions in changing the dressings is not lessened, but, on the other hand, is greater. The surgeon should, when possible, see to the dressings himself, or, at least, see that someone who thoroughly understands aseptic technique does so for him.

After the first twenty-four or forty-eight hours the best plan is to apply some form of apparatus which will drain 


\section{The After-Treatment of Operations}

away the urine and prevent it from accumulating in the dressings. There are several forms of apparatus for this purpose; the best, however, appears to be that devised by Mr. Hamilton Irving (see Fig. 33). This apparatus consists of a celluloid cap which fits over the wound, and is retained in place by straps passing round the body. From this cap there are two outlet pipes com. municating either with a urinal between the patient's thighs or with a receptacle at the side of the bed. There is a removable lid to the cap which allows the wound to be examined or the bladder irrigated without remoring the apparatus. It also enables continuous irrigation of the bladder to be very easily arranged for. When this apparatus is used no dressings are required, and all that is necessary is to see that it is lieptclean.

When such an apparatus is not available the dressings must be frequently changed, so as to lieep the patient as dry as possible; but after the first forty-eight hours plain sterilized dressings should alone be used, as medicated dressings soon cause soreness and resication of the skin.

The drainage-tube should be removed at the end of twenty-four or forty-eight hours, and many surgeons tie a large catheter into the urethra, so as to allow the urine a free escape by the normal channel.

The time wbich it takes for the suprapubic opening to close varies from about twelve days to three or four weeks, and even longer in some cases. The patient should be liept in the recumbent position, and not allowed to stand up for a week after the suprapubic wound has healed up, as otherwise there is some risk of its opening again. Care should also be talien to prevent the bladder becoming distended.

If there is much cystitis and the urine is very foul, 


\section{Genito-Urinary Tract Operations 221}

continuous irrigation of the bladder with warm water should be arranged for, and urotropine given by the mouth in full doses.

Suppression of urine has been already montioned under catheter fever. It is a condition calling for prompt treatment. The main indications are to relieve as far as possible the congestion of the renal tissues by leeches to the loin, and purgation, and at the same time to encourage the excretion of the urea, etc., by the skin and bowel, so as to tide the patient over the dangrerous period while the kidneys are not acting.

Hot antiseptic batlis of boracic or very weak perchloride are a good way of dealing with complications occurring after operations on the urinary tract when the patients are strong enough to stand them; but they are sometimes dangerous in old people, and in any case a competent attendant must be present.

\section{Prostatectomy.}

Complications.-(I) Hæmorrhage; (2) epididymitis; (3) incontinence ; (4) uræmia.

In the suprapubic operation the treatment of the wound is practically the same as in an ordinary suprapubic cystotomy. It is the practice of most surgeons to administer urotropine or urotropine and water freely for some days previous to and after the operation. This is advisable, as it tends-at any rate, to some extent-to asepticize the genito-urinary tract.

The bladder should be irrigated twice daily after the operation, and if there is much sepsis continuous irrigation should be arranged for. It is important, however, to avoid any distension of the bladder, especially during the first two days, as it might cause hæmorrhage. Any clots which are found to have formed in the bladder 


\section{The After-Treatment of Operations}

must be carefully removed. The irrigation should either be done with sterilized water or with some weak anti. septic solution, such as I in 5,000 potassium permanganate.

Irrigation shouid be stopped as soon as the patient commences to pass urine freely per urethram.

Hæmorrhage should be treated by irrigation with hazeline or silver nitrate solution ( $\mathrm{I}$ in 5,000 ) as hot as can be borne ( $110^{\circ}$ to $120^{\circ} \mathrm{F}$.). The foot of the bed should be well raised. If this fails to control the bleeding, an anæsthetic must be administered, and the bladder firmly packed with long strips of gauze, the ends of which are left projecting out of the wound; the gauze should be removed in twenty-four hours.

Incontinence or dribbling away of the urine may occur, and is a very unpleasant complication; it is due to excessive injury to the neck of the bladder, and destruction of the sphincter vesica.

In the perineal operation the tube is generally removed inside a week from the operation, and the wound should be closed in three weeks.

\section{Lithotrity.}

Complications.--These are the same as for cystotomy, but there is a greater liability to urinary fever and epididymitis. The patient should be kept in bed for a week or ten days; a large catheter should be tied into the bladder for the first thirty-six hours. He should be instructed to turn on to the side to pass water. Hot fomentations to the abdomen are very comforting to the patient during the first twenty-four hours, and morphia or some opium preparation may be administered if there is pain. The patient should be allowed to sit in a hot hip-batl for fifteen or twenty minutes two or three times 


\section{Genito-Urinary Tract Operations 223}

a day, and instructed to try and pass his water while in the bath. It is sometimes necessary to draw off the urine by means of a catheter for the first few days. Quinine or salicylate of soda may be administered by the mouth, and will do much to prevent the occurrence of fever. Morphia suppositories are very useful in relieving pain after the operation. The diet for the first few days should consist of milk, barley-water, and be comlined with stimulants, if necessary. Mr. Jacobson says: "It is advisable to once more thoroughly wash out the bladder with the evacuator a weel after the operation, as a safeguard against recurrence from small fragments left behind at the operation.

\section{Internal Urethrotomy.}

Complications.-(1) Hæmorrhage; (2) urinary fever; (3) epididymitis.

Hæmorrhage, should it occur, is best treated by tying in a catheter; if this proves insufficient a perineal bandage should be applied with a suitable pad so as to compress the bulb of the penis against the catheter. MIany surgeons tie in a large catheter after the operation, and leave it in for twenty-four hours; if this has been done it should be removed in a hot bath, and a large instru. ment, preferably a steel sound, passed every two days at first, and at the end of ten days or a fortnight the patient may be taught to pass it for himself, and told to do so once a week at first, and later at more distant intervals for some months to prevent recontraction of the scar in the urethra. Some surgeons, on the other hand, prefer not to pass any instrument till after the wound has healed, which will be in about ten days or a fortnight, and then to pass steel dilators (Mr. Freyer recommends

* 'The Operations of Surgery,' r 903 edit., rol. ii. 


\section{The After-Treatment of Operations}

Nos. I 3 to 15 English gauge) so as to insure the urethra being well dilated, and then to let the patient pass the instrument for himself at intervals for some months afterwards.

\section{External Urethrotomy.}

Complications.-(I) Pelvic cellulitis and peritonitis; (2) toxæmia ; (3) sloughing of the rectum; (4) epidily. mitis.

If a catheter has been tied in at the operation this should on no account be removed for two or three days, as it will be difficult and may be impossible to replace it.

If a perineal tube has been tied in it should be retained for four or five days and then removed. At the end of a week or ten days a steel sound should be passed along the urethra into the bladder, and this should be repeated every second or third day till the perineal wound has healed.

\section{Cireumcision.}

The dressing is usually a matter of some difficulty in these cases, as it is difficult to get it to keep on, and it easily becomes soiled. Dry gauze and collodion makes an excellent dressing if the wound heals aseptically, but is extremely troublesome to remove, and sometimes causes pain ; it is also very painful if erections occur. A very good way of dressing these cases is to wrap a narrow piece of dry cyanide gauze round the penis at the site of the wound, and then to put a larger strip orer the top of this and overlapping it. A pad of absorbent wool about 2 inches thick and large enough to cover the whole perineum and come well up into the abdomen is next taken, and a hole is made in it with scissors just large enough to admit the penis; the penis is placed in 


\section{Genito-Urinary Tract Operations 225}

this loole, and then the pad of wool fixed on by taking two or three turns of bandage round the body and thighs. This protects the penis, and adds very materially to the patient's comfort.

In hospital practice a very good dressing is made with strips of lint soaked in lotio plumbi (diluted one half) wrapped round the penis, and secured to the abdomen by a strip of plaster. The mother is given some of the lotion and instructed to keep the lint moist with it, or carbolic oil nay le used in the same way. The patient should be liept in bed for the first forty-eight hours, and on the day after the operation he should sit in a warm bath and soak off the dressings, a new dressing being applied afterwards; this should be repeated each day till the wound has healed. After the first two or three days an ointment dressing is the most comfortable. If there is much swelling and oedema after the operation, the bath should be used twice daily and weak lead lotion applied.

After operations on adults it is advisable to administer a dose of bromides at night for the first few days to prevent erections. The patient should keep his bed for the first two days, and remain resting on a sofa for a week, and when he first begins to get about should keep a large pad of wool round the penis to prevent its being knocked, etc. If catgut sutures have been used they may be left to come away of themselves, otherwise the stitches should be removed one or two at a time.

\section{Radical Cure of Hydrocele.}

The drainage-tube should be removed in twenty-four hours, and the wound sealed up with collodion. Pressure should be maintained by means of wool and bandaging over the wound so as to prevent the collection of blood 


\section{The After-Treatment of Operations}

or serum in the scrotum, and to promote rapid healing by keeping the sides of the wound cavity in contact. Care must be taken to keep the scrotum well up on to the pubes; this prevents œdema of the scrotum and pain, and assists to keep the dressings clean. For this purpose the best thing is a small cushion placed between the legs so as to support the scrotum, or a suspensory bandage made of gauze and pulled up firmly is an excellent plan. Some of the stitches may be removed on the fourth day, and the remainder a few days later; the patient should remain in bed for ten days or a fortnight, and should wear a suspensory bandage for some months.

\section{Varicocele.}

The treatment is the same as for the above, but no drainage being necessary, the wound should not be examined for five or six days, when the stitches may be removed. The patient may be allowed to get up in a week or ten days. A suspensory bandage should be worn for two or three months after the operation.

\section{Operations on the Uterus or Appendages.}

Retention of urine is common after any operation on the uterus or pelvis, and the greatest care must be exercised in relieving it by the catheter, as cystitis is readily set up and seriously complicates the after-treatment; the most careful aseptic precautions should be taken in using the catheter, and it should always be passed by sight and not under the clothes. The catheter should be passed frequently-every five or six hours-to prevent the bladder from becoming distended, as this will result in much discomfort to the patient. An attempt should be made to get the patient to pass her water while lying 


\section{Genito-Urinary Tract Operations 227}

on the side. As already stated many women are unable to pass their urine while in the dorsal recumbent position, and in consequence there is apt to be a collection of residual urine in the lyadder even when the catheter is in use.

The vagina must be kept as clean and aseptic as possible after the operation. This is best done by daily gentle irrigation with some mild antiseptic solution. A pad of cyanide gauze well dusted over with some antiseptic powder should be liept over the vulva and changed twice a day.

After many operations on the uterus, and especially those in which retaining stitches are placed in the uterine wall, there is very severe pain for some days after the operation. This pain can often be relieved by such drugs as phenalgin and aspirin, in full doses, repeated every four or five hours. Menstruation often comes on, although not due, after such operations, and may be irregular for some time afterwards. 


\section{CHAPTER XVI}

\section{OPERATIONS ON THE RECTUM, AND COLOTOMY}

\section{Operations for Fistula.}

Complications.-(1) Formation of f́resh sinuses: (2) bridging of the wound; (3) excessive tenderness of wound; (4) exuberant granulations; (5) wound refusing to heal.

In my opinion no surgeon should undertake an operation for fistula unless he is able and willing to supervise the after-treatment himself. Too often the surgeon operates upon a case of fistula, and then never sees the case again, or not until the wound has refused to heal. Most of the failures to heal in the case of fistula are due to the fact that those responsible for the after-treatment of the case do not understand what is necessary. In proof of this, the fact may be stated that the averace period before healing is complete after an operation for fistula at St. Mlark's Hospital is under four weelss, in spite of the fact that probably the practice of this hospital includes most of the worst cases of fistula in London. The actual figures for over 200 of the author's own cases at St. Marli's are as follows: Average period of healing in days-males, $25^{\circ}$; females, $\%_{7} \%$. Judging from the inquirios the writer has made. the arerage period before 
bealing is complete after a fistula operation at some of the large general hospitals is nearer two and a half months.

It is most important that the wound should be liept as clean as possible, and to insure this the dressing shoukt he changed frequently. In the case of a large fictula wound where there is much discharge, the dressing should be changed every six hours, or even oftener; and in the case of an ordinary fistula wound which is clean, it should be changed at lenst twice a day. It is never sufficient to dress the wound only once in twenty-four hours, or, as is sometines the practice adopted, once every two or three days. For the first three or four dave the wound should be dressed with bot fomentations, changed as frequently as pussible. The fomentations should he applied over the wool which is in the wound, and the latter should be left in situ for the first thirtysix hours, and then clranged as soon as it is soiled. The bowels should be opened on the third or fourth day by an aperient dose, aided by a small quintity of olive-oil injected into the bowel. After this, the pationt should be allowed to sil in a hot antiseptic bath night anl morning. The cotton-wool will soak out of the wound while he is in the bath, and fresh wool should be carefully laid in the wound after the hath. The wound is best dressed with flat strins of wool, which shoukd be of the best quality, and not the cheap flutf so often supplied in these days. A narrow, thin strip of wool should be wrapped around a dressing-probe, and by means of the probe, passed up into the deeper part of the wound until it enters the lumen of the lowel. If the probe is then gently pressed against the wound it can be remored, ledving the wool in position in the wound. The first tirnger of the left hand passed minto the bowel will often 


\section{The After-Treatment of Operations}

assist in placing the wool accurately in position. With the end of the probe the strip of wool should next be adjusted carefully so that it lies evenly along the floor of the wound. Then a few small flat strips of wool should be laid in any side-tracks or superficial portions of the wound. On no account should the wound be firmly plugged with dressing. Plugging of the wound is a mistake; in fact, there is no more effectual method of preventing healing.

When once the surface of the wound is covered with healthy granulations it is important to protect these and the growing edge of the skin from damage each time that the dressing is changed, and for this purpose there is nothing better than a dressing of wool soaked in olive-oil or vaseline. At this stage antiseptics should be avoided, as they tend to damage the delicate granulations and to delay healing. Peroxide of hydrogen, though useful as an application to clean up a sloughy wound, should not be used once the wound has cleaned up, as it tends to produce exuberant and unhealthy granulations. The wound always requires careful watching to see that healing is progressing satisfactorily. Occasional stimulation is often required. For this purpose lotiod rubra applied on wool for a day or two, or Friar's balsam applied once, is very useful. Weak silver nitrate, Io grains to the ounce, may sometimes be used with advantage, but strong silver nitrate should not be used except to destroy unhealthy granulations, as it usually does more harm than good. Scarlet red ointment is sometimes useful; but it is a mistalie to use stimulating applications trequently. The wound must be carefully watched for signs of bridging or the formation of new tracks. The latter may always be suspected if the discharge from the wound increases in amount or fails to stop. If a previously 
healthy wound suddenly begins to discharge, it is an aimost certain sign that a new track has formed. Any bridges of tissue that are discovered should be broken down with a steel probe or cut through with scissors, and new tracks must be at once laid open. When the wound is quite healtiny and nearly healed it is best to apply no dressing at all, but to keep the parts clean, and apply a little vaseline to protect the surface.

The patient should be kept in bed, or at least in the recumbent position, until healing is quite complete; and in order that the scar may become firm before it is subjected to much movement, he should not walk about more than is absolutely necessary for another week after this. It is a great temptation to both doctor and patient to ailow the latter to get about a little when the wound is nearly healed; but this wastes time in the long run, and is often responsible for considerable delay in the final healing of the wound.

During the whole process of healing care must be taken to insure that the stools are quite soft, as a hard stool may delay healing for a week or more.

Causes for Non-Healing of the Wound after an Operation For Fistula.-(I) Inadequate operation; (2) insufficient drainage; (3) too tight plugging of the wound; (4) bridging of the wound; (5) some constit11tional condition of the patient.

\section{The Operation for Piles.}

Complications. - (I) Pain; (2) hæmorrhage ; (3) ul. ceration; ( 4 ) stricture; (5) retention of urine: (6) formation of external piles; (7) fistula or fissure.

The dressing should be changed twice a day, and the external parts washed with weak carbolic lotion. If a tube has been inserted it shonld be removed in twenty- 


\section{The Afrer-Treatment of Operations}

four hours. There is no advantage in keeping the patient on a 'slop' diet. It is better to give ordinary food in small quantities until the bowels are opened, and after this a full ordinary diet. The patient may be allowed to move about freely in bed, so long as he does not disturb the bandages. The bowels are confined for two or three days, and are then relieved by the adninistration of an ounce of castor-oil, or some other suitable aperient, an injection of three or four ounces of olive-oil being made into the bowel with a soft catheter and funnel at the same time that the aperient is administered. Is an alternative to an aperient, the bowels may be relieved by an enema of olive-oil, 6 ounces, and thin gruel, I 4 ounces. The bowels should subsequently be liept acting daily with some mild aperient such as cascara or petroleum. In ordinary cases the patient may safely be allowed to use a night commode placed beside the bed. The patient should remain in bed, or at any rate in the recumbent position, until the ligatures bave separated, which is somewhere between the eighth and eleventh days. After this he should be liept on the sofa for a day or two longer.

Operations for piles have in the past had a rery bad name for causing a great deal of pain. All operat for piles used to be accompanied by considerable pain, and it was the custom to give morphia, or some other form of opium, for days after the operation. It is, however, now possible to prevent this pain if the operation is properly performed, and if the after-treatment is thoroughly carried out; and the operation for piles should result in no more pain than one for hernia or varicose veins. The pain after an operation for piles, as, indeed, after most operations, is due to swelling of the tissues and inflammation of the wound. If, after the removal of the piles, the wound is kept clean and the tissues aseptic 


\section{Operations on the Rectum 23,3}

for some hours, there is no severe pain. It is obw ously impossible to lieep the wound ciean for a long period. In order to keep it aseptic for a few hours after the operation it is necessary that the patient shall be so prefared for operation that one can be certain no facal material shall be found in the rectum, or come into the area of operation, either during or immediately after the operation. By careful attention to details this can be insured. The author has found by experience that if great care is taken, when operating upon piles, to make the wounds through clean tissues and to keep the wounds clean for some hours afterwards, pain is not present in any marlied degree in the majority of cases.

Should the patient complain of pain, to grains of aspirin every six hours will often relieve it. If the pain is severe, $\$$ grain of morphia should be administered hypodermically. Suppositories containing morphia or other drugs should not be used, as they are not aseptic and they act very slowly.

For the treatment of hæmorrhage after this operation, see p. 69. It is important to remember that when hæmorrhage occurs after an operation for piles, there is seldom any external evidence of its presence, as unless a tube has been inserted, the blood does not escape from the anus. Should a patient after such an operation become blanched and collapsed, the anus should at once be examined, and a finger passed into the rectum to ascertain if there is any bleeding. If ligatures have been used, they generally separate between the eighth and twelfth days, the average being the tenth day. The patient should not be allowed to get up until all the ligatures have come away; he may then be allowed to recline on a couch or easy-chair, but should be more or less restricted to the horizontal position 


\section{The After-Treatment of Operations}

until on examination all the wounds are found to have healed.

Ulceration of the rectum after an operation for piles is a most troublesome complication. It must be treated by frequent irrigation of the rectum with weak antiseptics and improving the patient's general condition by stimulants and good food. It can be avoided by careful attention to asepsis during and after the operation.

Stricture should not occur if the operation has been properly done, but should there be any tendency of narrowing of the anal orifice it must be met by the daily passage of bougies, and the patient should be instructed to pass a bougie for himself until all tendency to contraction has disappeared. Allingham's bougies, which are only tapered at the extreme end, are the best for this purpose. The results of a stricture of the anus are so serious that the greatest care should be talien to prevent it becoming permanent. Stricture can only occur if the operation has been badly done or there has been ulceration.

After Vhitehead's operation the treatment is the same. A finger should be occasionally passed into the bowel to ascertain if the parts are uniting correctly. The stitches uniting the mucous membrane to the slin should be allowed to come away by themselves. If, as sometimes happens, the mucous membrane tears away and retracts, the condition should not be left to heal by granulation or a serious stricture will probably result. In anæsthetic should be administered, and the mucous membrane pulled down and reunited to the skin margin by stitches.

Retention of Urine.-This is very common for the first day or so after all operations on the rectum, and more particularly if the anterior wall has been interfered with - as, for instance, by the ligature of a pile in this situa- 


\section{Operations on the Rectum}

tion. The patient should be encouraged to try and pass his water naturally if possible, and may be allowed to kneel up in the bed for the purpose. Should he still be quite unable to pass his water, a soft Jacque's catheter may be passed and the urine drawn off. The retention often lasts for several days.

Sometimes after an operation for namorhoids one or more external piles form at the anal margin. These are due to cedema of the slin at the anal marsin from the circulation being interfered with by the removal of the piles. They are not of much consequence, and will subside as the circulation is re-established. The following ointment applied on a piece of cotton-wool will relieve any pain they may cause, and also hasten their resolution. A compress of lead lotion nay also be used for the same purpose. If very large they may be cut off under local anæesthesia.

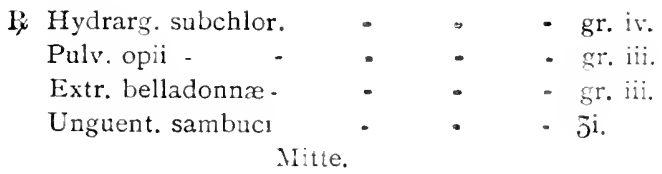

\section{Operations for Fissure.}

The after-treatment is practically the same; the recumbent position should be maintained until the wound has healed. The dressing should be changed twice a day, and the parts well washed with warm water. A small wisp of wool placed in the wound with a probe makes the best dressing.

\section{Colotomy.}

After the operation the patient should have a small pillow placed under the head and a bolster under the knees. If he complains of being unconfortable from 


\section{${ }_{23} 6$ The After-Treatment of Operations}

lying on the back, he may be allowed to turn on the side, providing that he does not turn on to the side on which the colotomy wound is situated. Very little food should be given until the intestine has been opened, though a little fluid diet may be allowed. Old people should be well propped up, almost into a sitting position, as this will prevent any tendency that they may have towards bronchitis, etc.

If the patient is comfortable the wound need not be dressed on the day after the operation. On the second day it should be dressed, and the intestine opened for about 1 inch in a transverse direction with a pair of scissors. After this it is a good thing to open the bowels with a. mild purgative, such as $\frac{1}{2}$ ounce of castor oil. On the tenth day the intestine must be completely divided in a transverse direction, and the clip, or whatever has been used to form the spur, removed. Any bowel that projects above the skin should be cut away with scissors. The best control is obtained by an opening in which the mucous membrane meets the skin at the margin of the opening without there being any prolapse. After this a pari should be applied to the wound, and a firm bandage applied over it to push back the gut and get it to retract back flush with the skin. There is often a little bleeding after the gut is divided. This bleeding generally comes from numerous small points, and if attempts are made to sponge away the clots and clip the vessels, they are often not only unsuccessful, but may result in the bleeding being made worse. The best thing to do is to put on a pad of wool, and exert firm pressure with a bandage over the wound. This is all that is usually necessary. Of course, if there is any ressel spurting, it should be canght in a clip, the clip either being left on or the vessel ticd in the ustual way. If the incision is made at right angles to the line of the gut, 
there is seldom any bleeding of moment. When no spur has been formed, it is sometimes not easy to find the gut when it is desired to open it, as it is covered in ly mph, and may be unrecognisable. Under these circumstances an incision must be made with a knife into the centre of the wound, until, by the escape of flatus, it is known that the gut is opened, and then the incision may be enlarged with scissors to the repuired size. The division of the intestine is quite painless and no anzesthetic is required. After the gut has been opened, the colon shonld be well cleared of any accunulated fieces it may contain by suit able purgatives. After this has been done, howerer, it is lest not to make use of purgatives at ali, unless ahsolutely necessary, as they are very liable to set up a sort of diarrhea, and cause soreness of the skin round the wound.

If there are freces in the lower and now useless portion of the colon, they may be washed out by syringing through from the upper opening, or by enemata. In ahout a fortnight from the operation the wound will be sufficiently healed to have a colotomy belt titted. The best sort of belt is that with a celluloid cup fitting over the opening in the intestine, and kept in place by a belt with an indiarubber interval in it where the cup comes. These belts are much more comfortable than those with a plug fitting into the gut, and are quite as efficient in preventing the escape of fæces. The same remarks apply equally to both lumbar and inguinal colotomy.

Colotomy biLts. - These are mainly of two kindsthose with a plug which fits into the opening, and those with a cup which fits over the ends of the gut. The cup is by far the best form. The chief objection to the plug belt or truss is that the presence of the plug in the intestine gives the patient the feeling of a constant desire 


\section{The After-Treatment of Operations}

to evacuate scmething from the opening; it also prevents the establisiment of any sphincter action at the artificial opening. The cup form does not possess any of these disadvantges. It consists of a celluloid cup with buttons on the outer side, and a belt which fits round the patient's body ; the belt is made of indiarubber where it passes over the cup. This holds the cup in place, and insures it being kept well up against the abdominal wall. 


\section{CHAPTER XVII \\ OPERATIONS ON THE JOINTS}

THERE are some features with regard to operations upon joints that require special notice. There are probably no operations in surgery after which sepsis is more dreaded or more prone to occur, if the most rigorous precautions are not talien, than those upon joints. The most scrupulous care is necessary in the dressing and after-treatment of these cases to prevent the possibility of organisms gaining an entrance and setting up sepsis. Again, it is of the utmost importance that the joint should be functional after the operation-that is to say, should be capable of free and painless movement, and, in the case of the leg, able to support the weight of the body-except, of course, in those cases where the joint is hopelessly disorganized, and the operation has been undertaken with the object of obiaining a stiff joint, as in the case of excision of the knee for tubercle.

After the cavity of a joint has been opened, or the synovial membrane interfered with, there is a great liability to the formation of adhesions, which, if they form, may lead to more or less permanent crippling, and will, in any case, result in much pain to the patient. Although these adhesions can often be got rid of satisfactorily later, it is much better surgery to prevent 


\section{$2 t^{\circ}$ The After-Treatment of Operations}

their forming at all. It should therefore be our object to prevent the formation of adhesions by moving the joint slightly each day from the earliest possible date.

After such operations as wiring the patella for fracture and the removal of a fractured or loose semilunar cartilage, movement of the joint should be commenced on the second or third day after the operation. In order to move the joint, the bandages and outer dressings must be removed, and the attendant should then pass his hand (we will assume that he is dealing with the knee-joint) under the knee, and gently raise it off the back splint (if one has been used), while with the other hand he holds the dressings in place, and supports the wound by firm pressure, so that no tension is put upon the slin in the neighbourhood of the wound. On the first occasion the joint should only be moved slightly two or three times, the knee being gently raised, and then allowed to assume its original position by its own weight. At the same time the patella should be moved from side to side, so as to prevent the formation of adhesions between it and the anterior surface of the femur.

This must be repeated each day, and after two or three days the patient should be made to move the joint for himself, the attendant at most only steadying the limb and dressings. The joint at this period should be moved through a much larger angle than at first. It is better not to use a splint in these cases, but if one has been used it should be dispensed with as soon as possible. At the end of ten days, when the wound should have healed, the stitches can be removed, and a dressing of collodion and gauze applied in such a way as to hold together the edges of the wound and so support the scar, and prevent its being stretched during morement of the joint. 
The patient should now be encouraged to move the joint as much as possible, and a very good plan in the case of the knee is to let the patient sit on the edge of the bed with the leg hanging over the edge, and the foot resting on a stool of appropriate height; he must then raise the foot off the stool by extending the knee, and then slowly lower it back again on to the stool; this should be repeated for fifteen minutes twice a day. At this period massage to the muscles moving the joint (in this case those of the leg and thigh) is very beneficial, both in keeping up the tone and development of the muscles and in getting rid of any adhesions that may have formed. The scar should be moved from side to side on the deeper tissues each day to prevent it from becoming adherent to the bone, which otherwise is very likely to take place and be the cause of pain later on. After the removal of a loose semilunar cartilage from the knee there is often a tendency for the scar to become adherent to the inner condyle of the tibia, and if this is allowed to take place a considerable amount of pain and disability may result.

After the operation for loose semilunar cartilage or fractured patella, the patient may usually be allowed to walk as soon as ever the wound has healed. It is not advisable for the patient to wear any sort of support to the knee as it tends to limit movement and prevent the proper development of the muscles supporting the joint, on the integrity of which the subsequent stability or otherwise of the joint mainly depends.

\section{Excision of the Elbow.}

After excision of the elbow-joint our object is to form a 'false joint,' and therefore movement must be com. 


\section{The After-Treatment of Operations}

menced early. The best plan is to fix the arm in a metal outsicle splint with a joint opposite the elbow and with a thumb-screw, so that the splint can be fixed at any desired angle at will, or by loosening which the splint can be made to move with the arm. Each day the thumb-screw can be loosened and the joint moved without removing the splint; the splint must, however, be renloved from time to time, so as to allow of movements of pronation and supination being carried out. In these movcments, while the wrist is being rotated the surgeon must fix the ulna, to insure the movements taking place correctly. At first the joint should be only slightly moved, commencing about a week or ten days after the operation, and all movements must be very gentle. As the wound heals the movements should be extended until they are free in all normal directions. The hand should be left free from the first, and the patient encouraged to use the fingers and wrist freely.

As soon as ever the parts are sufficiently firm to allow of it, the splint should be left off and the patient made to use the limb; the arm can be kept in a sling for part of the day at first, and a sling should be used as a protection against injury while out of doors for some months. Later on, when the parts have thoroughly consolidated, massage and regular exercises in a gymnasium are very useful in getting back power and free movement in the arm.

It will probably be several months before real stability of the new joint is obtained, but in favourable cases the patient should at the end of three or four months be able to use the limb for all ordinary purposes. Special care must be taken to see that the patient is able to get the hand up to the back of the head, as this is often difficult at first, and later on the patient will find it no trifling 


\section{Operations on the Joints}

inconvenience not to be able to get his hand up to the back of his neck for the purpose of doing up a collarstud, etc.

\section{Excision of the Shoulder.}

After excision of the shoulder movement should be commenced early and carried out in the same way as in the case of the elbow, but it is particularly important to insure the movements taking place between the humerus and the scapula, and not between the scapula and the trunk. The surgeon should fix the scapula by holding the angle firmly with his fingers, and then move the arm or instruct the patient to do so for himself; if this precaution is not taken, the movements, and especially that of abduction, are almost certain to take place between the scapula and the trunk instead of at the shoulder. joint.

The success or otherwise of most operations on the joints depends to such a large extent upon the care with which the movements are carried out during the aftertreatment, that too much care and patience cannot be expended upon them; and in the case of children, who form the largest percentage of the patients, much patience and perseverance is often necessary in order to obtain the desired result. A certain amount of pain is generally caused by the movements at first; and if this is sufficiently severe to warrant it, an anæsthetic may be given occasionally to insure that free movement is obtained.

\section{Excision of the Knee.}

Here, in contradistinction to the case of the arm, our object is to obtain bony ankylosis, and a properly fitting splint which will not allow the bones to get out of 


\section{The After-Treatment of Operations}

position is of the greatest importance. For this purpose there is probably no better splint than Howe's splint, though any form of well-fitting interrupted splint will do. There is often a considerable amount of pain after all excisions, and, in fact, after all operations involving the cutting of bone. Morphia must be given for its relief, and in the case of young children, to whom it is not advisable to give morphia, a few drops of laudanum, varying according to the age of the patient, should be given in a glass of water. Raising the limb, and especially slinging it well up in a cradle, if the splint will allow of this, often relieves the pain to some extent. It ought not to be necessary to change the dressing for a fortnight after the operation, and then it is often advisable to administer an anæsthetic for the first dressing. This also enables the surgeon to thoroughly examine the wound, and if any recurrent foci are found, to deal with them. At the end of six weeks to two months a wellfitting leather splint, strengthened up the back of the knee with a metal bar, should be substituted for the splint previously used, and the patient can then be got up. In about three months from the operation the patient can usually be allowed to walk, but the splint should be worn for at least a year, and in the case of children for two or three years. In children there is a great tendency for flexion of the knee to take place, and although this can often be prevented by the prolonged use of splints, it cannot always be so prevented, as it is due to the unequal growth of the epiphysis, and in these cases a subsequent partial resection is necessary later on to remedy the deformity. 


\section{Excision of the Hip.}

After excision of the hip-joint the two most important points that have to be attended to are: (I) To prevent external rotation of the lower fragment; (2) to prevent flexion of the hip-joint. In fact, the case has to be treated in very much the same way as for fracture of the neck of the femur.

It is generally advisable to apply an extension by weight and pulley to the foot of the affected limb. The extension strapping should always be carried above the linee, and in children it is better to affix longitudinal pieces of strapping up the sides of the limb and to bandage over these with an ordinary bandage, afterwards applying circular strips of strapping in two or three places so as to prevent its coming undone. The upper ends of the side-pieces should be turned down on themselves, and fixed with strapping so as to prevent their drawing through. This is much less irritating to the delicate skin of a child than applying strapping all the way up the limb. A long Liston or Dessault's splint should be applied from the axilla to the ankle, so as to prevent flexion at the hip. In young children it is better to use a Phelps's box-splint or a double Thomas's splint. If a long splint is applied it must not be put on so tightly as to interfere with the extension. The body should be steadied by passing a sheet across the trunk and holding it in position with sand-bags on each side of the body, the sand-bags being rolled up in the sheet on each side. To prevent rotation of the limb a cross-bar should be attached to the long splint just above the ankle, or a very good plan is to fix a flat piece of wood at right angles across the back of the knee with plaster of Paris bandages. In some cases the linb can be kept rrom 


\section{The After-Treatment of Operations}

rotating by the use of a sand-bag placed on each side of the thigh.

The limb after excision should be fixed in a position of slight abduction, as this enables the patient later on to overcome the shortening of the limb, which of necessity follows excision by tilting the pelvis down on the affected side. It is often possible to obtain a more or less movable false joint after excision of the hip by moving the joint two or three times each week after the wound has healed.

At the end of five or six weeks a Thomas's hip-splint, if it has not been used from the first, may be fitted, and the patient can then be got out of bed. No weight, however, should be borne on the limb for several months even with the splint on. If the child is old enough be may be allowed to get about with crutches and a patten on the boot of the sound leg. In young children it is better to fit a double Thomas's hip-splint with a pelvic band. After the Thomas's splint has been fitted, the patient should be got out of doors for several hours daily if possible. Some surgeons prefer to use a splint of plaster of Paris or leather, which encircles the pelvis and comes down below the knee. The use of removable splints is, however, always preferable to the use of fixed splints; when a Thomas's splint, however, fails to keep the limb in good position, a properly-fitting leather splint may be tried.

Regular massage of the muscles is of the greatest benefit in preventing wasting and in maintaining the proper nutrition of the limb after excision of the hip when the circumstances of the patient will allow of its being carried out. All the muscles of the limb should be massaged regularly two or three times a week throughout the treatment if possible, and when a false 
joint is desired suitable movements may be combined with it.

The after-treatment of osteotomy undertaken for the relief of deformity, as in the case of coxa vara or genu valgum, is practically the same as the treatment of a fracture of the bone in this sitnation. Special care should he taken to see that the movements of the joint in the vicinity of the operation are maintained during the period of rest necessary for the consolidation of the wone.

\section{Massage.}

Massage is of the sreatest value after many operations in bringing the muscles back to their normal condition of tone, etc. Massage does not talie the place of active exercise, either in developing the muscles or in improving the general circulation, but it gives us a most valuable means of passing from the condition of complete rest to that of ordinary activity without the trinsition being too sudden. It also acts as a very good substitute for exercise when rest is necessary. In cases of long and exhausting illness following operations, when the patient is obliged to remain in the recumbent position for many weeks or months, general massage is of great value; it promotes absorption and secretion, lieeps the skin acting properly, and often enables the patient to sleep naturally, besides very considerably diminishing the period of subsequent convalescence.

Massage must be commenced gently at first; the time occupied and the force used may be increased as the patient becomes accustomed to the treatment. Exhaustion nust never be produced. Massage should always be accompanied by passive or, if posible, active move- 


\section{The After-Treatment of Operations}

ments of the joints and respiratory exercises. Ten minutes a day is probably enough at first, and this time can be increased up to half an hour or an hour. When possible the massage should be carried out by a properly trained masseur; if this is not possible the nurse or some intelligent relation of the patient may be instructed in the treatment. There are several varieties of massage :

EFfleurage, or Rubbing.-This consists in stroking and rolling the skin and underlying muscles with the hand, in a direction towards the trunk-i.e., in the direction of the venous circulation. It must be commenced lightly and gradually increased in strength, the hand of the operator being made to grasp the muscles more and more firmly.

Petrissage, or Kneading.-This consists in kneading and squeezing the muscles between the thumb and fingers and the edge of the hand. It has for its object the increase in the flow of blood and lymph through the muscles towards the heart.

Friction.-This is practised by firmly rubbing the skin in a direction towards the heart with the closed fists or finger-tips.

TAPOTEMENT. - This consists of rapid blows delivered at right angles to the surface with the edges of the two hands (the ulna border). This method of massage stimulates the muscle and causes local contractions. It is one of the more vigorous methods of massage, and must not be used when dealing with damaged tissues or weakly subjects.

\section{Exercises.}

The use of appropriate exercises after some operations, especially those which affect joints, is of considerable importance. The great point in dealing with injured 


\section{Operations on the Joints}

joints or muscles is to persuade them to move rather than to compel them to do so. Thus the patient, supposing that he is able to move the injured joint within a certain angle, should exercise it by moving it within that angle, and should try each time to increase the range of movement. To assist the patient in this, the best apparatus is a cord running through a pulley, to one end of which a weight is attached, and to the other a suitable handle; the patient should then use the apparatus in such a way that the weight assists the movement instead of hindering it. For instance, in the case of a more or less stiff knee, the cord from the pulley should be attached to the ankle in such a way that the weight will assist flexion. 


\section{CHAPTER YYIII}

\section{THE AFTER-TREATMENT OF AMPUTATIONS, AND SOIME SPECIAL OPERATIONS}

\section{After-Treatment of Amputations.}

Complications.-(1) Shock; (2) hamorrhage ; (3) pain ; (4) adherent cicatrix; (5) conical stump; (6) persistent sinus.

After the operation the stump should be elevated as much as possible and steadied with sand-bags, as spasm of the muscles is very apt to take place, and this will tend to displace the dressings; this spasm of the muscles can be relieved to some extent by applying a very hot rubber water-bottle to the outside of the bandages, and by the use of morphia injections. As a rule, the dressings require changing on the day following the operation, as there is generally a considerable amount of oozing during the first twenty-four hours; the drainage-tube should be remored as soon as ever the amount of oozing is sufficiently diminished to warrant it. A kind of dark-brown discharge, which probally comes from the end of the bone, not infrequently persists for a considerable time in unhealthy individuals, and in these cases the drainagetube must be retained longer.

After the wound has almost healed and the stitches have been removed, it is advisable in many cases to apply 


\section{The After-Trcatment of Amputations 251}

some sort of support to the flaps to prevent stretching of the scar, and to hasten healing and consolidation of the end of the stump. This is particularly the case when a large muscle flap has been formed, as in Farabouf's amputation of the leg, Teal's amputation, and nost amputations through the thigh.

The edges of the flaps should be drawn together by large broad pieces of strapping; the tissues of the stump being well drawn down over the bone before the free

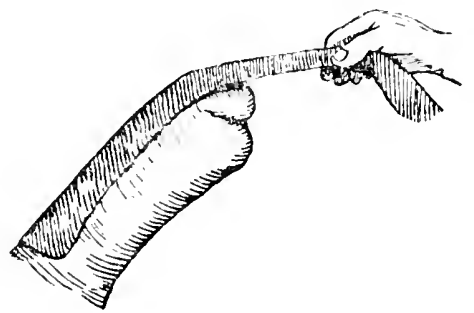

Fig. 34.-Method of applying Strapping to the Stump.

end of the piece of strapping is fixed. The stump must next be bandaged from above down - that is, towards the extremity, so as to draw down and support the muscles, and prevent them from pulling the skin and tissues tight over the end of the bone. A linen bag made to fit the stump like a sock should then be placed over all, and fixed by tapes round the waist or joint above the amputation. If no such bag is obtainable an ordinary stump-bandage may be applied. An excellent description of the methods of bandaging stumps after amputation will be found in 'A Manual of Surgical Treatment,' by Cheyne and Burghard.

Pain.-The pain after amputations is usually of a neuralgic type, and is probably due to the contraction of the scar tissue at the ends of the nerves, which have been 


\section{The After-Treatment of Operations}

cut; these attacks of neuralgic or starting pains often persist for several months after an amputation, and then gradually cease. At first they often cause the patient considerable distress, but this varies very much in different individuals. Hot-water bottles or hot stupes applied over the main nerves above the stump will often relieve the pain; thus in the case of the leg the heat should be applied over the sacral region or upper part of the back of the thigh, and in the arm over the clavicle and scapula.

Adherent Cicatrix. - This is a most troublesome condition, and should be prevented by gently moving the scar on the deep tissues daily after the wound has healed; the patient can easily do this for himself. If the cicatrix is allowed to become adherent, it is often the cause of constant pain and tenderness at the end of the stump, and not infrequently results in chronic and intractable ulceration of the scar later on. Should the cicatrix become adherent, an attempt may be made by gentle massage to loosen it from the bone; and if this is ineffectual, the scar must be loosened by cutting it away from the bone with a tenatome, and then moving it frequently to prevent it again becoming adherent.

Conical stump is generally the result of a faulty operation, but in children is liable to occur, however carefully the amputation has been planned. This is due to the growth of the bone, the latter tending to grow through the end of the stump. It may be to a large extent prevented by massage, the stump being massaged towards the end, and not towards the body, care being taken at the same time to prevent the scar from becoming adherent; or the stump can be bandaged in the way already mentioned to draw down the muscles.

Persistent simus after amputation is generally due to 


\section{The After-Treatment of Amputations 253}

some deep stitch or ligature acting as a foreign body, or to a piece of necrosed bone; in either case the cause must be sought for and removed.

As soon as the wound has thoroughly healed, which will usually be about a month after the operation, the patient should be measured for an artificial limb. In the leg (with the exception of Syme's and Stephen Smith's amputations), with but few exceptions, patients are never able to hear any weight on the end of the stump, nor is it advisable that they should do so; the weight is taken on the pelvis from the upper end of the socket, and the end of the stump should not come into contact with the end of the socket, but should be free except for contact with the sides. In a below-knee amputation the weight is taken on the sides of the head of the tibia and on the condyles of the femur.

No bad effects to the stump need be anticipated from fitting an artificial limb at an early date. There is another objection that is commonly brought forward against having an artificial limb fitted at an early date, namely, that so much contraction of the stump takes place after an amputation that the fit of the socket soon becomes loose, necessitating a new limb. This is not the case. It is true that a good deal of contraction does occur and renders the fit loose; but this will take place however long a period is allowed to elapse before fitting the limb, as a considerable amount of the fat in the stump disappears after the limb has been worn for a short time, and this makes the socket fit loosely. On the other hand, it is most important if the patient wishes to use the artificial limb with success that he should commence to use it before the muscles moving the stump have had time to waste and form adhesions. In order that the patient may obtain the best results 


\section{The After-Treatment of Operations}

from the use of an artificial limb, the muscies acting upon the stump will have to be trained to their new function; and if they have been allowed to waste to any considerable extent very great difficulty will be experienced in getting these muscles to fulfil their new function. The result will be that many patients will give up the attempt in despair, and remain more or less hopeless cripples for the rest of their lives. This is a most important point, especially in old people, who often have neither the pluck nor the adaptable musculature of youth.

A very considerable time is usually necessary before a patient can become accustomed to the use of an artificial limb, and especially is this the case with the leg, where the weight of the body has to be borne. New centres of equilibrium have to be developed in the brain and spinal cord, muscles have to take on unaccustomed functions, and parts previously free from pressure have to bear very considerable pressure without causing pain or becoming sore. Much pluck and perseverance will be required to attain these ends, and it is of primary importance that such a serious check as wasted muscles should not be added to the other difficulties. Should the stump shrink much after the limb has been worn for some time--as is usually the case-it can easily be remedied by having the inside of the socket built lip with cork or other suitable material.

A very close fit is not necessary in an artificial leg, and in the case of an arm a close fit can be secured by means of lacing. When the artificial limb is first worn, all bandages must be dispensed with, and if it is necessary to support the scar, a collodion dressing can be used. A woollen sock or socks should be worn over the stump, to prevent the slin from being chafed by contact with the socket. 


\section{Artificial Limbs.}

Artificial Hand or ArM.-No artificial hand can be fitted unless the amputation is at or above the wrist; however, two or even one finger or stumps of fingers are of more use to the patient than the best artificial hand that has ever been inverted. For an amputation in the middle of the forearm the limb is made with a wooden socket coning up to the elbow, into which the stump fits (Fig. 35); there is a broad leather strap round the lower part of the upper arm, which is attached to the socket by hinges. The grasp of the artificial hand is obtained by means of a cord attached to a belt round the opposite shoulder; a very slight movement of the shoulders is

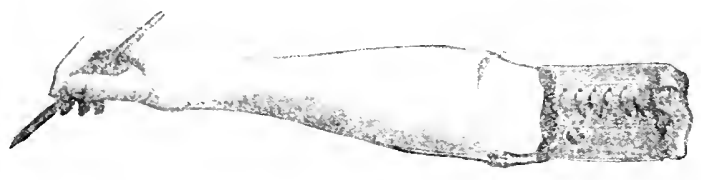

Fig. 35 .

sufficient to open the hand, and by relaxing the pull on the strap the hand closes by means of a spring. After the patient has become accustomed to using the apparatus a great deal of use can be made of it.

For an amputation above the elbow the socket is made to come up over the shoulder, and is fixed in place by a strap round the body (Fig. 36); a cord is used in the same way as in a below-elbow limb for obtaining the hand movement, and another cord passing behind the shoulder is used for obtaining movement at the elbow. Most of the friction comes upon the sides of the stump, and not upon the end, so that a circular method of amputation is particularly well suited to arm amputations. The im- 


\section{The After-Treatment of Operations}

portant points about an artificial arm are lightness, simplicity, and a good fit.

To Measure for an Artificial Arm.-Stump: length from top of shoulder to end, length from point of axilla to end, circumference every 2 inches. Sound arm: length from top of shoulder to base of fingers (the arm being in the extended position), length from point of axilla to

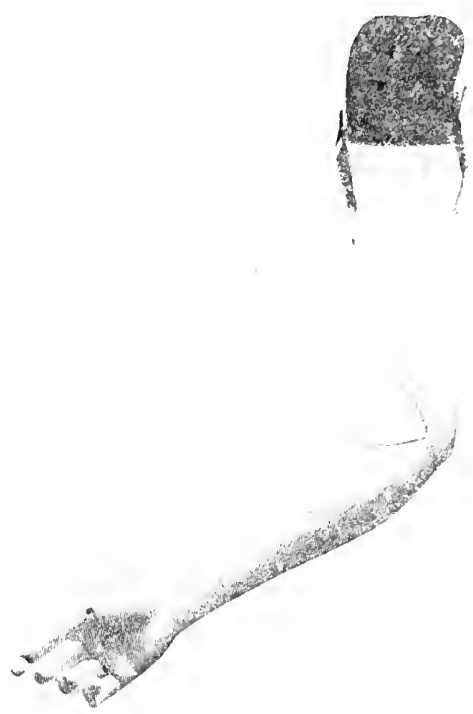

FIG. 36.

elbow, and from elbow to wrist, also circumference every 2 inches. If a below-elbow amputation, measure also from elbow to end of stump. It is much better for the instrument maker to take the measurements himself when possible.

Artificial Legs.-It is practically impossible to fit any appliance that will act satisfactorily to any amputa- 


\section{The After-Treatment of Amputations 257}

tion of the foot short of a Syme's. Such amputations as Chopart's and Lisfranc's make very minatisfactory stumps as a general rule; this is che to the lever formed by the normal foot being destroyed. No artificial appliance can take its place, as there is very little space to work in, and the tapering shape of the stump nualies it impossible to get any purchase for the artificial foot. The best appliance for such stumps is a boot into which a piece of cork has been fitted, to fill up the vacant space left by the removal of part of the foot. Ifter a Syme's amputation a very iseful artificial foot can be fitted (Fig. 37); the shortening of the limb resulting from the operation is generally ahout $2 \frac{1}{2}$ inches, which allows room for an artificial ankle-joint to be placed below the end of the stump. A halfsocket is made, so as to fit up the calf of the leg and prevent the foot from turning forward; this socket is held in place by cross-straps over the shin; the weight is talien on the end of the stump. A Pirogoff stump

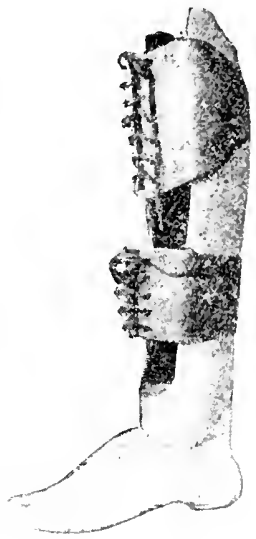

FIG. 37 . is not so satisfactory as a Syme, as the shortening of the limb afterwards is only about I to $I \frac{1}{2}$ inches, and this does not allow room for a joint below the end of the stump. The joint has in this case to be fitted outside, and this causes a very unsightly widening of the ankle.

For amputations below the knee a socket is made in to which the stump fits. The weight is taken on the sides of the stump and on the head of the tibia; the end of the stump should not take any of the weight (at first. at any 


\section{The After-Treatment of Operations}

rate). The limb is held in place by a short leather socket fitted round the lower part of the thigh and tightened by lacing up the front; this leather socket is attached to the woodell one by side steel hinges (Fig. 38). This form of artificial leg works very well when the stump below the knee is not too short; if the

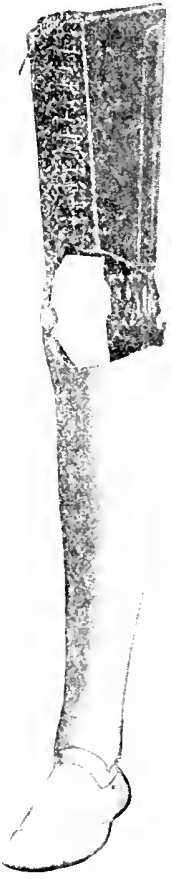

FIG. 38. stump is short flexion is very liable to occur, and render the wearing of an artificial leg impossible; also the short stump does not obtain sufficient purchase on the artificial leg to enable the patient to control it. The so-called seat of election probably represents the very worst place that it is possible to remove the leg, if it is desired that the patient should subsequently use an artificial limb.

After amputation through the knee-joint the weight can be taken on the end of the stump, the limb being fixed in place by a leather socket fastened round the thigh by lacing. Unfortunately, chafing and soreness of the end of the stump are rather liable to occur, and as almost the whole of the weight must of necessity be taken on the end of the stump, this may prove very troublesome; careful attention to the fit of the limb will do much to get over this difficulty. Special attention should be paid towards the prevention of any lateral play in the socket.

For amputations above the knee, the weight is taken on the pelvis-in fact, the patient may be said to be sitting on the top of the socliet; it is therefore very important that the upper end of the socket should fit accurately 


\section{The After-Treatment of Amputations 259}

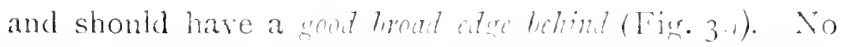
weight should, as a rule, we taken on the end of the stump, and the latter should nut come down to the end of the sockict.

The limb can be held in place either by nucans of a shoulder-strap or by a broad helt round the waist: the beli has a ruming cord and pulleys, one end of the cord leing attached to the lar is of the $\lim l$ socket with a flat elastio: strap, and the other attached to the front by an adjustalile strap. The belt is by far the lucter method of attaching the limh.

In having a suitable instrument fitted to a lower limb stump it is important to see that the artificial leg is strongly made, as the weight that it will have to bear is considerable (in fact, the whole weight of the body), and in many positions of the limb this weight will be acting at great mechanical adrantage; but, at the same time, if the moring parts, and especially the foot, are too heavy the limb will not more quickly enough for easy prorression, and will tend to act like a pendulum. The fixed parts of an artificial limb-that is to say, the socket-

FIG. 3y.

can be made heary without any disadrantase; but it is of the utmost importance that the moving parts should be light, otherwise a most unsightly gait will be the result. 


\section{The After-Treatment of Operations}

In the better class of artificial limbs sheepskin is shrunk on to the surface of the wood; this prevents it splitting, and enables the limb to be made very light while maintaining considerable textile strength.

The important things to notice in examining the fit of an artificial limb are to see that the pressure is distributed over a large area, and does not come principally on one or two points, and to see that at first no pressure comes on the end of the stump, with the exception of a Syme's and knee-stump.

How' to Measure for an Artificial Leg.-Length from perineum to floor (when the patient is standing), length from lower edge of patella to end of stump, and on the sound side from same point to floor. If for an aboveknee amputation, length from perineum to end of stump, and on sound side from same point to lower edge of patella; circumference of thigh at base on both sides and every 2 inches all the way down. Then, with the patient sitting, and the knee on the sound side bent at right angles, measure from the back of the linee to the ground and from the top of the knee to the ground. It is much better for the instrument maker to make his own measurements, but when this is impossible, the above vill generally prove sufficient. Outlines of the stump drawn on paper placed against the limb should also be sent, and the size of boot should be stated or an old boot sent.

\section{After-Treatment of some Special Operations : Varicose Veins.}

Complications.-(I) Gaping of the wound after the removal of the stitches; (2) sloughing of some portions of the skin edges ; (3) cedema of the leg.

After the operation the limb should be elevated, either 


\section{After-Treatment of Special Operations 26 I}

by supporting the splint on cushions, or by slinging it in a suitable cradle. There is no occasion to change the dressings for ten days or a fortnight after the operation, but it is as well to examine them from time to tinte to ascertain that they have not slipped, and to see that they are not constricting the limb above. $\Lambda$ fter the stitches have been removed, the edges of the wound should be drawn together with strips of strapping, and the wound itself powdered with boracic powder, and then the leg should be bandaged, from the foot up, with a Domet or flannel bandage. As a rule, it is not advisable for the patient to be allowed to walk for quite three weeks after the operation, as the wound after these operations on the veins heals very slowly. In many cases, when the condition of the veins before the operation was bad, it is best to order an elastic stocking to be worn for six months afterwards. The elastic stocking must not, however, be brought above the linee. Or an excellent substitute for an elastic stocking, and one which is cleaner if the patient is intelligent enough to apply it properly, in an elastic or Velpeau bandage.

Gaping of the wound when the stitches are removed cannot always be prevented, though it is often due to the edge becoming turned in when the wound is being sewn up. The edges should be brought together as accurately as possible, and held in position with small pieces of strapping.

Sometimes the edges of the wound are so thin and so badly nourished that sloughing occurs. This considerably delays the healing, and it is best, if possille, to keep the patient in the recumbent position for some time longer, or else to prevent movement of the slin by the application of strapping.

Some cedema of the leg is not uncommon after 


\section{The After-Treatment of Operations}

operations on the reins, and especially when the patient is first allowed to get up. Careful bandaring, from the foot up to the linee, is all that is required to prevent this.

\section{Laminectomy.}

Complications.- (I) Chest troubles; (2) distension of the abdomen ; (3) diarrhcea; $(t)$ bed-sore.

As most of the patients on whom laminectomy has been performed are paralyzed, the greatest care is necessary in the after-treatment, and the most skilled nursing is a necessity. If the intercostal muscles are paralyzed, and the respirations are being carried out by the diaphragm only, chest trouble, usually in the form of moist bronchitis, is very liable to occur. Coughing is, under these circumstances, impossible, and the patient is in great danger of being unable to breathe, owing to the mucus in the lungs obstructing respiration. When this is the case, an attempt may be made to dry up the secretion by the use of drugs, such as beliadonna and morphia, and the patient should be tumed on to the side, so as to clear one lung. Expectorants must, of course, on no account be given. When the cause of the paralysis is high up in the cord, distension of the abdomen often prores extremely troublesome. The best way of treating this is by the use of the rectal tube, after clearing the lower bowel with enemati. If, as is often the case, this does not prove sufficient, direct pressure on the abdomen while the tube is in place may be tried. The pressure can either be applied directly with the hands, or by passing a towel round the abdomen and splitting the ends of the towel, the ends being then passed through each other, and pulled upon from opposite sides in such a way as to compress the 


\section{After-Treatment of Special Operations 263}

abdomen. In any case, the pressure shoutd only be exerted during expiration, as otherwise it may so embarrass the respiration as to prevent the patient from breathing. Even atter a successful laminectomy the paralysis seldom passes off for some considerable time, and recovery is usualiy an extremely slow process. The condition of the muscles should be liept up, as far as possible, by the use of massage and galvanism throughout the after-treatment.

There is, of course, in all these cases of paralysis, a great liability to bed-sore and cystitis. The greatest care and attention are necessary to prevent these complications. 


\section{A P P E N D I X}

\section{Rectal Feeding.}

THIs may be either by means of rectal suppositories or by enemata. Rectal suppositories have become very popular of late on account of the ease with which they can be administered and retained; but owing to the comparatively small amount of material contained in them, a very large number would have to be given in order to talie the place of feeding by the mouth and maintain the patient's weight. A combination of both methods of rectal feeding is probably the best in most cases. If suppositories are used, alternate ones of meat and milli should be introduced every two hours. A little vaseline is smeared on the suppository, and then it is pushed well up the rectum above the internal sphincter. A soap-andwater enema must be given to clear the rectum once a day.

When enemata are used the lower bowel must be well cleared with a copious warm-water enema administered half an hour before the nutrient. The patient should lie on the left side near the edge of the bed, and have the buttocks raised slightly; a No. Io or I2 soft Jacque's catheter should be passed well up into the rectum, a little vaseline or glycerine being first smeared on it to facilitate introduction; a glass funnel is then attached to the free end of the catheter, and the nutrient enema allowed to flow in slowly. If it is allowed to flow in too quickly there will be difficulty in getting the patient to retain it. After the enema the patient should lie quiet without moving for about an hour. 


\section{Appendix}

The quantity of the enema should be from about 5 to 7 ounces of fluid. If there is difficulty in getting the enema retained, the addition of a little claret or burgundy will often prove effectual, or to minims of tinct. opii can be added to the enema. All nutrient enemata should be digested before being used either with Benger's liquor pancreaticus or any of the numerous other peptonizing materials. It has been shown that the addition of common salt to egg-albumin renders it capable of absorption by the rectal wall as readily as peptonizing it would do, and it has not the disadrantage of being irritating, as is the case with most of the fluid peptones. All nutrient enemata should be used at body temperature.

The ease with which the different food-stuffs are absorbed by the rectum varies greatly. Milk is very extensively used as a medium for enemata, although its proteids are not well absorbed by the rectal wall; eggalbumin is well absorbed if combined with a certain amount of common salt. Raw-beef juice is probably the best absorbed of any of the proteid-yielding foods. Sugar is well absorbed, but has the objection that it is very irritating to the rectal mucous membrane, and consequently is not well retained; it should only be used in dilute solutions. Raw starch is very easily absorbed, and has not the same objection as sugar; fats are very slightly absorbed, and are practically useless for rectal alimentation.

The following enemata are easily absorbed, and can be recommended:

(I) White of three eggs.

Milk, 4 ounces.

Starch (raw), I ounce.

Salt, $\frac{1}{2}$ ounce.
(2) Ox serum, 5 ounces.

Milk, 2 ounces.

Starch, 6 ounces.

(3) Grape sugar, 60 grammes.

Milk, 250 c.c.

One of the above enemata should be administered every six hours.

The following nutrient enema is highly recommended by Ewald: Two tablespoonfuls of wheat-flour are stirred up with I 50 c.c. of lukewarm water or milk. To this one or two eggs and a pinch of salt are added, and the 


\section{The After-Treatment of Operations}

whole is beaten up with 50 c.c. of a 5 per cent. solution of grape-sugar. A little claret may be added.

If no fluids are being administered by the mouth, a large warm-water enema must be given once or twice daily to supply the proper complement of fluid.

\section{Nasal Feeding.}

This is most commonly used in children when forced feeding is necessary, and also after certain operations on the mouth, when it is desirable not to allow mastication or swallowing. It is also sometimes necessary after tracheotomy and certain operations on the larynx to prevent food getting into the air-passages. The child should be placed lying down on its back, and an assistant should he at hand to hold the head. A soft rubber catheter, No. + or 6 (according to the age and size of the child), is then passed along the floor of the nose until it reaches the posterior pharyngeal wall, and then it must be pressed steadily on until the stomach is reached; a funnel is attached to the end of the catheter, and a fluid feed allowed to run in slowly, the amount introduced being, of course, the same as would be given by the mouth.

\section{Subcutaneous Feeding.}

This is not a very common method of feeding, but is one that in certain cases may prove useful. As an accessory to rectal feeding, it may prove very useful in cases where a patient is failing rapilly from want of nourish. ment; and in cases where the patient cannot swallow and the rectum has become irritable and will not retain nutrient enemata it can he used for a few days till the rectum has had time to recover. Patients have been kept alive for many days without losing weight by this method of feeding alone. The food used must be able to he sterilized, and must be of such a nature that it needs no digestion. A 10 per cent. solution of grape-sugar can be used, but is very apt to set up irritation at the site of injection. Sterilized olive oil seems to give the best results: 30 to to c.c. of sterilized olive oil should be 


\section{Appendix}

injected into the subcutaneons cellutar tissue of the groin with a sterilized glass syringe. The ofit should be injected slowly, and it is best not to inject it all in one place, but to inject the 30 c.c. in two or three cifferent places. The injection should only be done once a cay. and the part should be massaged after the injection io promote absorption.

The following is recommended by Freidrick for use as a subcutancons foed:

$\begin{array}{llllll}\text { Sodium chloncle } & : & - & - & - & 02 \\ \text { Grape-sugir } & : & - & - & - & 3.5 \\ \text { Peptone : } & : & - & - & - & 07 \\ \text { Water } & - & - & - & - \text { to } & \text { ICo }\end{array}$

It should, of course, be sterilized by boiling before injection.

\section{Diets.}

Ment.-Raw meat is a most useful diet after many operations when the puwers of digestion are impaired. The ease with which raw meat is dicested, and the small amount of residue which it leaves behind after digestion, makes it a diet of the greatest value in affections of the alimentary tract. The best way of preparing raw meat is to scrape the filires away from the connective tissue with the back of a knife; the pulp thus obtained can be mixed with a small quantity of ordinary beffea, and flavoured with celery salt of other suitable flavouring. As a rule, it is wise not to tell the patients that they are being fed with raw meat, as some people dislike the idea. Of course, it is most important to insure that the meat comes from a reliable source and is quite fresh. Meat extracts, such as leef-ter, etc., are of 110 value as foods, and but inferior stimulants; moreover, they are very liable to set up diarrhoik. In order that such extracts as beeftea, borril, Liebig, etc., may he made use of as fuods, they would hare to be alministered in the concentrated form by the ounce or more many imes a day.

Milk.-Milk leares a larger residue in the intestine than most other liquid foods, and is very liable to undergo fermentation and give rise to the formation of large 


\section{8 'The After-Treatment of Operations}

quantities of gas in the intestinal tract, a most unfortunate circumstance after abdominal operations.

Of all fluid diets milk has probably always been the most popular, though the reason for this is in some ways a little difficult to understand. It must be remembered that milk is not a fluid after it has been swallowed, but that within a quarter of an hour of its having entered the stomach it sets into a tough leathery clot, which may offer very considerable resistance to the digestive action of the stomach. Milk remains a considerable time in the stomach in a semi-solid state; it would therefore seem to be contra-indicated in all operations on the stomach. There are several ways, however, in which the clotting of milk can be altogether prevented, or can be rendered much less dense and resistant than normally. Thus, simple dilution with water will make the clot less dense and more easily digested. A better way, however, is to dilute the milk with lime-water in the proportion of I part of lime-water to 2 of milk; this greatly reduces the density of the clot. The addition of soda-water to the milk, or the simple aeration of it by means of a 'sparklet,' will render the clot much more readily digestible. Boiled milk, though outside the stomach it clots less easily than raw milk, in the stomach clots just as readily and into just as tough a mass as raw milk. With regard to the ease and completeness with which milk is absorbed by the intestine, it has been shown that when milk is given entirely by itself it is absorbed worse than any other animal food. Under the most favourable conditions only about 90 per cent. of the available potential energy ever reaches the blood, the remainder leaving the body as waste. Children, however, seem to be able to absorb milli very much better than adults.

Milk, though rich in proteids and fats, does not contain enough carbohydrates to make it an ideal diet; it is therefore better to combine it with some other diet, such as in bread and milk, and gruel, or to add sufficient sugar to it to raise the proportion of carbohydrates to the proper extent. It is, however, a very valuable diet in many cases after operations. It is easily digested with but little expenditure of energy, and although it leaves a 


\section{Appendix}

comparatively large residue, it does not cause much peristalsis of the intestine. The larese amount of phosphates contained in milk renders it valuable as a diet in cases where there is much bone formation soing on, as after excisions, etc.

Koumiss.-This is a preparation of mill of great vahe in cases of wasting disease. It is much more readily digested and absorbed than ordinary milk, and thus allows of very large quantities of nourishment being given to patients whose digestive functions are not working properly, and who would therefore be unable to assimilate such a large amount of nutriment in other forms. Koumiss is prepared from mare's milk by fermentation, and contains about 2 per cent. of alcohol. One of its great advantages as a diet is that the casein is in such a state that it cannot form into clots in the stomach, and is already partly digested. The alcohol and carbonic acid which it contains are of value in assisting its digestion in the intestine.

KEPHIR, which is a similar preparation made from cow's milk, is almost as valuable as koumiss, and is easily obtainable in England. The leading dairy companies now supply both koumiss and kephir at reasonable prices.

EGGs.-Eggs are very well absorbed by the intestine, and leave a very small residue. Eggs are much more rapidly digested than milk: I pint of milk remains three and a half hours in the stomach; two lightly. boiled eggs remain one and three-quarter hours in the stomach. The food value of one egg equals $\frac{1}{2}$ pint of milk. Twenty eggs would be required to supply all the proteid material required by a healthy individual in twenty-four hours.

To prepare Egr-albumin.-Beat up the white of four fresh eggs in $\frac{1}{2}$ pint of water until the whole is thoroughly mixed, then add lemon and sugar to taste, or, if preferred, salt or celery salt may be added instead.

Plasmon, which is very similar to egg-albumin, and has the advantage of being cheaper, is prepared as follows :

Add three tablespoonfuls of tepid water to three teaspoonfuls of plasmon, stir, and rub into a paste: then add 


\section{The After-Treatment of Operations}

gradually $\frac{1}{2}$ pint of tepid water, place on the fire, bring to the boil, stirring well all the time, and boil for two minutes. This can now be added to mill or other liquid beverage. When cold the dissolved plasmon will form into a jelly, which when whisked will turn into a thick cream. The jelly or cream can be added to food, or by the addition of water can be made into a beverage and flavoured to taste.

All the casein preparations, such as plasmon, protene, nutrose, etc., have the disadvantage, as compared with pure egg-albumin, that they clot in the stomach in the same way as milk. Plasmon, which appears in many ways to be the best of these preparations, when tested with rennet does not clot into nearly so firm a mass as pure milk, but into a very light friable clot, and, if limewater is added, does not seem to clot at all. Plasmon and the other casein preparations are of very little value for rectal alimentation, as they seem not to be absorbed. Egg-albumin is a much better form of proteid for this purpose.

GELATIN--Jellies which are made from gelatin form: an excellent diet, and are very readily digested; 4 ounces of good jelly equals $I \frac{3}{4}$ ounces of solids, of which half is gelatin and the rest sugar. Gelatin has the advantage of being digested more readily by the stomach than almost any other food. It was estimated by Uffelmann that peptonization is complete within one hour. Gelatin must not, howerer, lie looked upon as a substitute for proteid, but rather as a useful addition to other diets. Its chief value lies in its property of economizing proteid. It is on this account that it has been called a proteidsparer.'

SUGAR.-One of the great adrantages of sugar as a diet is the ease with which it can le absorbed. Grapesugar (dextrose) can pass into the blood without any digestion, and is therefore valuable in conditions where the digestive power is impaired. It has been repeatedly proved that, as a muscle-former, sugar is extremely valualle, and therefore it would seem to be indicated as a diet in combating muscle waste. The value of sugar as part of an invalid diet is not sufficiently recognised; 


\section{Appendix}

the ease with which it is alsenlyod, its hich nutritive value, and its lighl potential energy, all help to nalie it one of the most useful forms of diet in convalescent states.

Unfortunately, all forms of sugar tend to undergo fermentation if long retained in the alimentary tract. Also sugar in a concentrated form is irritating to mucous membranes. It is therefore important when using sugar as a diet not to rive it in too larpe puantities at a time, and not to give it in too concentrated a form. When patients ohject to a swert diet, milk-susar, which is alunost free from a sweet taste, can be used in place of other forms of sugar.

$$
\text { HEFPRTNCES. }
$$

'Food and the Principles of J fictutics': Robert Hutchison.

'Encycloparia Necilca.' 



\section{IXI) IiX}

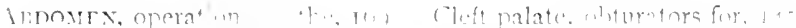

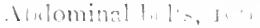

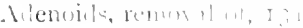

$$
\begin{aligned}
& \text { 1.m rris a + is }
\end{aligned}
$$

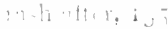

whesins. 112

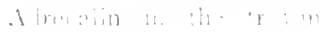

$$
\text { Heser, } 93
$$

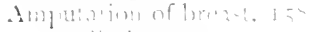

$$
\begin{aligned}
& \text { of } \lim l \mathrm{~s}, 25 \\
& \text { secmmaly }
\end{aligned}
$$

Anothera, complication

$$
1 ;
$$

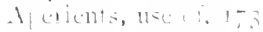

Aychlicilis. 205

Arciti ial appliances 145. Is

lamis, 255 when til lit. 253

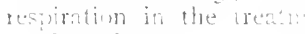
if =hick. of

liwhire, is

lielts, after lagor tomy. Ii,

$$
\text { colotomy: } 237
$$

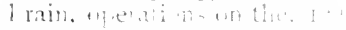

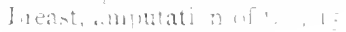

Jirathing carcier, i'

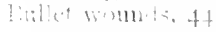

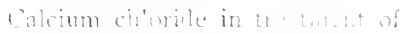
tw molwets 55

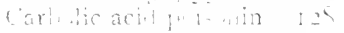

Satheter late 21;

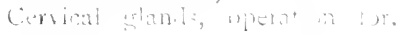
I $\div-$

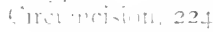

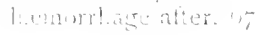

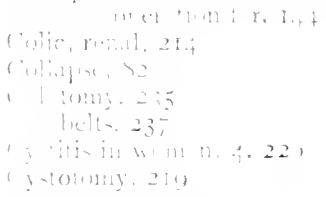
$1100+11+1]+1 .+1$ 
Flatulence, i 7

Fomentations, 39, 46

Foreign bodies in gunshot wounds, 44 left in abdomen, 194

Fractures complicating bullet wounds, 49

Gall-bladder, operations on the, 203

Gauze in dressing wounds, 38

Genito-urinary tract, operations on the, 215

Glands in neck, removal of, 157

Goitre, operations for, I 55

IIrematemesis, 104, 201

Hrematuria, 213

Hæmophilia, 56

Hrmoptysis, IO 4

Hremorrhage, $5 \mathrm{I}$

after special operations, 62.

203,222

constitutional treatment for, 72

internal, $6 \mathbf{I}$

recurrent, 52

secondary, 57

from bullet wounds, $5 \mathrm{~S}$

Hæmorrhoids, $23 \mathrm{I}$

Harelip, operations for. $I_{4} 2$

Head, operations on the, I 14

Hernia, 208

cerebral, I42

ventral, 193

Hip, excision of the, 245

Hydrocele, 225

Infarction, 109

Insanity, post-operative, 20, 103

Insomnia, Io

Intestinal obstruction after opera. tion, IS9

fodoform poisoning, I 27

Irrigation of wounds, 37,46 rectal, in peritoniti=, 197

Jaundice, a cause of hxmorrlage, 56

Joints, injuries of, 50

operations on, 239
Kidney, operations on the, 2 I I

Kinee, excision of the, $2+3$

Laminectomy, 262

Laparotomy, 169

complications after, I $\$ 2$

diet after, 176

in chiluren, 8

Leucocythemia, 57

Lithotomy, hæmorrhagre after, 67

Lithotrity, 222

Mania, 20

Massage, 247

Mercurial poisoning, 129

Meteorism, I Sz

Nasal feeding, 266

Neck, operations on the, 149

Nuse, operations on the, I 39

Obstruction after laparotomy, i 89

Obturators for cieft palate, I 45

Esophagotomy, I 54

l'ain, I I, I 2

after special operations, 2 I 2 ,

232,251

Paralysis, post-anxsthetic, IO4

Parotitis, i 87

Peritonitis, $18_{5}, 197$

Piles, operation for, 231 pain after, 232

Pituitary extract for relief of flatulence, is

in the treatment of shock, 93

Plugging of rectum, 70

Pneumonia, I02, I98

Position after operation, 3

after laparotomy, 7

after operations on the

stomach, 2OI

in cases of shock, $\$ 5$

Post-anzsthetic complications, 97

I'rone position, 4

l'rostatectomy, 221

Rashes, post-operative. I16

due to enemata, 123

liectal feeding, 20.4 
Rectum, operations on the, 225

hementhage form the, (a)

1) lusgring of the, 70

ketention of urine, 210, 234

Saline infusion in the treatment of shock, 87 . \&8

Scarlet tever, pat-operatib:, I I I Sepsis, 36

treatment of, 40

Septicxmia, fI, IIT

Septic hullet wounds, ft) raslies, is 0

Serum, treatment with, 4 I

shock, symptoms of, 75

physiology of, 76

treatment of. $\$ 2$

prevention of, $s$;

shoulder, excision ot the. 243

Sinus, persistent, $50,160,252$

-leeplessness after operatiun, I

smoking. 15

citimulants in the treatment of shock, $\$ 6$

Stitch suppuration, $\mathbf{I}_{5}$

Sititches, removal of, 32

Stomach, acute dilatation of the, 193 operntions on the, ins

Stricture after operation for pies, 234
Strychnire prisonng, I 39

sulucutanes as feeding, 260

Telephone probe, $4^{6}$

Temperature after operations, 26

Thirst, I6

Thrombusis. 106

Thyruil gland, operations on the, I 55

Tompue, excision of the, $13 \mathrm{~S}$

Tomals, removal of, i 3 i

Touth-extraction, I 37 hiemorrhage affer, ${ }^{3}$ hemorihage after, $6_{5}$

Trachentomy. I +9

Transfusicn, 88

Lrxmia, 212

Lrethrotomy, external, 224 internal. 223

Uterus, operations on the, 22s

Vaccines in sepsis, 4 I

Varicucele, 226

Varicose veins. 260

Tomiting, os

persistent, 2 I0, 2 I 3

regurgitant, 1,0. 199

Nound:, 3 I

gunshet 43

THE END

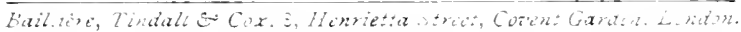




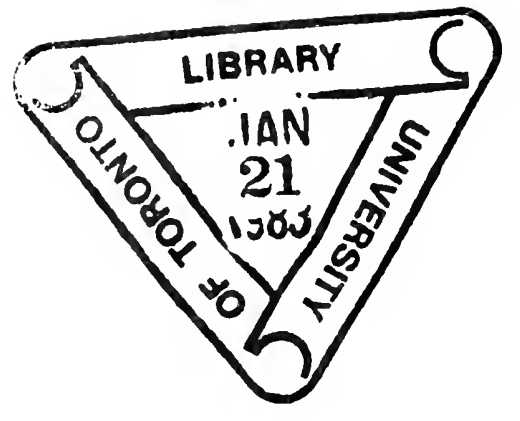





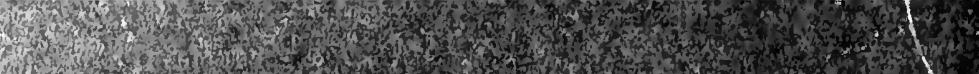

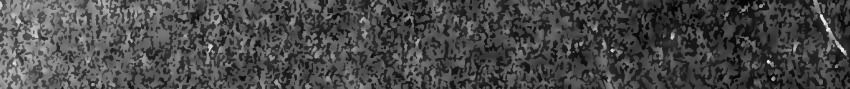

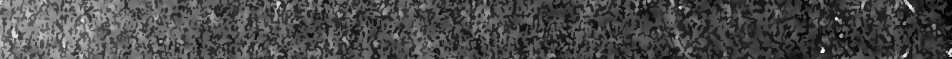
1. 18. (4) s.

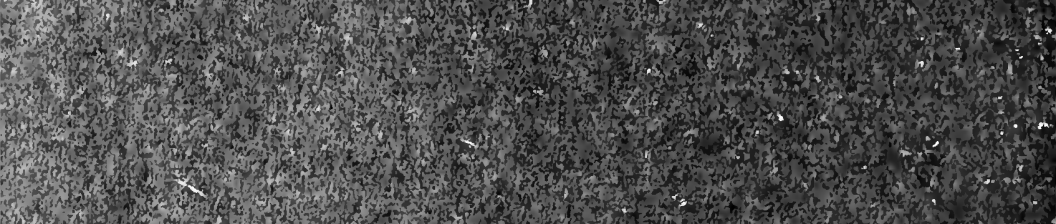
S.

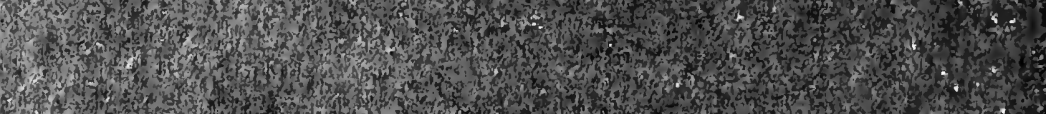

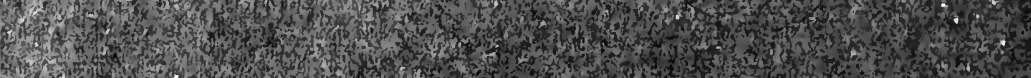

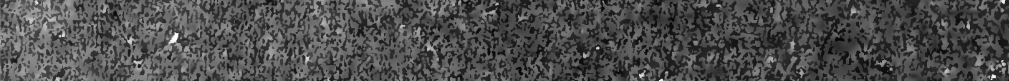
4. 1. 1 3. (3) 2.

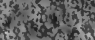

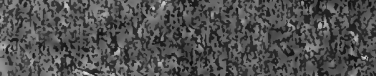

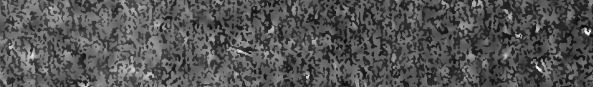

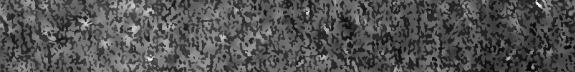

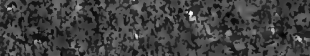

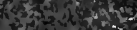

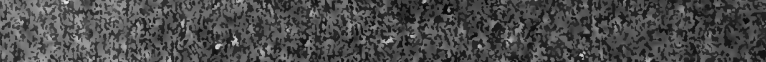

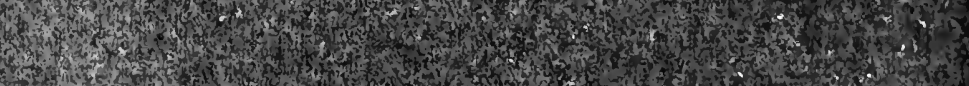

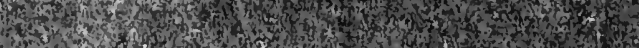

2
3

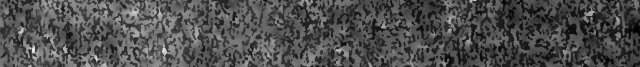

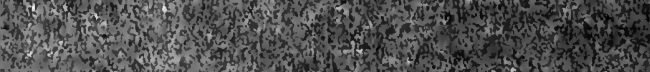

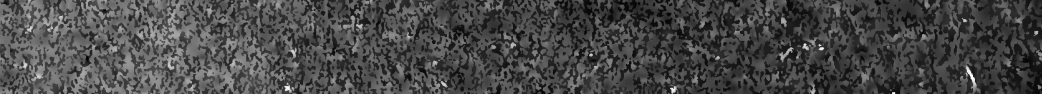

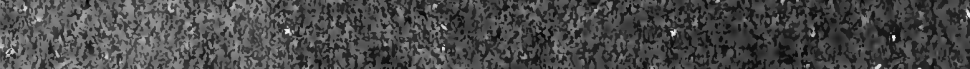

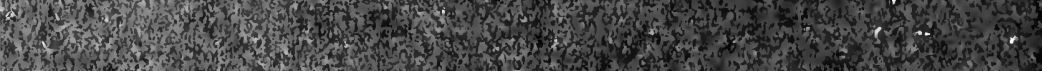

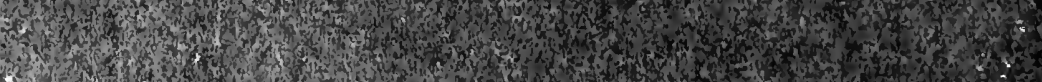

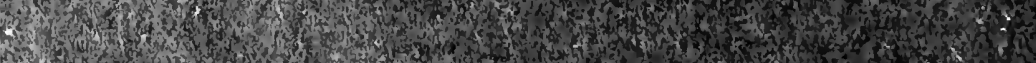

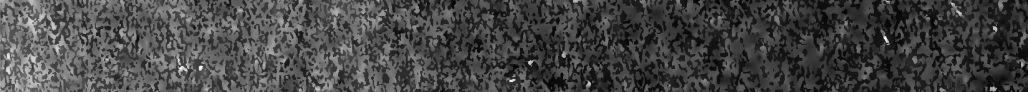

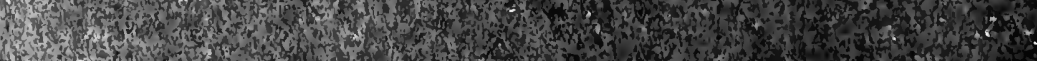




\section{PLEASE DO NOT REMOVE CARDS OR SLIPS FROM THIS POCKET UNIVERSITY OF TORONTO LIBRARY}


